$$
\begin{gathered}
\text { Universidade de São Paulo } \\
\text { FFCLRP - Departamento de Física }
\end{gathered}
$$

Pós-graduação em Física aplicada à Medicina e Biologia

$$
\text { HEITOR HÁKIME CUNHA }
$$

\title{
Desenvolvimento de um software para geração de redes complexas formadas a partir de estimativas de conectividade cerebral: Um estudo da espessura cortical no cérebro de indivíduos saudáveis e pacientes com epilepsia
}

Dissertação apresentada à Faculdade de Filosofia, Ciências e Letras de Ribeirão Preto da Universidade de São Paulo, como parte das exigências para a obtenção do título de Mestre em Ciências, Área: Física aplicada à Medicina e Biologia.

Ribeirão Preto - SP

2014 


\section{Desenvolvimento de um software para geração de redes complexas formadas a partir de estimativas de conectividade cerebral: Um estudo da espessura cortical no cérebro de indivíduos saudáveis e pacientes com epilepsia}

Dissertação apresentada à Faculdade de Filosofia, Ciências e Letras de Ribeirão Preto da Universidade de São Paulo, como parte das exigências para a obtenção do título de Mestre em Ciências.

Área de Concentração:

Física aplicada à Medicina e Biologia.

Orientador:

Carlos Ernesto Garrido Salmon.

Versão original

Disponível na FFCLRP - USP

Ribeirão Preto - SP

2014 
Autorizo a reprodução e divulgação total ou parcial deste trabalho, por qualquer meio convencional ou eletrônico, para fins de estudo e pesquisa, desde que citada a fonte.

\section{FICHA CATALOGRÁFICA}

\section{Cunha, Heitor Hákime}

Desenvolvimento de um software para geração de redes complexas formadas a partir de estimativas de conectividade cerebral: Um estudo da espessura cortical no cérebro de indivíduos saudáveis e pacientes com epilepsia / Heitor Hákime Cunha; orientador Carlos Ernesto Garrido Salmon. Ribeirão Preto - SP, 2014.

93 f.:il.

Dissertação (Mestrado - Programa de Pós-graduação em Física aplicada à Medicina e Biologia) - Faculdade de Filosofia, Ciências e Letras de Ribeirão Preto da Universidade de São Paulo, 2014.

1. Espessura cortical. 2. Conectividade cerebral. 3. Redes complexas. 4. Envelhecimento. 5. Imagens por ressonância magnética. 6. Epilepsia. 
Nome: Cunha, Heitor Hákime

Título: Desenvolvimento de um software para geração de redes complexas formadas a partir de estimativas de conectividade cerebral: Um estudo da espessura cortical no cérebro de indivíduos saudáveis e pacientes com epilepsia

Dissertação apresentada à Faculdade de Filosofia, Ciências e Letras de Ribeirão Preto da Universidade de São Paulo, como parte das exigências para a obtenção do título de Mestre em Ciências.

Aprovado em:

\section{Banca Examinadora}

Prof(a). Dr(a).

Instituição:

Julgamento:

Assinatura:

Prof(a). Dr(a). :

Instituição:

Julgamento:

Assinatura:

Prof(a). Dr(a).

Instituição:

Julgamento:

Assinatura: 


\section{Agradecimentos}

Aos meus pais Getúlio e Cecília por terem tornado minha caminhada aqui na Terra tão mais suave. Sempre me incentivaram, deram-me todas as oportunidades, mostraram-me o valor dos estudos e do conhecimento, não apenas com palavras mas com atos. Mãe, quando ainda pequeno você sempre estudava comigo antes das provas e pai, nossas conversas sobre os mais variados temas têm um significado inimaginável. Obrigado por tudo, essa conquista não seria possível sem vocês. Quero ser para o Gabriel ao menos um pouco daquilo que vocês são pra mim.

A minha amada Isamara pelo apoio, compreensão e paciência por ter me esperado estudar em muitos dias e finais de semana. Certamente não foi fácil. Esta vitória também é sua. Obrigado por estar sempre comigo e me dar forças para não desistir mesmo nos momentos mais difíceis.

Ao Prof. Dr. Carlos Garrido agradeço primeiramente por ter acreditado em mim. Ao tentar ingressar no mestrado, fui julgado por muitos professores por estar trabalhando. Dentre todos, você foi aquele que acreditou na minha palavra e me deu um voto de confiança. Sou muito grato pela paciência e por tudo que me ensinou, não apenas na área acadêmica, como também na vida. Obrigado por ter incentivado e me ensinado a fazer pesquisa. Serei eternamente grato.

À todos os diretores da Eddydata, em especial ao Sr. Edward Carlos Teixeira e Rodrigo Teixeira, pelo investimento, apoio e por toda a flexibilidade que me conferiram com os horários do trabalho, permitindo que me dedicasse aos estudos e nunca questionando sequer uma ausência. Dificilmente outra empresa faz o que vocês fizeram. Lembro também do meu 
amigo Cássio Freitas que segurou as pontas com os clientes todas as vezes que eu estava ausente em Ribeirão Preto e também não deixou os prazos estourarem. Muito obrigado pela paciência e confiança de todos vocês.

Em especial, agradeço à Deus pela vida de cada pessoa acima. Nenhum homem é uma ilha, vivemos em sociedade e ao meu redor estão pessoas fantásticas, que fazem da minha vida um dom digno de ser vivido! Obrigado Senhor, pela realização de mais um sonho! 
"Assim, em tudo, façam aos outros o que vocês querem que eles lhes façam, porque esta é a Lei e os profetas.

Jesus Cristo 


\section{Resumo}

CUNHA, H. Desenvolvimento de um software para geração de redes complexas formadas a partir de estimativas de conectividade cerebral: Um estudo da espessura cortical no cérebro de indivíduos saudáveis e pacientes com epilepsia. 2014. 93 f. Dissertação (Mestrado - Programa de Pós-graduação em Física aplicada à Medicina e Biologia) - Faculdade de Filosofia, Ciências e Letras de Ribeirão Preto, Universidade de São Paulo, Ribeirão Preto - SP, 2014.

O cérebro humano é considerado uma rede complexa em termos estruturais e funcionais em diferentes escalas. A caracterização da arquitetura desta rede pode ser considerada uma importante ferramenta no auxílio ao estudo de diferentes doenças neurodegenerativas. No presente estudo propusemos um software desenvolvido em JAVA para investigar esta arquitetura com base na correlação estatística de características morfológicas entre diferentes regiões do córtex. Foram utilizados dados de espessura cortical obtidos a partir de imagens de ressonância magnética de 191 indivíduos saudáveis e 93 pacientes com epilepsia. Foi proposto um modelo não linear para considerar o efeito da idade na espessura cortical com identificação de duas etapas: amadurecimento e envelhecimento. Os pacientes, quando comparados aos controles, apresentaram uma redução significativa na espessura cortical fundamentalmente nas regiões para-central, pericalcarina e do pré-cuneo no hemisfério 
direito. Esta diminuição também se manifestou ao longo da idade, com uma maior taxa de queda na região parahipocampal direita. Considerando a conectividade anatômica aqui calculada, o grupo de pacientes evidenciou alterações em $31 \%$ das possíveis conexões e de forma difusa. Adicionalmente, nas redes cerebrais dos pacientes houve uma diminuição de $15 \%$ no comprimento médio do caminho e no coeficiente de agrupamento. Aplicando-se um algoritmo de agrupamento, foram detectadas três comunidades para os indivíduos saudáveis e seis comunidades para os pacientes, confirmando uma quebra de organização estrutural neste ultimo grupo. Com este software esperamos trazer à comunidade mais uma ferramenta para análise das conexões cerebrais e suas modificações em determinadas patologias, contribuindo com seu entendimento e possível diagnóstico.

Palavras-chave: 1. Espessura cortical. 2. Conectividade cerebral. 3. Redes complexas. 4. Envelhecimento. 5. Imagens por ressonância magnética. 6. Epilepsia. 


\section{Abstract}

CUNHA, H. Development of a software to generate complex networks from estimates of brain connectivity: A study of cortical thickness in the brain of healthy subjects and patients with epilepsy.. 2014. $93 \mathrm{f}$. Dissertation (M.Sc. - Postgraduate program in Physics applied to Medicine and Biology) - Faculty of Philosophy, Sciences and Literature, University of São Paulo, Ribeirão Preto - SP, 2014.

The human brain can be characterized as a complex network structurally and functionally in different levels. The description of the architecture of this network can be considered an important tool in understanding different neurodegenerative diseases. In the present study, we developed a software in JAVA to investigate this architecture based on statistical correlation of morphological characteristics between different cortex areas. It was used a database of cortical thickness obtained from magnetic resonance images of 191 healthy subjects and 93 patients with epilepsy. It was implemented a non-linear model to consider the effect of age in cortical thickness with identification of 2 stages: maturation and aging. The patients, when compared to healthy subjects, showed a significant reduction in cortical thickness, particularly at the areas precentral, pericalcarine and pré-cuneus of right hemisphere. This decrease also could be noted through the age, with a higher decrease rate at the right parahipocampal area. Considering the anatomical connectivity 
calculated, the patients group showed diffuse changes in $31 \%$ of the possible connections. Furthermore, in the patients brain network it was found a decrease of $15 \%$ in the characteristic path length and clustering coefficient. By applying a clustering algorithm, 3 clusters were detected in the healthy subjects and 6 clusters in the patients, confirming a breakdown of the structural organization in this last group. With our software we hope to bring to the community another tool to improve the brain connectivity analysis and its modifications in some pathologies, contributing with its understanding and possible diagnosis.

Key-words: 1 . Cortical thickness. 2. Brain connectivity. 3. Complex networks. 4. Aging. 5. Magnetic resonance imaging. 6. Epilepsy. 


\section{Lista de Figuras}

2.1 Imagens ponderadas em densidade protônica, $T_{1}$ e $T_{2}$ obtidas através de uma sequencia spin-echo. . . . . . . . . . 6

2.2 Contraste ponderado em $T_{1} \ldots \ldots \ldots \ldots \ldots$

2.3 Típica sequencia de pulsos do tipo gradiente de eco para obtenção de imagens tridimensionais. . . . . . . . . . . . . . 9

2.4 Fronteiras das substâncias branca, cinzenta e o fluído cérebro-espinhal. . . . . . . . . . . . . . 11

2.5 Formas mais comuns de obter medidas de espessura cortical. . . 12

3.1 Fluxo de processamento dos dados. . . . . . . . . . . . . 19

3.2 Interface do software construído. . . . . . . . . . . . 20

3.3 Exemplo de rede com três comunidades. . . . . . . . . . . . . . 26

3.4 Diagrama de casos de uso do software implementado. . . . . . . . 30

4.1 Alterações de espessura do córtex ao longo do tempo. . . . . . . . 34

4.2 Mapa do final do amadurecimento e início do envelhecimento. . . 35

4.3 Mapa do final do amadurecimento e início do envelhecimento diferenciado por sexo. . . . . . . . . . . . 36

4.4 Taxa de envelhecimento em indivíduos saudáveis. . . . . . . . . 38

4.5 Impacto da retirada do efeito da idade no coeficiente de correlação. 40

4.6 Matriz de correlações. . . . . . . . . . . . . . . . . . . . . . . . . 40

4.7 Rede de conectividade não ponderada. . . . . . . . . . . . . . . . 41

4.8 Propriedades de rede de mundo pequeno em função do coeficiente de correlação de corte. . . . . . . . . . . . . . . . 44 
4.9 Comunidades encontradas nos indivíduos saudáveis. . . . . . . . . 45

4.10Taxa de envelhecimento em pacientes com epilepsia. . . . . . . . 48

4.11 Rede de conectividade para pacientes com epilepsia. . . . . . . . 50

4.12 Diferenças nas conexões anatômicas de indivíduos saudáveis e pacientes com epilepsia. . . . . . . . . . . . . . 51

4.13Comparação dos parâmetros de rede para indivíduos saudáveis e pacientes com epilepsia. . . . . . . . . . . . . 53

4.14Comunidades encontradas nos pacientes com epilepsia. . . . . . . 54

A.1 Planilha de dados utilizada para execução do software. . . . . . . 68

B.1 Folha contendo as idades de amadurecimento e equações bi-exponenciais de regressão encontradas para cada região na análise dos indivíduos saudáveis. . . . . . . . . . . 70

B.2 Folha contendo as médias das derivadas encontradas para a função de regressão que modela o envelhecimento, divididas em 3 grupos: adultos jovens (até 40 anos), meia idade (entre 40 e 60 anos) e idosos (acima de 60 anos). . . . . . . . . . . . 71

B.3 Folha contendo a matriz de correlações encontrada. . . . . . . . . 72

B.4 Folha contendo a matriz de conectividade encontrada após o cálculo do coeficiente de correlação de corte. . . . . . . . . . 73

B.5 Folha contendo os parâmetros de rede calculados para o intervalo de análise solicitado. . . . . . . . . . . . . . . . . . 74

B.6 Folha contendo as comunidades encontradas segundo o algoritmo explicado na seção 3.2.5 . . . . . . . . . . . . . . 75

C.1 Arquivo TSV gerado na execução do software. . . . . . . . . . 77

C.2 Arquivo contendo o mapa de cores a ser utilizado no FreeSurfer para montagem de ilustrações. . . . . . . . . . . . . . 78 


\section{Lista de Tabelas}

2.1 Tempos de relaxação $T_{1}$ e $T_{2}$ in-vivo para alguns tecidos do corpo

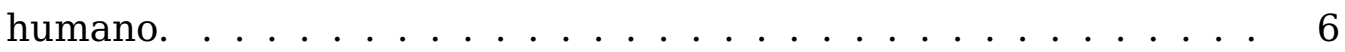

3.1 Exemplo de planilha de entrada contendo dados para processamento. . . . . . . . . . . . . . . 21

4.1 Comparação dos diferentes modelos de regressão. . . . . . . . . 33

4.2 Regiões mais fortemente conectadas em indivíduos saudáveis. . . 43

4.3 Regiões com maior taxa média de decaimento de espessura cortical em indivíduos saudáveis e pacientes com idades até 40 anos (A), entre 40 e 60 anos (B) e acima de 60 anos (C). . . . . . . 49

4.4 Regiões mais fortemente conectadas em pacientes com epilepsia. 52 


\section{Lista de Abreviaturas}

FFCLRP Faculdade de Filosofia Ciências e Letras de Ribeirão Preto.

FMRP Faculdade de Medicina de Ribeirão Preto.

HC Hospital das Clínicas

USP Universidade de São Paulo.

$T_{1} \quad$ Tempo de relaxação longitudinal.

$T_{2} \quad$ Tempo de relaxação transversal.

RMN Ressonância magnética nuclear

DTI Sigla em inglês para Diffusion Tensor Imaging

EEG Eletroencefalografia

MEG Magnetoencefalografia

FMRI Sigla em inglês para Functional Magnetic Resonance Imaging

IRM Imagem por ressonância magnética 


\section{Lista de Símbolos}

D Grau médio da rede.

$C_{p} \quad$ Coeficiente de agrupamento.

$L_{p} \quad$ Comprimento médio do caminho.

$C_{P}^{\text {real }} \quad$ Coeficiente de agrupamento encontrado na rede submetida ao software

$C_{P}^{\text {aleat }} \quad$ Média do coeficiente de agrupamento gerado para as várias redes aleatórias construídas pelo software para fins comparativos

$L_{P}^{\text {real }} \quad$ Comprimento médio do caminho encontrado na rede submetida ao software

$L_{P}^{\text {aleat }} \quad$ Média do comprimento médio do caminho gerado para as várias redes aleatórias construídas pelo software para fins comparativos

$L_{P}^{\text {real }} \quad$ Comprimento médio do caminho encontrado na rede submetida ao software

$\gamma \quad$ Razão entre o coeficiente de agrupamento da rede analisada e a média dos coeficientes de agrupamento de redes aleatórias com mesma característica

$\lambda$ Razão entre o comprimento médio do caminho da rede analisada e a média dos comprimentos médios dos caminhos de redes aleatórias com mesma característica 
$\sigma$

Q

R

$\mathrm{P}$

Razão entre $\gamma$ e $\lambda$

Fator de modularidade

Coeficiente de correlação de Pearson

Nível descritivo das correlações 


\section{Sumário}

Lista de Figuras $\quad$ xi

Lista de Tabelas

Lista de Abreviaturas xiv

Lista de Símbolos $\quad$ XV

1 Introdução 1

2 Conectividade estrutural do cérebro humano usando imagens por ressonância magnética $\quad 4$

2.1 Princípios das imagens por ressonância magnética . . . . . . . . . 4

2.2 Medida de espessura cortical através de imagens por RM . . . . . 8

2.3 Conectividade estrutural . . . . . . . . . . . . . . . 13

3 Materiais e métodos $\quad 17$

3.1 Imagens de entrada e pré-processamento . . . . . . . . . . . . 17

3.2 O software . . . . . . . . . . . . . . . . . 18

3.2.1 Entrada de dados . . . . . . . . . . . . 20

3.2 .2 Retirada do efeito da idade . . . . . . . . . . . . . 21

3.2.3 Montagem da matriz de correlações . . . . . . . . . . . 22

3.2.4 Construção da rede de conectividade . . . . . . . . . 23

3.2.5 Detecção de comunidades . . . . . . . . . . . . 25

3.2 .6 Saída de dados . . . . . . . . . . . . . . . . . . 28

3.2 .7 Casos de uso . . . . . . . . . . . . . . . . 29 
4 Discussão dos resultados 31

4.1 Efeito da idade . . . . . . . . . . . . . . . . 32

4.1 .1 Amadurecimento . . . . . . . . . . . . . . 33

4.1.2 Envelhecimento . . . . . . . . . . . . 36

4.2 Montagem da rede de conectividade . . . . . . . . . . . 39

4.3 Detecção de comunidades . . . . . . . . . . . . . . . . . . . . 44

4.4 Indivíduos saudáveis vs pacientes com epilepsia de lobo temporal 46

5 Conclusão

$\begin{array}{ll}\text { Referências Bibliográficas } & 57\end{array}$

$\begin{array}{ll}\text { Anexo A - Planilha de entrada de dados } & 67\end{array}$

$\begin{array}{lc}\text { Anexo B - Planilha de saída de dados } & 69\end{array}$

Anexo C - Outros arquivos de saída $\quad 76$ 


\section{Capítulo}

\section{Introdução}

O cérebro humano constitui-se em uma grande, interativa e complexa rede que possui características topológicas não-triviais (SPORNS et al., 2004; STAM, 2004; EGUíLUZ et al., 2005; ACHARD et al., 2006; STAM et al., 2007). O mapeamento e a caracterização dessa rede é um importante problema em neurociência, na medida em que consegue revelar padrões de conectividade funcional e estrutural e ajudar-nos a compreender melhor como o cérebro humano gera informações e integra-as em tempo real (SPORNS et al., 2004).

Atualmente, de maneira geral, quando se fala em conectividade cerebral, duas vertentes de pesquisa vêm sendo desenvolvidas ao longo dos anos. A primeira delas é focada na exploração de graus de conectividade funcional, definidos como a dependência temporal de padrões de atividade neuronal em regiões anatomicamente separadas do cérebro (AERTSEN et al., 1989; FRISTON et al., 1993) e a segunda foca na exploração de padrões de conectividade estrutural entre as regiões cerebrais (GONG et al., 2009a). O mapeamento do mecanismos de entrada de informações em uma região cerebral é importante pois determina as informações disponíveis naquela região, enquanto que a detecção das saídas permite demonstrar a influência que essa região pode ter em outras áreas. Com esses estudos de conectividade, é possível realizar inferências sobre as especializações funcionais de cada região, bem como entender melhor os padrões e distúrbios estruturais que ocorrem em alguns tipos de doenças (JOHANSEN-BERG; 
RUSHWORTH, 2009).

O mapeamento das conexões estruturais cerebrais não é um assunto recente. Desde o século XVII, pesquisadores iniciaram os estudos nessa área desenvolvendo metodologias de imersão em óleo e dissecação do cérebro para tentar mapear as conexões entre as diversas regiões. Métodos contemporâneos de pesquisa baseiam-se na exploração de mecanismos ativos de transporte, utilizando substâncias de rastreamento tais como vírus, enzimas ou substratos fluorescentes, que são injetados na área de interesse de um animal vivo que é monitorado e sacrificado após um período pré-determinado. Após o sacrifício, o cérebro é retirado e analisado sob várias formas para detecção dos locais para onde as substâncias injetadas estavam sendo transportadas e conseqüentemente realizar o mapeamento cerebral (MORECRAFT et al., 2009)

Embora poderosas, técnicas de rastreamento obviamente não podem ser aplicadas para estudos de cérebros humanos in-vivo e por isso a neuro-anatomia humana está menos sedimentada que a neuro-anatomia em não humanos (CRICK; JONES, 1993). Desenvolvimentos recentes nas aquisições de imagens utilizando ressonância magnética possibilitaram o surgimento de novas técnicas para mapeamento das conexões estruturais cerebrais de forma não invasiva. Uma delas é chamada Diffusion Tensor Imaging (DTI), na qual o sinal de ressonância magnética é "sensibilizado"para detectar a difusão das moléculas de água nas diversas direções e com isso estimar de forma simplificada um mapa dos diversos caminhos pelos quais a molécula de água pode mais facilmente se deslocar no cérebro humano. Isso é útil pois em se tratando de estruturas anisotrópicas, como a substância branca do cérebro, a difusão da água depende diretamente desta anisotropia. Em um feixe de fibras, a difusão ocorre mais facilmente ao longo do que através dele, sugerindo que haja uma rota conectando os extremos de tais feixes. Segundo essa técnica, a partir da aplicação de um modelo matemático nas imagens adquiridas, é possível gerar um mapeamento das conexões 
estruturais cerebrais (JOHANSEN-BERG; RUSHWORTH, 2009).

Embora seja uma técnica que vem se desenvolvendo constantemente ao longo dos anos, a DTI ainda sofre com algumas limitações na aquisição de dados e nas abordagens de processamento de cruzamentos ou intersecções de fibras (DOUGHERTY et al., 2005; TUCH et al., 2005). Em 2005, foi proposta uma nova técnica de pesquisa para explorar os padrões de conectividade anatômica cerebral humana, na qual duas áreas foram consideradas anatomicamente conectadas se elas mostrassem associações estatísticas significativas em suas respectivas espessuras corticais (MECHELLI et al., 2005).

No presente estudo, nosso objetivo foi criar um software capaz de detectar sub-redes de conectividade estrutural com base em associações estatísticas significativas de uma característica morfológica cerebral. Para tal, retiramos o efeito da idade através de um modelo não linear de regressão, calculamos a matriz de correlações dos dados, implementamos um algoritmo para detecção de grupos ou sub-redes na rede global encontrada e por fim validamos as implementações submetendo ao software dados de espessura cortical de indivíduos saudáveis e pacientes com epilepsia de lobo temporal, comparando os resultados encontrados. 


\section{Capítulo}

\section{Conectividade estrutural do cérebro humano usando imagens por ressonância magnética}

A obtenção de imagens por ressonância magnética (IRM) é um método já bastante estabelecido na prática clínica e em crescente desenvolvimento. Dada a alta capacidade de diferenciar tecidos e o uso de radiação não ionizante, a gama de aplicações se estende a todas as partes do corpo humano e viabiliza a exploração de aspectos anatômicos e funcionais tanto de pacientes quanto indivíduos saudáveis.

No presente capítulo abordaremos as etapas para se obter uma rede complexa de conectividade estrutural do cérebro humano com base em imagens obtidas por meio da ressonância magnética. Discorreremos de forma sucinta desde os princípios de obtenção das imagens até o pós processamento necessário para dividi-las em regiões e transformá-las em uma rede com seus respectivos nós e conexões.

\subsection{Princípios das imagens por ressonância magnética}

O fenômeno físico da ressonância magnética nuclear (RMN) foi descrito inicialmente em 1946 em artigos independentes (BLOCH, 1946; PURCELL; TORREY; POUND, 1946). Entretanto, a as primeiras imagens do corpo 
humano só foram possíveis cerca de 30 anos depois.

O detalhamento dos princípios físicos abrangendo a técnica de ressonância magnética não é o foco do presente estudo e maiores informações podem ser encontradas em (POOLEY, 2005; MAZZOLA, 2009; RINCK, 2013). De forma simplicada, pode ser descrita como o resultado da interação de diferentes campos magnéticos produzidos pelo equipamento com os núcleos físicos dos tecidos presente no corpo humano. Para que aconteça o fenômeno de ressonância são necessários dois campos magnéticos: um campo estático e um campo variável, na faixa das radiofrequências. O campo estático cria uma magnetização nuclear de equilíbrio na sua direção, a qual chamar-se-a longitudinal, forçando uma precessão dos momentos magnéticos dos núcleos presentes nos tecidos corporais. Já o campo de radiofrequência excita tais núcleos gerando alterações nas componentes de magnetização longitudinal e transversal da amostra. No caso das imagens, um terceiro campo magnético, chamado campo de gradiente, também é aplicado para fazer a codificação espacial do sinal de RM. Como o núcleo mais abundante é o hidrogênio $\left({ }^{1} H\right)$, a grande maioria das técnicas de imagens está associada ao mesmo.

Um conceito importante na qualidade das imagens e na posterior segmentação é o contraste. Trata-se da capacidade de diferenciar tecidos permitindo identificar com maior acuracidade as fronteiras de cada um. As imagens formadas por meio das técnicas de ressonância magnética garantem um bom contraste entre tecidos moles do corpo, o que as tornam úteis especialmente no estudo do cérebro, tecidos musculares, coração e tumores (RINCK, 2013).

Existem diversos mecanismos de contraste que podem ser explorados para a geração das imagens, destacando-se os baseados na densidade protônica $(\rho)$ e em tempos característicos do fenômeno de relaxação magnética nuclear: relaxação longitudinal $\left(T_{1}\right)$ e relaxação transversal $\left(T_{2}\right)$. A escolha do contraste a ser utilizado depende dos objetivos de cada estudo. Por exemplo, quando a intenção é analisar a estrutura cerebral do ponto 
de vista anatômico o contraste mais indicado é aquele com base em $T_{1}$ pois permite uma maior diferença entre as substâncias branca, cinzenta e o fluido cérebro-espinhal, com maiores tons de cinza na imagem final, permitindo uma melhor definição das fronteiras de cada tecido. Nota-se pela figura 2.2 que, para um mesmo corte, as imagens produzidas por cada mecanismo de contraste são diferentes. Na tabela 2.1 podem ser vistos os tempos $T_{1}$ e $T_{2}$ típicos para alguns tecidos in-vivo do nosso corpo estimados em uma máquina de RMN de 3 Tesla.

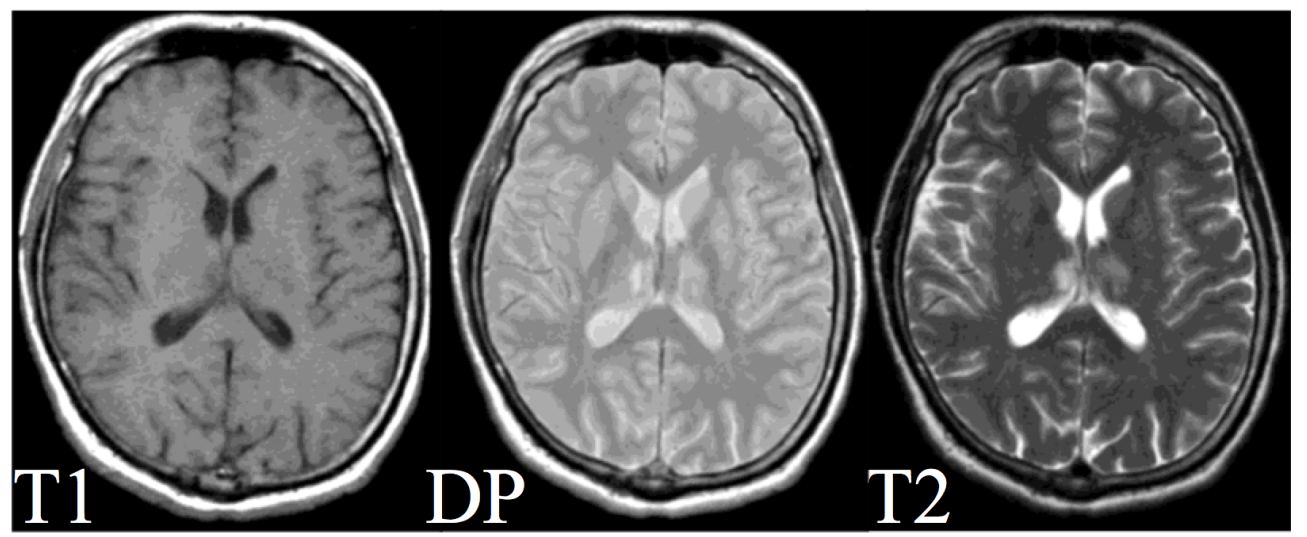

Figura 2.1: Imagens ponderadas em densidade protônica, $T_{1}$ e $T_{2}$ obtidas através de uma sequencia spin-echo. As três imagens mostram grandes variações em contraste para os tecidos humanos, razão pela qual se faz necessária uma análise para identificar qual ténica melhor se aplica à cada objetivo.

\begin{tabular}{lll}
\hline Tecido & $T_{1}$ (ms) & $T_{2}$ (ms) \\
\hline \hline Músculo & $1420 \pm 38$ & $32 \pm 2$ \\
Substância Branca & $832 \pm 10$ & $79,6 \pm 0,6$ \\
Substância Cinzenta & $1.331 \pm 13$ & $110 \pm 2$ \\
Sangue & $1.550 \pm 50$ & $*$ \\
\hline \hline
\end{tabular}

Tabela 2.1: Tempos de relaxação $T_{1}$ e $T_{2}$ para alguns tecidos do corpo humano. Valores extraídos de (STANISZ et al., 2005), obtidos em uma máquina de 3 Tesla. *Valor não reportado na referência utilizada.

Na figura 2.2 é apresentada uma imagem ponderada em $T_{1}$ e uma curva de recuperação da magnetização longitudinal de alguns tecidos logo após 
um pulso de radiofrequência. Nota-se que a recuperação da magnetização longitudinal na substância branca ocorre mais rapidamente que a recuperação na substância cinzenta, essa última mais rápida que o fluido cérebro-espinhal, tal como ilustrado na tabela 2.1. No caso do contraste $T_{1}$, caso uma imagem seja gerada no momento em que essas curvas estejam mais separadas, será possível obtê-la com a maior diferenciação entre tais substâncias, permitindo identificar com maior precisão as fronteiras de cada tecido.
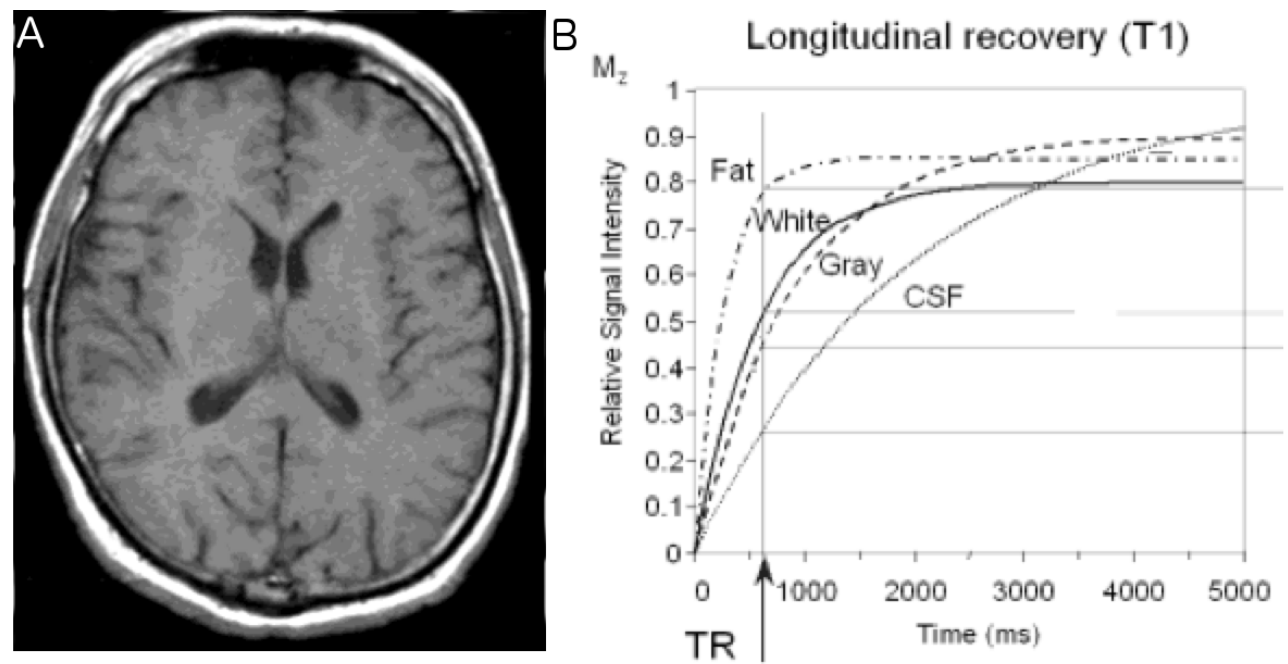

Figura 2.2: Contraste ponderado em $T_{1}$. Em A) podemos ver uma imagem gerada através da ponderação em $T_{1}$. Em B), verificamos um gráfico de evolução temporal da magnetização longitudinal após um pulso de $90^{\circ}$ para diferentes tecidos do cérebro. Nota-se que os diferentes tecidos possuem diferentes tempos de relaxação. Nesse caso, a substância branca contribuirá com pixels mais claros, o fluido cérebro espinhal terá pixels mais escuros e a substância cinzenta será composta de pixels de intensidade intermediária. Quanto maiores os níveis de contraste melhor para saber a fronteira de cada tecido. Imagens obtidas de (BUSHBERG et al., 2012)

Além da escolha do mecanismo de contraste e definição de alguns parâmetros temporais, outra variável que influencia na imagem de ressonância magnética é a sequencia de pulsos a ser utilizada. Uma das mais comuns é a spin-eco que consiste na geração de um pulso de radiofrequencia seguido, após um período, por um pulso de refocalização e culminando com a leitura do eco do sinal gerado (HARGREAVES, 2012). Trata-se de uma sequencia largamente estudada e utilizada tendo sua maior desvantagem no 
tempo de aquisição das imagens, geralmente na ordem de minutos (PLEWES, 1994). Para resolver essa questão, foi desenvolvida uma sequencia chamada gradiente de eco, a qual permite a obtenção das imagens de forma bem mais rápida, na ordem de segundos ou milionésimos de segundos. Mais detalhes sobre essa sequencia podem ser vistos em (PRICE, 1995; HARGREAVES, 2012).

Em geral, quando se fala em IRM, pensa-se em imagens com alto nível de detalhamento, indicadas para medir o volume de pequenas estruturas ou espessuras de finas superfícies. Entretanto, para obtenção de imagens com alta resolução espacial, na ordem de $1 \mathrm{~mm}$ isotrópico, o ideal é a utilização da técnica tridimensional, que consiste na aplicação de outro gradiente de fase ao invés de pulsos de seleção para excitar diferentes fatias no volume de interesse. Assim, a área de interesse vai sendo lida de forma contínua, garantindo um maior nível de detalhes na imagem final. Sua desvantagem reside no fato de que o tempo total de aquisição fica bem maior.

Em geral, quando se deseja construir uma imagem bem detalhada de uma região utilizando o contraste $T_{1}$, costuma-se combinar a técnica tridimensional com a sequencia gradiente de eco (ou suas variações), permitindo uma aquisição em tempo razoável com alto grau de detalhamento (HARGREAVES, 2012). Um detalhamento desse cenário pode ser visto na figura 2.3.

Todas as técnicas apresentadas constituem-se de estratégias para geração das imagens. Contudo, uma vez obtidas, diversos estudos podem ser realizados a partir delas. Discorreremos sobre alguns deles no tópico a seguir.

\subsection{Medida de espessura cortical através de imagens por $R M$}

As imagens geradas por meio da ressonância magnética se mostram bastante eficazes tanto na discriminação de tecidos, como no detalhamento de diferentes órgãos (RINCK, 2013). Contudo, diversos estudos estão focados 


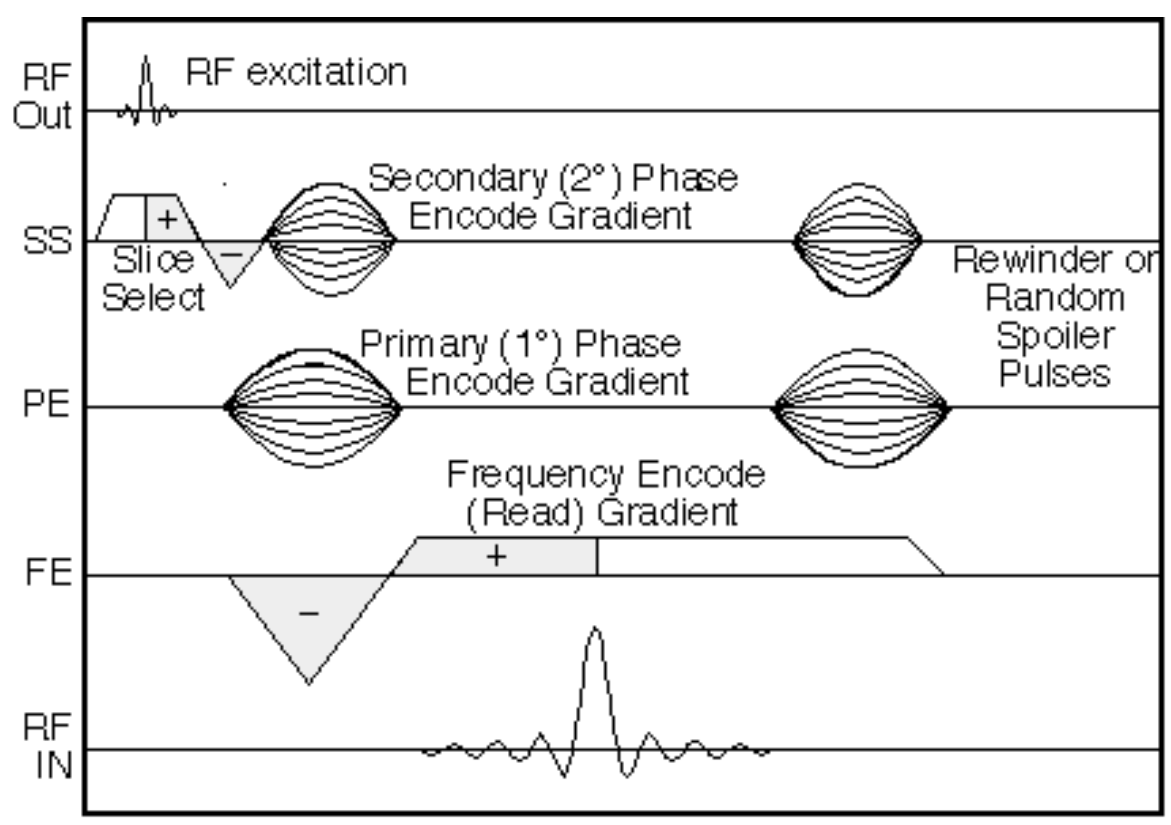

Figura 2.3: Típica sequencia de pulsos do tipo gradiente de eco para obtenção de imagens tridimensionais. Sequencias gradiente de eco geralmente consistem de repetidos pulsos de radiofrequência com ângulo $\alpha$ (ângulo de flip) espaçados por um tempo TR. Cada uma das linhas horizontais representam os diferentes canais no aparelho: Out (Saida de radiofrequencia), SS (Gradiente de seleção da fatia), PE (Gradiente de fase), FE (Gradiente de leitura ou frequencia), RF IN (Aquisição). Ao final de cada leitura, aplica-se um gradiente de destruição para eliminação do sinal remanescente e consequente diminuição do TR e diminuição no tempo de aquisição final. Imagem obtida de (HARGREAVES, 2012)

não no processo de geração das imagens, mas sim nas informações que podem ser obtidas das mesmas. Em se tratando do cérebro humano, a partir de um conjunto de imagens é possível obter diversos parâmetros morfométricos tais como volume de uma determinada região, espessura ou área de curvatura. Essa obtenção pode ser feita por um profissional especializado ou de forma automatizada, através de algoritmos computacionais.

Existem

diversos softwares executando algoritmos para o processamento de IRM do cérebro visando a extração de parâmetros morfométricos. Dentre aqueles com código aberto, os mais comuns são o Caret (ESSEN, 2013) e o FreeSurfer (FISCHL, 2013). De maneira simplificada, tais algoritmos incluem primeiramente a remoção de tecido não cerebral (SEGONNE et al., 2004), transformação 
das imagens em um modelo de referência para futuras comparações entre diferentes sujeitos, determinação das fronteiras entre as substâncias branca, cinzenta, e o fluído cérebro-espinhal (DALE; FISCHL; SERENO, 1999; DALE; SERENO, 1993; FISCHL; DALE, 2000), divisão em regiões de acordo com um atlas de referência (DESIKAN et al., 2006; FISCHL et al., 2004) e obtenção de parâmetros tais como espessura cortical, volume ou curvatura de cada região mediante aplicação de diferentes técnicas (FISCHL; DALE, 2000). Discorreremos a seguir sobre algumas técnicas implementadas nos softwares supra citados para definição da espessura cortical, métrica escolhida para ser submetida ao software desenvolvido no presente estudo.

O córtex cerebral humano constitui-se de uma extensa fita de neurônios conectados com uma espessura média de 2,5mm, variando entre 1 e 4,5mm em diferentes partes do cérebro (FISCHL; DALE, 2000). O mesmo desempenha um papel fundamental na maioria dos processos cognitivos, tais como visão, linguagem e cálculo e sofre alterações com o processo normal de envelhecimento e/ou doenças neuro-degenerativas (CLARKSON et al., 2011). Recentemente, estudos com imagens mostraram diferenças entre as espessuras corticais de pacientes e indivíduos saudáveis em diversas doenças, tais como Alzheimer (LERCH et al., 2005; KNIGHT et al., 2011), degeneração do lobo fronto-temporal (ROHRER et al., 2009), esclerose múltipla (SAILER et al., 2003), doença de Huntington (ROSAS et al., 2008), além de alterações normais que ocorrem com o processo de envelhecimento (SALAT et al., 2004).

Idealmente, a medida da espessura cortical deveria ser o comprimento das conexões dos axônios ao longo de todo o córtex (LERCH; EVANS, 2005; LOHMANN; PREUL; HUND-GEORGIADIS, 2003). Entretanto, devido à limitações na resolução das imagens, em geral da ordem de $1 \mathrm{~mm}$, tais comprimentos não são distinguíveis e portanto tal medida não é possível atualmente. Com isso, diversos métodos de medida indireta foram propostos, a maioria deles traçando primeiramente uma fronteira entre as substâncias branca e cinzenta e na sequência outra fronteira entre essa última e o fluido 
cérebro espinhal, tal como mostrado na figura 2.4.

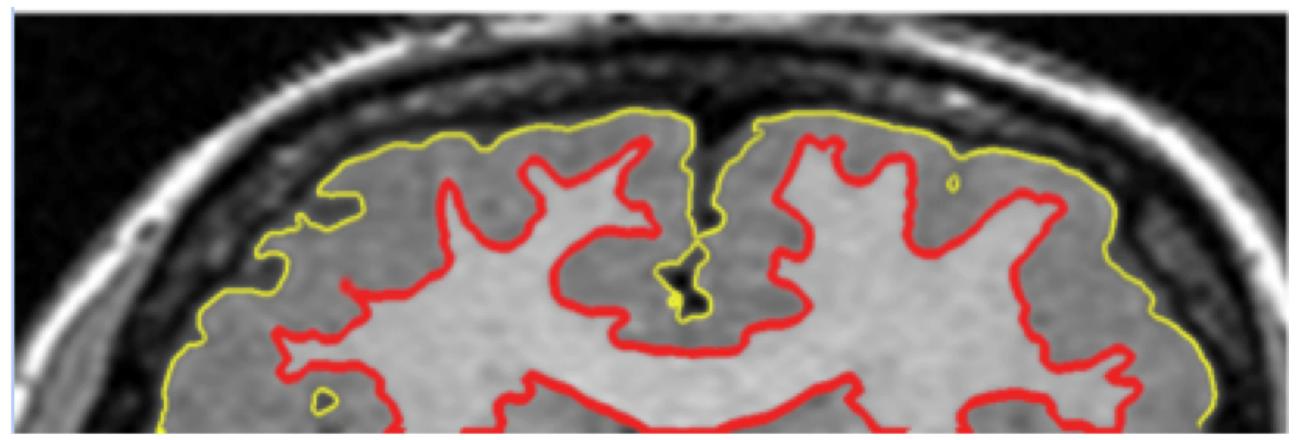

Figura 2.4: Fronteiras das substâncias branca, cinzenta e o fluído cérebro-espinhal. O passo inicial para estimativa da espessura cortical é definir as fronteiras de cada tipo de tecido. A linha vermelha indica a fronteira entre as substâncias branca e cinzenta enquanto a linha amarela indica a fronteira entre a substância cinzenta e o fluído cérebro-espinhal.

A comunidade científica ainda não chegou à um consenso sobre qual seria a forma mais apropriada de medir a espessura cortical. Muitos trabalhos têm sido publicados acerca dessa questão e as técnicas descritas a seguir reunem uma boa representação dos métodos mais utilizados na literatura para essa finalidade (AGANJ et al., 2009).

Métodos de superfície acoplada (FISCHL; DALE, 2000; MACDONALD et al., 2000) definem uma quantidade de pontos na superfície interior, os quais são expandidos até a fronteira da superfície exterior. Após tal processo, a espessura cortical é calculada como sendo a distância euclidiana entre pares de pontos correspondentes em ambas as superfícies. Sua desvantagem reside no fato de que uma superfície deslocada pode resultar em uma super estimativa da espessura real (figura 2.5A). Esse é o método atualmente utilizado pelo FreeSurfer (FISCHL, 2013).

Os métodos de ponto mais próximo (MILLER et al., 2000), computam, para cada ponto de uma das superfícies, o ponto mais próximo na outra superfície. O grande desafio aqui é que a espessura não é simétrica, o que significa que muitas vezes não será possível obter a mesma medida se a superfície onde está localizado o ponto de referência inicial for trocada (figura 2.5B). 
Métodos baseados no formalismo de Laplace (HAIDAR; SOUL, 2006; JONES; BUCHBINDER; AHARON, 2000; YEZZI; PRINCE, 2003) resolvem a equação de Laplace entre as fronteiras de cada superfície para criar uma série de superfícies equipotenciais usando uma simulação matemática de campos eletrostáticos. O comprimento das linhas de fluxo entre as duas superfícies definem a espessura, conforme ilustrado na figura 2.5C. Com essa abordagem, cada ponto terá apenas uma medida de espessura entretanto ainda se faz necessária uma segmentação prévia das superfícies interna e externa e o tempo computacional necessário para o cálculo ainda é um desafio.

Outra categoria de métodos define a espessura fazendo uso de um eixo central (PIZER et al., 1998). A mesma é estimada como o diâmetro da maior espera fechada na substância cinzenta. A figura 2.5D mostra que uma mudança relativamente acentuada no diâmetro pode causar uma nova ramificação e afetar a topologia da medida.

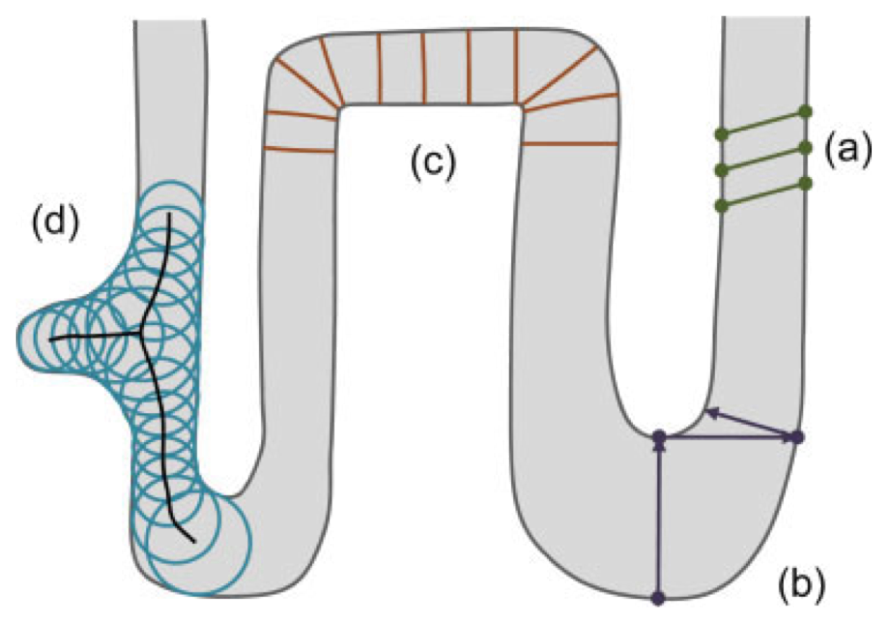

Figura 2.5: Formas mais comuns de obter medidas de espessura cortical. (a) Método de superfície acoplada, (b) Método de ponto mais próximo, (c) Método baseado no formalismo de laplace e (d) Método de maior esfera fechada. Imagem obtida de (AGANJ et al., 2009)

Assim como a espessura, os demais parâmetros morfométricos são utilizados em diversos estudos relacionados à idade, desenvolvimento cerebral e patologias. No tópico a seguir discorreremos sobre alguns procedimentos que permitem a utilização de tais parâmetros para construção de uma rede de 
conectividade cerebral.

\subsection{Conectividade estrutural}

Na última década, houve um aumento na quantidade de estudos discorrendo sobre conectividade cerebral (BULLMORE; SPORNS, 2012; SPORNS, 2012; GUYE et al., 2010), tanto no âmbito de conectividade funcional, com técnicas de EEG, MEG e fMRI (MICHELOYANNIS et al., 2006; STAM, 2004; STAM et al., 2007; ACHARD et al., 2006; BASSETT; BULLMORE, 2006; EGUíLUZ et al., 2005; GREICIUS et al., 2003; VERTES et al., 2012), quanto no âmbito de conectividade estrutural (BULLMORE; SPORNS, 2009; CHEN et al., 2008; HE et al., 2009; HE; CHEN; EVANS, 2007) foco do presente estudo.

Quando se fala em conectividade estrutural cerebral, muitos grupos vêm empregando técnicas de imagens ponderadas em difusão e tractografia visando examinar a conectividade como sendo um fenômeno da substância branca (BIHAN; JOHANSEN-BERG, 2012). Tais técnicas se expandiram rapidamente a partir de suas origens (BASSER; MATTIELLO; LEBIHAN, 1994), passando por muitos avanços tanto no processo de aquisição, quanto análise (TUCH et al., 2002), porém ainda sofrem com algumas limitações, incluindo a dificuldade de mensurar longos caminhos, desconsideração de cruzamentos existentes, sensibilidade ao algoritmo escolhido, parâmetros utilizados nos processamentos, entre outras (BASTIANI et al., 2012). Assim, além dessas abordagens têm sido crescente o interesse nas correlações morfológicas entre diferentes regiões cerebrais, como uma forma alternativa de construir redes de conectividade estrutural, mais recentemente chamada conectividade anatômica. Ramnani (RAMNANI et al., 2004) propôs novos mecanismos para análise da conectividade cerebral utilizando covariância de características morfológicas, as quais foram posteriormente analisadas por (MECHELLI et al., 2005); He e colaboradores criaram uma rede de conectividade baseada em dados de espessura cortical e posteriormente 
analisaram suas alterações com a doença de Alzheimer (HE; CHEN; EVANS, 2007; HE; CHEN; EVANS, 2008); Chen e colaboradores analisaram a estrutural modular de uma rede de conectividade criada com base em parâmetros morfológicos (CHEN et al., 2008); Gong e colaboradores fizeram uma comparação entre correlações de espessura cortical e conectividade baseada em DTI e analisaram diferenças entre as redes anatômicas provenientes de homens e mulheres (GONG et al., 2009b; GONG et al., 2012).

A morfologia do córtex cerebral humano varia consideravelmente de acordo com alguns fatores tais como influência genética, envelhecimento, alimentação e comportamento, porém o grau de contribuição de cada um na correlação morfológica entre as diferentes regiões permanece obscuro (EVANS, 2013). Ainda assim, é possível utilizar tais covariâncias para montagem de uma rede de conectividade cerebral de forma análoga à técnica de conectividade funcional. Enquanto esta última utiliza, para montagem da rede de conectividade, correlações entre os sinais regionais de fMRI e/ou EEG/MEG ao longo do tempo em um indivíduo, a primeira se vale da correlação entre medidas morfológicas regionais ao longo de diferentes sujeitos. É importante notar que a existência de uma correlação morfológica entre determinadas regiões não significa necessariamente a existência de uma fibra direta de conexão entre elas. Tal como ocorre na correlação funcional, a correlação anatômica pode surgir de uma conexão indireta (EVANS, 2013). Diversos parâmetros morfológicos podem ser utilizados como base para cálculo das correlações entre as diferentes regiões cerebrais, dentre eles espessura, volume ou área do córtex cerebral, sendo o primeiro o mais comum na literatura atualmente (THAMBISETTY et al., 2010; HE; CHEN; EVANS, 2007; FISCHL; DALE, 2000; LERCH et al., 2005; SALAT et al., 2004). Conforme já detalhado, tal parâmetro pode ser obtido através de técnicas computacionais e o grau de correlação entre tais espessuras ao longo de vários indivíduos pode ser utilizado para determinar a existência das conexões.

Por tratar-se de uma técnica de conectividade estrutural, é natural 
que sejam feitas diversas comparações entre a covariância morfológica e abordagens baseadas em DTI, já mais consolidadas em estudos dessa finalidade. Gong e colaboradores compararam padrões de correlação de espessura cortical e mapas probabilísticos provenientes de tractografia em adultos saudáveis e identificaram que aproximadamente $40 \%$ das correlações de espessura estavam em consonância com os resultados de DTI. Além disso, a grande maioria das correlações negativas (em torno de 90\%) não obtiveram correspondentes nas conexões por difusão, o que demonstra indícios de uma ligação entre ambas as técnicas (GONG et al., 2012).

Uma vez montada uma rede de conectividade, é possível aplicar conceitos de análise de grafos para estudar os parâmetros da rede de conectividade e analisar suas alterações em diferentes circunstâncias. Tais análises já foram massissamente realizadas em estudos de conectividade funcional ou baseados em DTI (BULLMORE; SPORNS, 2012; LATORA; MARCHIORI, 2001). A completa descrição das métricas obtidas em análises de grafos não é o foco do presente trabalho e poderá ser vista com mais detalhes em (RUBINOV; SPORNS, 2010), contudo, algumas métricas mais comuns utilizadas incluem grau (D): número de conexões de um nó, coeficiente de agrupamento $\left(\mathrm{C}_{P}\right)$ : fração dos vizinhos de um nó que também são vizinhos entre si e comprimento médio do caminho $\left(\mathrm{L}_{P}\right)$ : média dos caminhos mais curtos encontrados entre todos os pares de nós da rede. Nas equações 2.1 e 2.2 estão descritas as formulas para cada parâmetro usado nesse trabalho, nas quais $n$ é o número de vértices da rede, $e_{i}$ é o número de pares conectados entre todos os vizinhos do vértice $i, k_{i}$ é o número de vizinhos do nó $i$ e $d\left(v_{i}, v_{j}\right)$ é a menor distância existente entre os nós $i$ e $j$.

$$
\begin{gathered}
C_{p}=\frac{1}{n} \sum_{i=1}^{n} \frac{2 e_{i}}{k_{i}\left(k_{i}-1\right)} \\
L_{p}=\frac{1}{n(n-1)} \sum_{i \neq j} d\left(v_{i}, v_{j}\right)
\end{gathered}
$$

De acordo com Watts e Strogatz (WATTS; STROGATZ, 1998), é possível 
classificar as redes complexas de acordo com as variáveis acima $\left(C_{p} \mathrm{e}\right.$ $\left.L_{p}\right)$. Redes puramente aleatórias são caracterizadas por um pequeno $L_{p}$ (tipicamente o logaritmo natural do do número de nós) e um pequeno $C_{p}$. Por sua vez, redes de mundo pequeno são caracterizadas por um alto $C_{p}$ (quando comparado ao valor esperado para uma rede aleatória com a mesma característica) e um pequeno $\mathrm{L}_{P}$ (valor semelhante ao encontrado para uma rede aleatória). Redes desse tipo apresentam poucas conexões de longo alcance que agem como atalhos, permitindo uma rápida transferência de informação ao longo de toda estrutura. 


\section{Capítulo}

\section{Materiais e métodos}

No presente capítulo, descreveremos o funcionamento do software desenvolvido no presente estudo, capaz de gerar redes de conectividade estrutural anatômica cerebral baseadas em uma determinada característica morfológica escolhida pelo usuário, tal como espessura cortical, volume, área ou curvatura.

\subsection{Imagens de entrada e pré-processamento}

O software desenvolvido no presente estudo recebe dados provenientes de um pré-processamento de imagens de ressonância magnética cerebral. Para gerar a massa de dados necessária para executá-lo, utilizamos imagens de dois grupos de pessoas. No primeiro grupo, foram selecionadas imagens de 191 indivíduos saudáveis com idade variando de 6 à 88 anos, desvio-padrão 21,4 anos e média 35,2 anos, dos quais 95 eram do sexo feminino e outros 96 do sexo masculino. Todos foram testados previamente e necessitavam preencher alguns requisitos para serem considerados saudáveis tais como possuir visão normal, estar bem de saúde e não sofrer de doenças que afetam o sistema nervoso central como hipotiroidismo, esclerose múltipla, doença de Parkinson ou traumas cranianos. Já no segundo grupo, foram utilizadas imagens de 93 pacientes com idades variando de 23 à 67 anos (desvio-padrão: 9,2 anos e média: 42,4 anos), dos quais 47 eram do sexo feminino e os outros 46 do sexo masculino. Todos os pacientes desse grupo possuíam confirmação 
de diagnóstico de epilepsia de lobo temporal seguindo indicadores clínicos previamente definidos (VELASCO; TERRA-BUSTAMANTE, 1999). As amostras foram obtidas como parte da nossa colaboração com o Prof. Dr. Antônio Carlos dos Santos, no Centro de Imagens e Física Médica do Hospital das Clínicas da Faculdade de Medicina de Ribeirão Preto. Todos os participantes com idade acima de 18 anos e pais ou responsáveis no caso das crianças, assinaram um termo de conscientização autorizando a utilização das imagens em pesquisas científicas.

As imagens de ambos os grupos de indivíduos foram adquiridas usando uma bobina de cabeça de oito canais em uma máquina Philips, modelo Achieva de 3 Tesla. Para aquisição, foi utilizada uma sequencia de pulsos em 3D, ponderada em $\mathrm{T}_{1}$ usando a técnica MP-RAGE (Magnetization Prepared Rapid Gradient Echo), com os seguintes parâmetros: tempo de inversão: 900ms; ângulo de flip: 8 graus; tempo de eco: 3,2ms; espaçamento de eco: $7 \mathrm{~ms}$; tempo de repetição: 3.000ms; matriz de visualização 240x240x160 pixels; campo de visão: $240 \mathrm{~mm}$. De cada indivíduo foram coletadas 160 fatias sagitais com voxels isotrópicos de $1 \mathrm{~mm}$.

Finalizado o processo de aquisição, as imagens foram processadas no software FreeSurfer versão 4.5.0 (FISCHL, 2013). Nesse processo, o cérebro de cada indivíduo foi dividido em 64 regiões, sendo 32 em cada hemisfério, tal como descrito no atlas proposto por Fischl (FISCHL et al., 2002). Para cada região, foi calculada pelo FreeSurfer a espessura do córtex mediante técnicas já descritas na seção 2.2 , bem como outras características como volume, área e curvatura. Os arquivos gerados foram então submetidos à um script para consolidação dos dados em um arquivo único, utilizado como entrada para o software implementado no presente estudo.

\subsection{O software}

O software desenvolvido pode ser dividido em 6 etapas. Primeiramente é feita a entrada dos dados provenientes do FreeSurfer, seguida por um 
processamento para retirar o efeito da idade, montagem da matriz de correlação, construção da rede de conectividade, aplicação de um algoritmo para cálculo de comunidades (clusters) na rede encontrada e saída dos dados. Um esquema pode ser visto na figura 3.1 e cada etapa será detalhada nas seções posteriores.

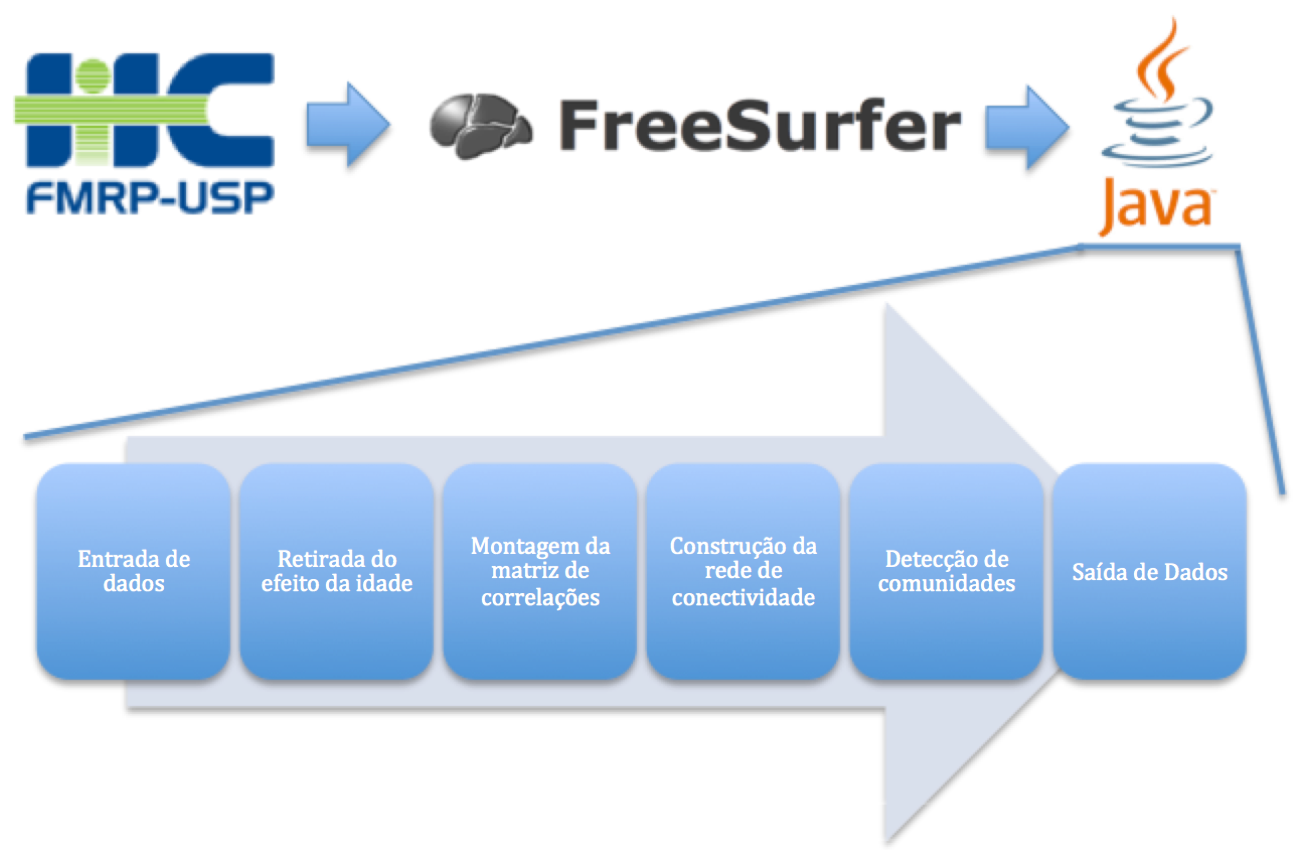

Figura 3.1: Fluxo de processamento dos dados. Inicialmente as imagens foram coletadas no centro de imagens do HC-FMRP-USP, seguidas por um processamento no FreeSurfer e por fim são analisadas por um software desenvolvido em JAVA para suportar o presente trabalho e auxiliar novas pesquisas com diferentes massas de dados.

Na figura 3.2 pode ser vista a interface do software construído. O usuário escolhe o arquivo de entrada, método para retirada do efeito da idade, estratégia para cálculo do coeficiente de correlação de corte, quantidade de redes aleatórias, intervalo de análise dos coeficientes de corte e pasta de destino onde serão gravados os arquivos gerados. Cada item será visto com mais detalhes a seguir. 


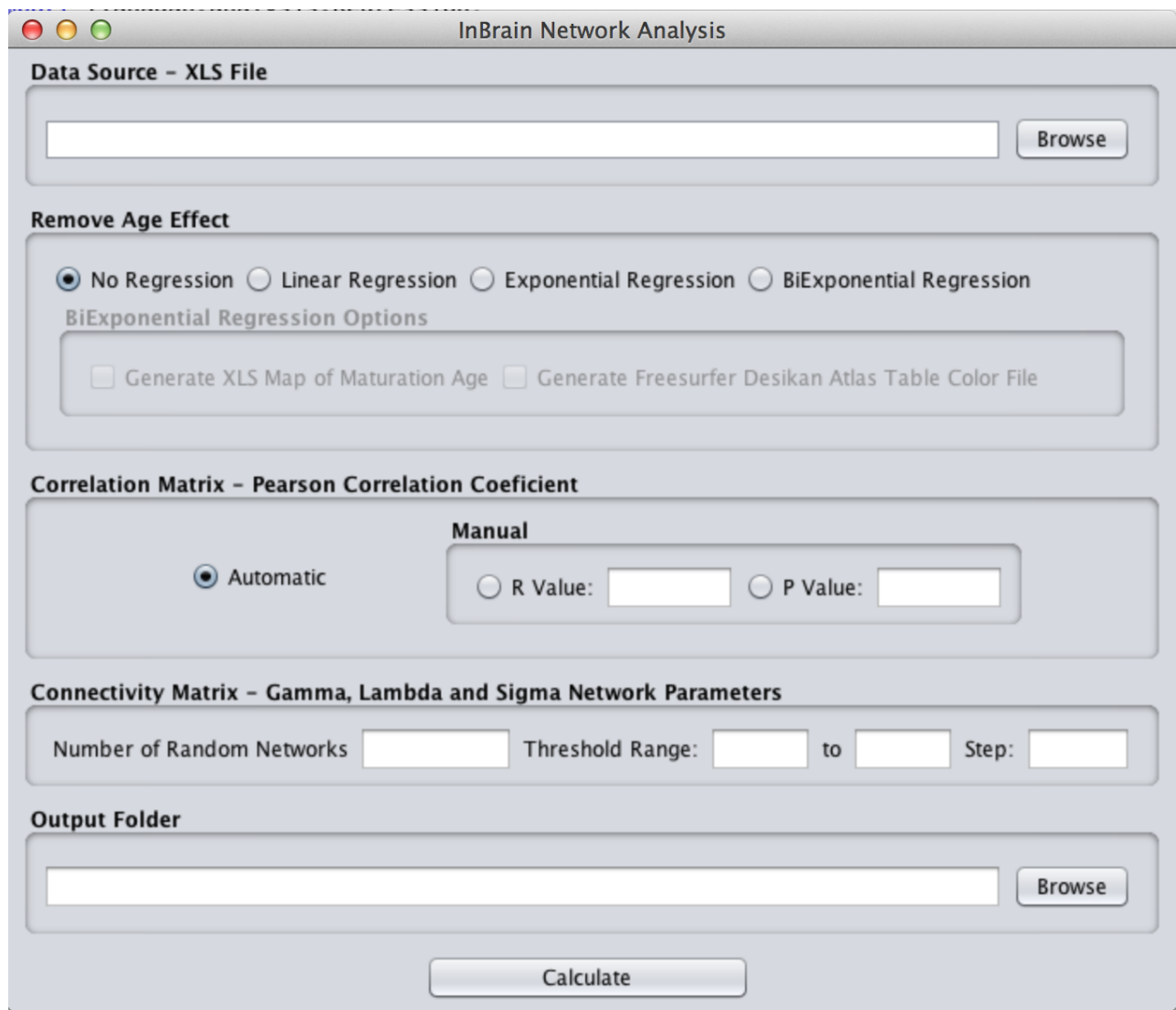

Figura 3.2: Interface do software construído. Por meio dessa interface o usuário escolhe as opções antes da execução.

\subsubsection{Entrada de dados}

A primeira etapa do processamento após a saída do FreeSurfer se refere à entrada dos dados. Para tal, é necessário uma planilha em formato XLS contendo em suas linhas os dados dos indivíduos e nas colunas o parâmetro morfológico de cada região cerebral, a qual pode ser gerada automaticamente através da aplicação de um script nos dados processados pelo FreeSurfer. Para tornar o sistema mais flexível, o mesmo foi preparado para suportar qualquer quantidade de regiões (visto que podem ser utilizados diferentes atlas), bem como qualquer parâmetro morfológico, tais como espessura cortical, volume ou área ou curvatura. Um exemplo de tal planilha pode ser visto na tabela 3.1 e a mesma é parametrizada no software por meio da seção Data Source - XLS File, ilustrada na figura 3.2. 


\begin{tabular}{llllll}
\hline Identificador & Sexo & Idade na RM & Região 1 & Região 2 & Região 3 \\
\hline \hline 0001 & $M$ & 6 & 3,815 & 2,297 & 2,488 \\
0002 & $\mathrm{M}$ & 25 & 3,136 & 2,552 & 2,042 \\
0003 & $\mathrm{~F}$ & 55 & 2,486 & 2,272 & 1,715 \\
\hline \hline
\end{tabular}

Tabela 3.1: Exemplo de planilha de entrada contendo dados para processamento. Aqui estão ilustradas três regiões como exemplo porém o sistema se adequa à qualquer quantidade inserida.

\subsubsection{Retirada do efeito da idade}

Definimos na seção 2.3 conexão anatômica como sendo associações estatísticas relevantes entre regiões, as quais podem ser verificadas através do cálculo de coeficientes de correlação. No entanto, para garantir que a correlação encontrada não seja decorrente dos efeitos naturais do envelhecimento, podem ser utilizadas utilizadas técnicas de regressão. $\mathrm{Na}$ literatura, os estudos envolvendo conectividade anatômica em geral realizam regressões lineares (HE; CHEN; EVANS, 2007; CHEN et al., 2008) para retirada do efeito da idade, no entanto, identificamos outras abordagens que poderiam ser mais adequadas nesses casos. Implementamos, além do algoritmo de regressão linear, outros dois modelos não lineares de regressão, um exponencial e outro bi-exponencial. Esse último, seguindo a equação 3.1.

$$
r(x)=\left\{\begin{array}{l}
A+B e^{C x}, x<\text { idade de corte } \\
D+E e^{F x}, x \geq \text { idade de corte }
\end{array}\right\}
$$

Para encontrar a idade de corte mencionada na equação 3.1, o sistema realiza uma varredura analisando todas as idades de corte possíveis e escolhendo aquela na qual o conjunto de ambas as curvas apresente a menor soma quadrática dos resíduos da regressão, tentando uma aproximação mais correta da realidade e analisando cada região individualmente buscando retirar mais fielmente o efeito da idade dos dados analisados. Por fim, 
os valores encontrados pelo FreeSurfer são substituídos pelos resíduos da regressão e utilizados como base para cálculo da matriz de correlações.

Caso o usuário opte por algum método de regressão não linear, o software também realiza o cálculo das derivadas em cada idade e em cada região do atlas utilizado. Tal informação é útil, por exemplo, em análises comparativas relacionadas à taxas de decaimento da característica morfológica analisada em determinadas regiões. O método de regressão linear pode ser escolhido através da seção Remove Age Effect, descrita na figura 3.2. Caso seja escolhido o método Bi-Exponencial, é possível gerar também um mapa com as idades de corte encontradas e ainda caso seja escolhido o atlas Desikan (FISCHL et al., 2002), implementado por padrão no FreeSurfer, é possível gerar também um mapa de cores para tais idades o qual pode ser utilizado posteriormente no próprio FreeSurfer para geração de um mapa de cores cerebral tal como mostrado na figura 4.2.

\subsubsection{Montagem da matriz de correlações}

Um ponto chave na construção de redes de conectividade cerebral é a construção da matriz de conectividade anatômica. No presente estudo, definimos conexões anatômicas como sendo associações estatísticas relevantes de uma determinada característica morfológica entre diferentes regiões cerebrais conforme detalhado na seção 2.3. Para cálculo de tais associações, podem ser utilizadas técnicas de correlação tais como correlação parcial ou correlação de Pearson. Em nosso software, implementamos essa última por tratar-se de uma técnica simples, largamente utilizada e de fácil interpretação. A fórmula utilizada para o cálculo pode ser vista na equação 3.2. Ao final, obtivemos uma matriz de correlação $\mathrm{N} \times \mathrm{N}$, onde $\mathrm{N}=64$ é o número de regiões analisadas neste trabalho.

$$
R=\frac{\sum_{i=1}^{n}\left(x_{i}-\bar{x}\right)\left(y_{i}-\bar{y}\right)}{\sqrt{\sum_{i=1}^{n}\left(x_{i}-\bar{x}\right)^{2} \sum_{i=1}^{n}\left(y_{i}-\bar{y}\right)^{2}}}
$$

Futuras evoluções podem tratar novas métricas de correlação, até 
mesmo para fins comparativos. Para o cálculo dos coeficientes de correlação de Pearson e geração da matriz de correlações, adaptamos uma biblioteca nomeada Java Scientific Library (FLANAGAN, 2013). Através da matriz de correlação gerada, é possível obter uma rede de conectividade, conforme será visto a seguir.

\subsubsection{Construção da rede de conectividade}

Assim como em outros estudos presentes na literatura (HE; CHEN; EVANS, 2007; CHEN et al., 2008), obtamos pela montagem de uma rede de conectividade binária e não ponderada. Essa abordagem nos força a escolher um valor de corte para o coeficiente de correlação encontrado na seção 3.2.3 a partir do qual as regiões em questão serão consideradas anatomicamente conectadas. No presente estudo, o software construído aceita um coeficiente de correlação de corte fornecido manualmente pelo usuário, mediante a determinação do valor de $\mathrm{R}$ ou $\mathrm{P}$, ou também oferece um cálculo automático, definido pelo maior coeficiente de correlação possível que mantenha todas as regiões com ao menos uma conexão, ou seja, nenhuma região isolada das demais. Tais opções são escolhidas na seção Correlation Matrix - Pearson Correlation Coeficient, descrita na figura 3.2. Vale lembrar que P, também conhecido como p-valor, é a probabilidade de se obter uma estatística de teste igual ou mais extrema que aquela observada em uma amostra, sob a hipótese nula.

Uma vez obtida a rede de conectividade anatômica binarizada, tal estrutura pode ser descrita como um grafo não ponderado e não direcional, contendo $\mathrm{N}$ vértices e $\mathrm{K}$ arestas, com os vértices representando as regiões e as arestas representando as conexões. Conforme citado na seção 2.3, algumas métricas podem ser obtidas de tais grafos, tais como $D, \mathrm{C}_{P}$ e $\mathrm{L}_{P}$, as quais podem ser utilizadas para verificação do comportamento global da rede. Tais cálculos também foram implementados no software proposto no presente estudo. 
Estudos anteriores (HE et al., 2009; LATORA; MARCHIORI, 2001; HUMPHRIES; GURNEY; PRESCOTT, ; BERNHARDT et al., 2011; STAM, 2004; ACHARD et al., 2006), identificaram que as redes de conectividade cerebrais, tanto funcionais quanto estruturais, apresentam uma arquitetura de redes de mundo pequeno. Visando analisar tal aspecto das redes montadas em nosso estudo, implementamos também um mecanismo para examinar as propriedades de rede de mundo pequeno obtidas em nossas redes de conectividade. Para tal, os valores de $\mathrm{C}_{P}^{\text {real }}$ e $\mathrm{L}_{P}^{\text {real }}$ obtidos são comparados com os valores $\mathrm{C}_{P}^{\text {aleat }}$ e $\mathrm{L}_{P}^{\text {aleat }}$ de outras $\mathrm{K}$ redes aleatórias, sendo $\mathrm{K}$ um valor fornecido pelo usuário na seção Connectivity Matrix - Gamma, Lambda and Sigma Network Parameters -> Number of Random Networks, descrita na figura 3.2. Para geração das redes aleatórias, utilizamos o algoritmo de (MASLOV; SNEPPEN, 2002), o qual constrói as redes preservando o mesmo número de vértices, grau médio e distribuição de graus da rede original. Tipicamente, uma rede de mundo pequeno deve satisfazer duas condições: $\gamma=\frac{C_{P}^{\text {real }}}{C_{P}^{\text {aleat }}}>1$ e $\lambda=\frac{L_{P}^{\text {real }}}{L_{P}^{\text {aleat }}} 1$ (WATTS; STROGATZ, 1998), as quais podem ser unificadas em uma métrica quantitativa $\sigma=\frac{\gamma}{\lambda}>1$ (HUMPHRIES; GURNEY; PRESCOTT, ; ACHARD et al., 2006). É razoável imaginar que tais parâmetros serão afetados com a troca do coeficiente de correlação de corte utilizado para converter a matriz de correlações na rede de conectividade. Quando tal corte é elevado, algumas conexões fracas são excluídas e as redes resultantes se tornam mais esparsas, resultando em uma diminuição no grau médio $k$ e alteração global da estrutura. Nosso software permite que o usuário forneça um intervalo de valores para o coeficiente de correlação e faz o cálculo dos parâmetros acima descritos para cada coeficiente do intervalo fornecido, permitindo uma rápida análise das propriedades de rede à medida em que é alterado o coeficiente de correlação de corte, eliminando a necessidade de executar o programa diversas vezes para consolidar os dados. Tal intervalo é fornecido na seção Connectivity Matrix - Gamma, Lambda and Sigma Network Parameters -> Threshold range, ilustrada na figura 3.2. 


\subsubsection{Detecção de comunidades}

Modularidade é uma das mais importantes características presentes nos sistemas complexos da natureza, tanto nas áreas sociais quanto biológicas (NEWMAN, 2006; HARTWELL et al., 1999). A detecção de módulos em uma rede pode auxiliar na identificação de sub estruturas relevantes relacionadas à importantes funções, provendo um elo de ligação entre estrutura e função em redes complexas (FORTUNATO; BARTHELEMY, 2007). Evidências de estudos envolvendo mamíferos indicam uma potencial modularidade na topologia da rede cerebral humana, contudo, identificar módulos funcionais baseado em uma abordagem estrutural ainda permanece um desafio devido ao ainda incompleto entendimento e mapeamento detalhado das ligações neuronais no cérebro humano, conhecido como "connectome"(CHEN et al., 2008).

A idéia natural por trás de qualquer mecanismo de detecção de comunidades é que um grande conjunto de dados pode ser organizado e classificado em um certo número de grupos (CHEN et al., 2008). Tais mecanismos visam extrair diferentes níveis de organização, vinculando cada região à uma determinada comunidade, utilizando para tal apenas similaridades ou diferenças entre os nós da rede. Ao contrário de redes aleatórias, redes reais complexas são geralmente compostas de grupos possuindo nós mais conectados entre si que aos demais nós da rede (GFELLER, 2007). Tais grupos são geralmente denominados clusters ou comunidades. A figura 3.3 demonstra um exemplo de uma rede com 3 comunidades.

Existem diversos mecanismos para detecção de comunidades descritos na literatura e sua análise detalhada não é o foco do presente estudo. Em nosso software, implementamos o algoritmo proposto por (NEWMAN, 2006), pois trata-se de um algoritmo utilizado em diversas áreas, desde pesquisas relacionadas à transportes (LEO et al., 2013), redes sociais (CHEN; CHIANG; POOR, 2013), linguagem (VANDENBERGHE et al., 2013), conectividade cerebral (CHO; CHOI, 2010), doenças e epidemias (PENG et al., 2013), entre 


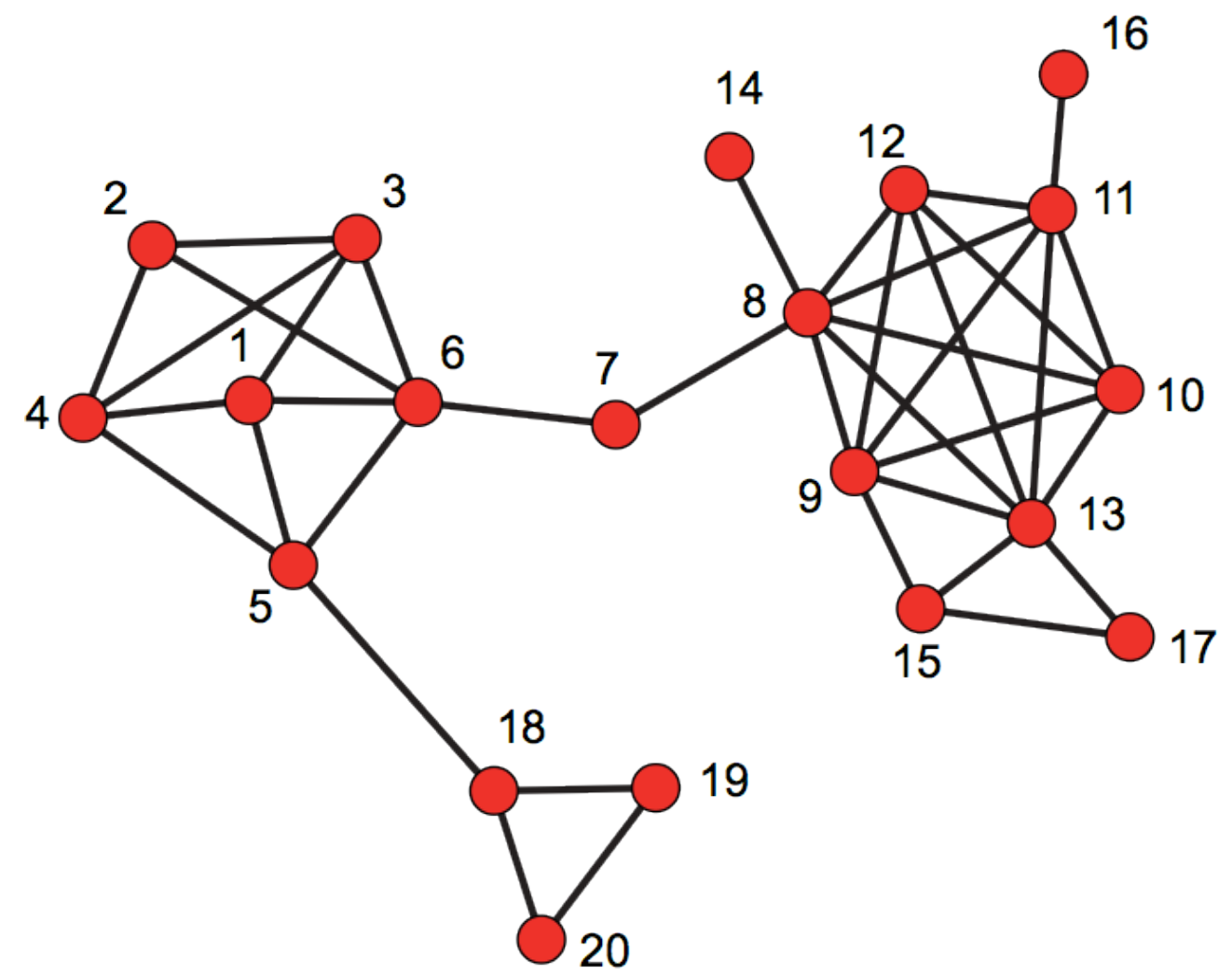

Figura 3.3: Exemplo de rede com três comunidades. É evidente, por exemplo, que os nós 10 e 12 pertencem à mesma comunidade, tendo exatamente os mesmos vizinhos. Contudo, devemos considerar o nó 14 como uma outra comunidade? À qual comunidade o nó 7 pertence? Como encontrar comunidades para redes de larga escala que não podem ser visualizadas trivialmente? Tais questões são solucionadas por algoritmos específicos destinados à essa finalidade. Imagem obtida de (GFELLER, 2007)

outros. Outro motivo da nossa escolha foi que encontramos algumas funções já codificadas em Java. De forma resumida, o algoritmo visa maximizar um parâmetro nomeado modularidade (Q), descrito na equação 3.3, sendo que $l_{s}$ é o número de arestas entre os nós pertencentes à comunidade $s$; $d_{s}$ a soma dos graus de todos os nós da comunidade $s ; L$ o número total de comunidades encontradas e $M$ o número total de arestas da rede (NEWMAN, 2006).

$$
Q=\sum_{s=1}^{L}\left[\frac{l_{s}}{M}-\left(\frac{d_{s}}{2 M}\right)^{2}\right]
$$

A motivação para definir a modularidade $\mathrm{Q}$ dessa maneira vem da observação de que tal valor é uma comparação da fração de nós que conectam 
nós do mesmo tipo (mesma comunidade) menos o valor esperado dessa mesma quantidade em uma rede com o mesmo número de comunidades, porém com conexões aleatórias entre seus nós. Caso o número de arestas de uma comunidade não seja melhor que a forma aleatória, Q será próximo de zero. Valores próximos à 1 indicam estruturas comunitárias fortes. Na prática, os valores de $\mathrm{Q}$ variam de 0,3 à 0,7 para a maioria das redes sociais e biológicas (NEWMAN, 2006).

O algoritmo implementado parte da rede completa, dividindo-a em duas comunidades de forma a maximizar o fator de modularidade Q. Uma vez separadas, cada comunidade é novamente submetida ao algoritmo para uma nova divisão e assim sucessivamente de forma recursiva até que nenhuma divisão possível resulte em um maior valor de $Q$, sendo essa portanto a condição de parada. Para ilustrar seu funcionamento vamos analisar sua execução na rede descrita na figura 3.3. O algoritmo parte da rede completa e calcula o valor de Q considerando todas as possíveis divisões da rede completa em duas sub-redes e escolhe a divisão que resultar no maior valor calculado. Os 3 maiores valores de Q encontrados ocorreram nas divisões entre os nós 7 e 8,6 e 7 e 5 e 18. As fórmulas para tais valores estão descritas nas equações $3.4,3.5$ e 3.6 .

$$
\begin{aligned}
& Q_{7-8}=\frac{16}{38}-\left(\frac{33}{76}\right)^{2}+\frac{21}{38}-\left(\frac{43}{76}\right)^{2}=0,4913 \\
& Q_{6-7}=\frac{15}{38}-\left(\frac{31}{76}\right)^{2}+\frac{22}{38}-\left(\frac{45}{76}\right)^{2}=0,4567 \\
& Q_{5-18}=\frac{3}{38}-\left(\frac{7}{76}\right)^{2}+\frac{34}{38}-\left(\frac{69}{76}\right)^{2}=0,1409
\end{aligned}
$$

Nesse cenário, o maior valor de Q encontrado foi 0,491 quando houve a divisão das comunidades entre os nós 7 e 8. De forma recursiva, cada uma das 2 sub-redes encontradas é submetida novamente ao algoritmo para verificação de uma possível nova divisão que resulte em um valor ainda maior de Q. Dessa 
vez, ao criar mais uma comunidade entre os nós 5 e 18, obteremos a equação 3.7.

$$
Q_{5-18}=\frac{3}{38}-\left(\frac{7}{76}\right)^{2}+\frac{12}{38}-\left(\frac{26}{76}\right)^{2}+\frac{21}{38}-\left(\frac{43}{76}\right)^{2}=0,5017
$$

Qualquer outra divisão realizada nas comunidades encontradas resultaria em um valor de $\mathrm{Q}$ menor que 0,501. Com isso, a rede global foi dividida em 3 comunidades. Procedimento análogo é aplicado às redes de conectividade encontradas pelo software desenvolvido no presente estudo.

\subsubsection{Saída de dados}

Após executado, o software implementado no presente trabalho gera por padrão um conjunto de arquivos variando de 2 a 4 dependendo do conjunto de opções selecionado. Os dois primeiros arquivos gerados em qualquer execução são uma planilha em formato XLS e um arquivo texto em formato TSV. A planilha contém os coeficientes de correlação de Pearson calculados para cada par de regiões, a rede de conectividade binarizada e também as comunidades encontradas e pode ser aberta em qualquer editor compatível com formatos XLS, tal como Microsoft Excel. Já o arquivo TSV é um arquivo em formato textual contendo todos os pares de regiões conectadas separados por uma tabulação TAB, podendo ser aberto em qualquer editor de texto ou softwares como MatLab, permitindo um intercâmbio com outros estudos.

Caso o usuário escolha uma opção de regressão para remoção do efeito da idade, seja ela linear, exponencial ou bi-exponencial conforme mostrado na seção Remove Age Effect da figura 3.2 a planilha XLS indicada acima conterá uma nova aba com as equações de regressão calculadas para cada região. Caso o método escolhido seja não linear, será gerada uma nova aba contendo os valores médios das derivadas da curva de regressão em cada região, separadas em três grupos: adultos jovens, com idades entre 21 e 40 anos; adultos, com idades entre 41 e 60 anos e idosos, com idades acima de 60 anos. Tal informação é útil para analisar a taxa de decaimento da característica morfológica estudada em cada região individualmente. Mais 
especificamente, caso seja escolhida a opção de regressão bi-exponencial, o quadro BiExponential Regression Options sera habilitado e o usuário poderá ainda marcar as opções Generate XLS Map of Maturation Age e Generate Freesurfer Desikan Atlas Table Color File, as quais podem ser vistas na figura 3.2. Marcando a primeira opção a planilha XLS indicada acima conterá uma nova aba com as idades de corte de cada região e marcando a segunda opção, o software irá gerar 2 novos arquivos em formato texto, um para cada hemisfério, os quais podem ser abertos com o FreeSurfer e permitem a geração automática de mapas semelhantes aos vistos na figura 4.2, contemplando uma visualização gráfica das idades de corte de cada região.

\subsubsection{Casos de uso}

Para ilustrar as possibilidades de utilização do software, foi montado um diagrama de casos de uso ilustrando as possibilidades nas quais o mesmo pode ser utilizado para auxílio em análises de natureza semelhante ao presente estudo. O mesmo pode ser visto na figura 3.4. Nota-se que o software pode ser utilizado em diversas situações e diversos outros estudos, não necessariamente de conectividade cerebral. Realiza cálculo de regressões lineares ou não lineares, cômputo do coeficiente de correlação de Pearson, calcula automaticamente o coeficiente de correlação de corte, analisa o comportamento da rede encontrada comparando-a com redes de mundo pequeno e permite a detecção de comunidades e grupos de regiões. Todas as opções de utilização descritas na figura 3.4 podem ser executadas de forma independente, possibilitando que um usuário execute apenas a opção desejada para seu estudo, tal como detecção de comunidades para redes de conectividade funcional, análise de um comportamento de rede de mundo pequeno para um estudo de comportamento social ou cálculo do coeficiente de correlação de Pearson em um estudo estatístico por exemplo. Isso confere ao software um caráter bem mais flexível e abrangente, aumentando as chances 
de futuras contribuições da comunidade acadêmica.

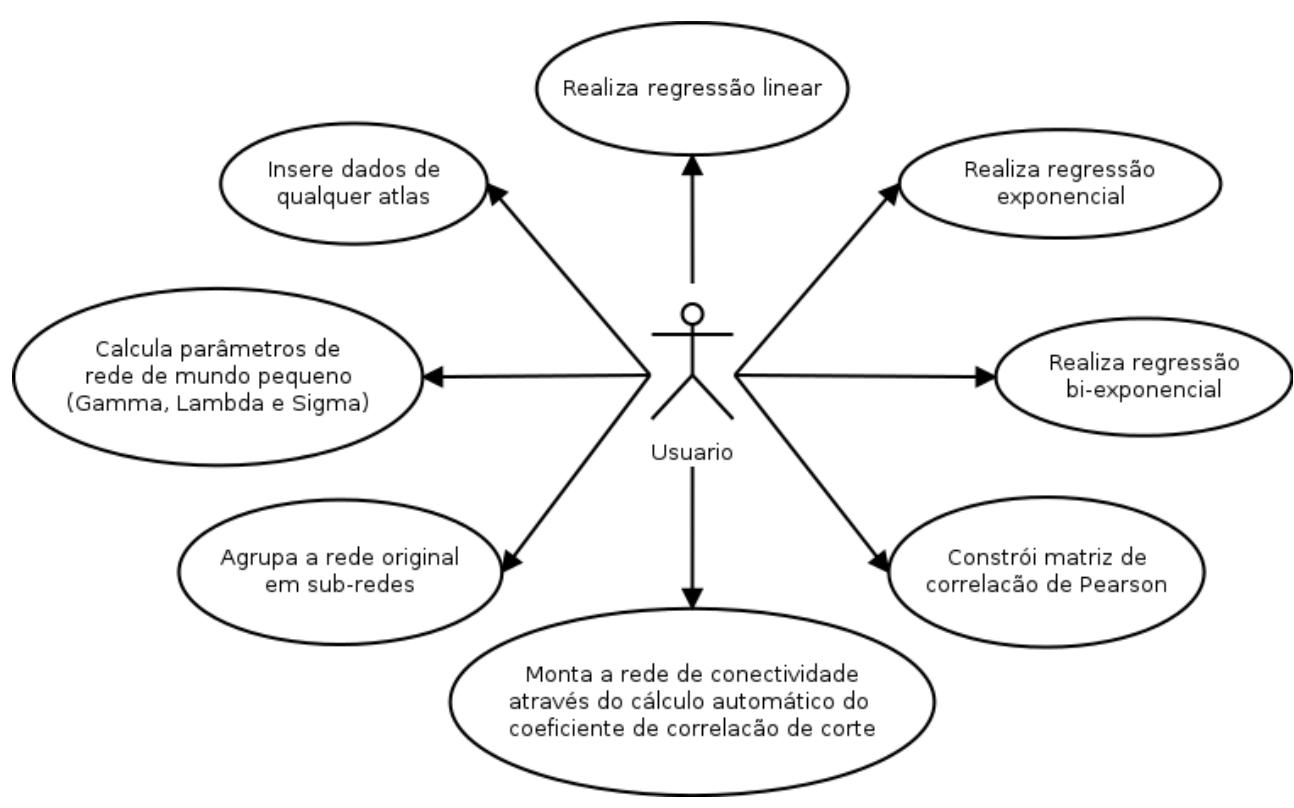

Figura 3.4: Diagrama de casos de uso do software implementado. O software possibilita ao usuário realizar diversas tarefas utilizando quaisquer atlas ou conjunto de dados. 


\section{Capítulo}

\section{Discussão dos resultados}

Conforme discutido na seção 2.3, o presente estudo visa montar uma rede de conectividade estrutural cerebral com base em associações significativas de uma determinada característica morfológica. Escolhemos utilizar, como base para cálculo da rede de conectividade, a espessura do córtex cerebral de cada região. Tal escolha se deu pois este parâmetro é o mais comum na literatura (HE; CHEN; EVANS, 2007; CHEN et al., 2008; GONG et al., 2012; CLARKSON et al., 2011; LERCH et al., 2005; SALAT et al., 2004; LOHMANN; PREUL; HUND-GEORGIADIS, 2003; FISCHL; DALE, 2000). Todavia, nada impede que as mesmas análises a serem mostradas a seguir sejam realizadas também com outros parâmetros morfológicos, uma vez que não há restrição dessa natureza.

Para testar e validar o desempenho do software implementado, o mesmo foi executado duas vezes, na primeira recebendo como entrada dados de um grupo de indivíduos saudáveis e na segunda com dados de um grupo de pacientes com epilepsia. Discorreremos na seqüencia sobre alguns pontos relevantes encontrados na análise de cada rede encontrada, porém não nos aprofundaremos em detalhes nas discussões visto que envolvem diversos fatores fisiológicos, os quais fogem do nosso conhecimento e do objetivo principal do presente trabalho que é criar uma ferramenta capaz de montar redes de conectividade baseadas em parâmetros morfológicos. 


\subsection{Efeito da idade}

Visando garantir que o coeficiente de correlação encontrado entre determinadas regiões não seja decorrente de efeitos naturais do envelhecimento, é necessário retirar o efeito da idade antes de efetuar o cálculo da correlação. Os estudos envolvendo conectividade anatômica em geral realizam regressões lineares para retirada do efeito da idade (HE; CHEN; EVANS, 2007; CHEN et al., 2008). Entendemos que tal abordagem talvez não seja a mais apropriada visto que, em se tratando de espessura, tal regressão tende à um valor negativo, o que é incoerente do ponto de vista fisiológico, além de pressupor uma taxa única de decaimento e não se adaptar com precisão aos dados observados. Por tal razão, propusemos primeiramente um modelo exponencial, contendo múltiplas derivadas e tendendo a uma espessura aproximadamente constante nas idades mais avançadas.

Após propor o modelo exponencial, identificamos também que os estudos ora focam nos efeitos da idade em indivíduos adultos (18 anos ou mais) ora consideram apenas o desenvolvimento inicial, discorrendo sobre a correlação da idade com outros fatores como milienização, alterações neuronais e poda sináptica (THAMBISETTY et al., 2010; KNIGHT et al., 2011; SALAT et al., 2004; HE; CHEN; EVANS, 2007; CHEN et al., 2008; COFFEY et al., 1998). Não houve, para nosso conhecimento, um trabalho que tenha reportado estudos dessa natureza, contemplando ambas as etapas. Propusemos então um modelo matemático bi-exponencial visando reunir essas duas vertentes de estudo de idade em uma abordagem única, desconsiderando possíveis implicações fisiológicas. Em nosso modelo, para encontrar a melhor maneira de descrever as reduções na espessura cortical no decorrer dos anos, a análise global foi dividida em duas etapas: amadurecimento, focada em descrever o processo inicial de melhor definição da fronteira substancia branca/cinzenta na imagem, traduzido como com a queda na espessura cortical que ocorre nos primeiros anos da vida e envelhecimento, visando descrever o lento processo de redução na espessura cortical resultante do 
desgaste natural do corpo humano. Para cada etapa, foi proposto um modelo de regressão exponencial, de acordo com a equação 3.1 .

A tabela 4.1 mostra a soma dos resíduos quadráticos das regressões linear, exponencial e bi-exponencial para diferentes etapas da vida. Nota-se que o modelo que modelo bi-exponencial é aquele que melhor se adequa aos dados, apresentando o menor resíduo. O modelo linear apresenta resíduos $34 \%$ maiores que aqueles encontrados no modelo bi-exponencial para idades menores que 21 anos, contudo essa diferença cai para 6\% quando comparados os grupos dos idosos (acima de 60 anos). Por apresentar um menor resíduo, o modelo bi-exponencial se mostra mais indicado, ainda mais quando o estudo abranger tanto crianças quanto adultos, faixa etária com a maior diferença encontrada.

\begin{tabular}{llll}
\hline Faixa etária & $\begin{array}{l}\text { Resíduos } \\
\text { regressão linear }\end{array}$ & $\begin{array}{l}\text { Resíduos } \\
\text { regressão } \\
\text { exponencial }\end{array}$ & $\begin{array}{l}\text { da } \\
\text { Resíduos da } \\
\text { regressão } \\
\text { bi-exponencial }\end{array}$ \\
\hline \hline Até 21 anos & 425,79 & 336,77 & 317,83 \\
Entre 22 e 40 anos & 180,82 & 166,29 & 164,69 \\
Entre 41 e 60 anos & 63,31 & 63,16 & 61,58 \\
Acima de 60 anos & 84,94 & 81,41 & 79,30 \\
Total & 754,86 & 662,31 & 623,40 \\
\hline \hline
\end{tabular}

Tabela 4.1: Comparação dos diferentes modelos de regressão. Na tabela estão descritos a soma dos resíduos quadráticos das regressões encontradas para as diferentes faixas etárias. Valores expressos em $\mathrm{mm}^{2}$.

\subsubsection{Amadurecimento}

De acordo com (LEMAITRE et al., 2012; RAZ, 2001), as regiões que apresentaram a maior queda na espessura cortical com o decorrer da idade foram as frontais superiores (em torno de $0.007 \mathrm{~mm} / \mathrm{ano}$ ) e os polos frontais (em torno de $0.005 \mathrm{~mm} / \mathrm{ano}$ ). Dessa forma, escolhemos tais regiões para demonstrar as curvas encontradas em nosso modelo de regressão 
bi-exponencial. A figura 4.1 descreve as espessuras do córtex observadas para cada região, bem como os dois modelos exponenciais gerados na análise estatística e a idade de corte numericamente otimizada.

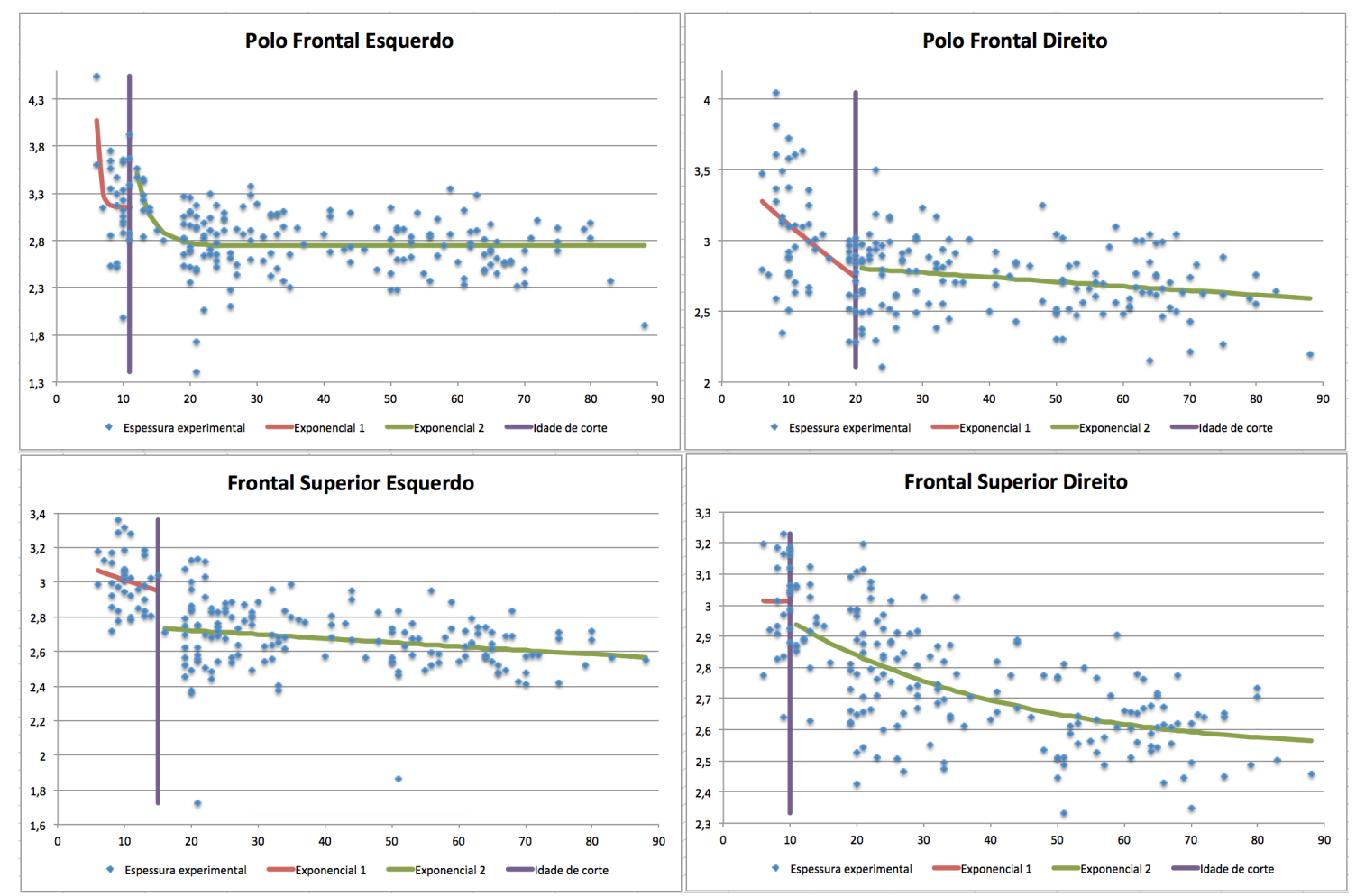

Figura 4.1: Alterações de espessura do córtex ao longo do tempo. Os pontos representam a espessura experimental obtida para cada indivíduo, de acordo com o método implementado no FreeSurfer (em milímetros). A primeira exponencial representa o período de amadurecimento da respectiva região enquanto a segunda exponencial representa o período de perdas decorrentes do envelhecimento. As idades de corte encontradas foram 10, 11, 15 e 20 para as regiões frontal superior direita, polo frontal esquerdo, frontal superior esquerda e polo frontal direito, respectivamente.

Após analisar algumas regiões específicas, vamos verificar como o amadurecimento se comporta em todo o cérebro. A figura 4.2 mostra as idades nas quais, segundo nosso modelo, termina o amadurecimento e inicia o envelhecimento para cada região de ambos os hemisférios individualmente.

Atualmente, diversos estudos vêm discutindo as diferenças existentes nos cérebros humanos relacionadas ao sexo. Na média, homens possuem cérebros maiores que mulheres, uma diferença que não pode ser explicada 


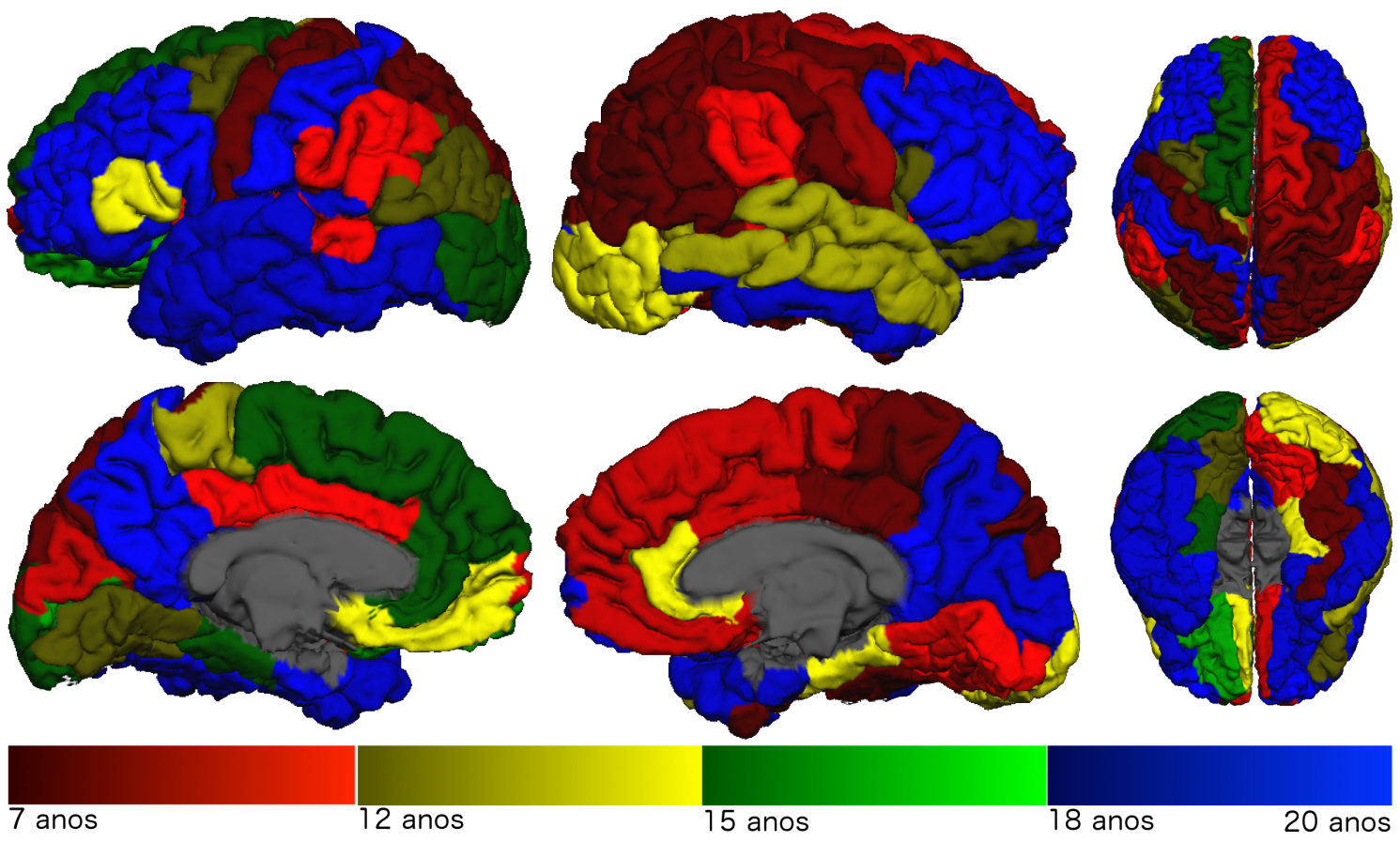

Figura 4.2: Mapa do final do amadurecimento e início do envelhecimento. As regiões vermelhas finalizam o amadurecimento entre os 7 e 11 anos enquanto nas regiões azuis esse processo ocorre entre os 18 e 20 anos (a última idade encontrada). As regiões cinzas não foram estudadas pois são indefinidas pelo FreeSurfer e foram descartadas do presente estudo.

totalmente pela diferença no tamanho corporal (PETERS et al., 1998). Sowel e outros mostraram que existem diferenças na espessura cortical de homens e mulheres, independentemente da idade ou volume cerebral (SOWELL et al., 2007). Um estudo mostrou que alterações no volume absoluto de substância cinzenta podem ocorrer primeiramente em meninas que em meninos na maioria das regiões cerebrais (GIEDD et al., 1999). Outro estudo reportou que o amadurecimento ocorre mais rapidamente em meninos que em meninas (BELLIS et al., 2001) enquanto outros indicaram que os efeitos causados pela idade na substância cinzenta são mais relevantes nos meninos (COFFEY et al., 1998; XU et al., 2000; RAZ et al., 2004; SULLIVAN et al., 2004; DECARLI et al., 2005). Em nosso estudo, aproveitando o modelo proposto para retirada do efeito da idade, também analisamos o comportamento do amadurecimento cerebral para cada gênero. A figura 4.3 ilustra essa comparação e podemos verificar um amadurecimento mais rápido para os homens na maioria das 

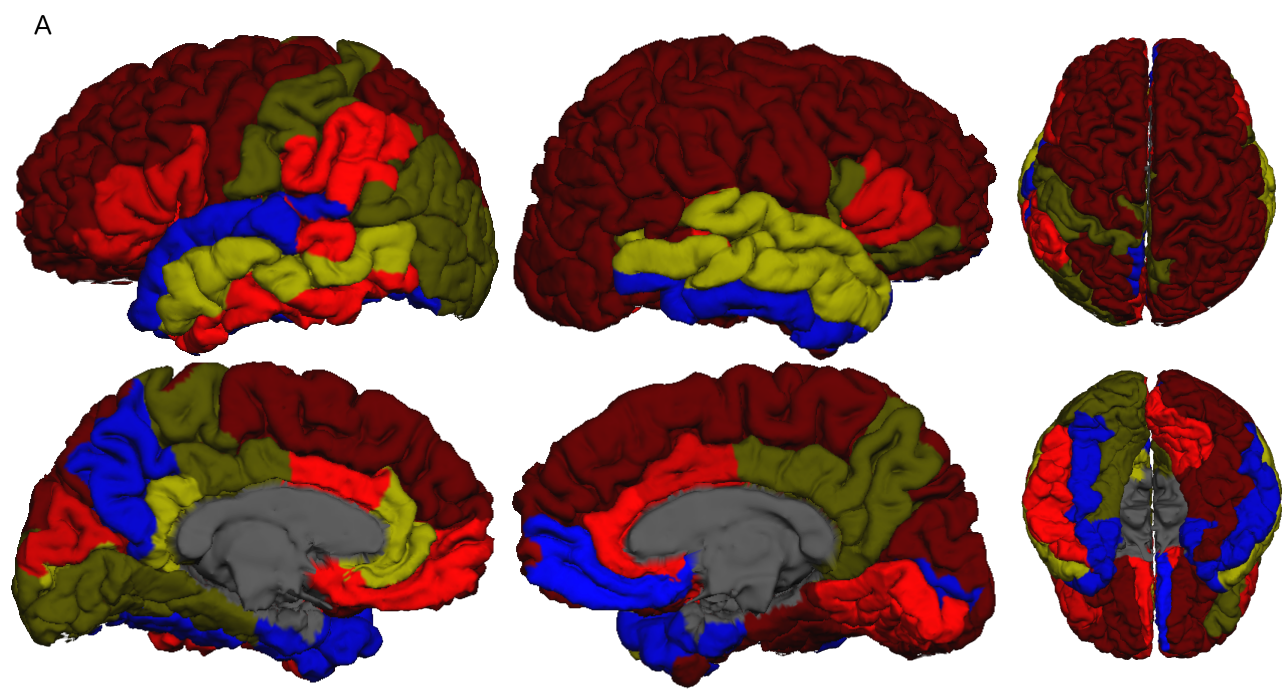

B
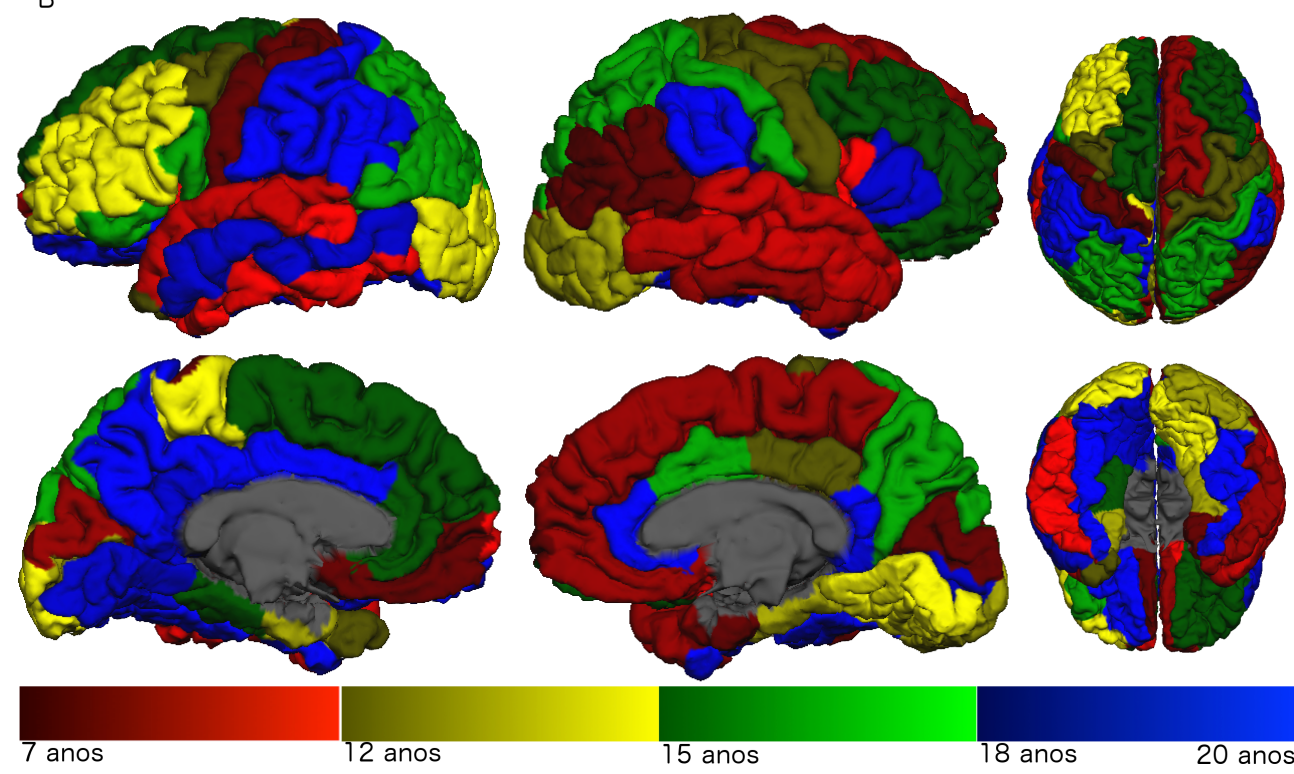

Figura 4.3: Mapa do final do amadurecimento e início do envelhecimento diferenciado por sexo. Tratam-se de mapas análogos à figura 4.2, porém em (A) foram considerados apenas sujeitos masculinos enquanto em (B) apenas femininos. As regiões cinzas não foram estudadas pois são indefinidas pelo FreeSurfer e foram descartadas do presente estudo.

regiões, em linha com vários dos estudos já mencionados.

\subsubsection{Envelhecimento}

Existem diversos estudos discutindo a relação existente entre a diminuição da espessura cortical e a idade. Salat (SALAT et al., 2004) mediu 
a espessura cortical de 106 indivíduos de 18 à 93 anos e seus resultados indicaram que diferenças associadas à idade podem ser notadas em todo o cérebro com um destaque para as áreas do córtex pré-frontal. Fjell (FJELL et al., 2009) mediu a espessura cortical de 6 diferentes amostras totalizando 884 indivíduos e também encontrou correlações significativas entre idade e espessura em diversas áreas, com destaque para os giros frontais superior, inferior e regiões superiores do lobo temporal. Thambisetty (THAMBISETTY et al., 2010) estudou as alterações longitudinais da espessura cortical de 66 adultos de 60 à 84 anos. Algumas regiões tais como os giros precentral, poscentral e orbitofrontal no hemisfério esquerdo e parietal inferior e orbitofrontal no hemisfério direito apresentaram alterações significantes ao longo do tempo. Lemaitre (LEMAITRE et al., 2012) mediu o volume do cortex, área de superfície e espessura cortical de 216 indivíduos saudáveis com idades entre 18 e 87 anos e eles mostraram que as maiores reduções na espessura cortical surgiram nos giros frontal superior, paracentral e frontal inferior (acima de $0.0055 \mathrm{~mm} / \mathrm{ano}$ ). Ainda de acordo com esse estudo, reduções acima da média foram encontradas no hemisfério esquerdo, nas regiões: giro precentral, giro posterior cingular, precuneus, giro precentral e no hemisfério direito no giro paracentral, giro inferior parietal, giro inferior frontal e giro superior frontal.

Em nosso estudo, propusemos um modelo não linear contendo duas curvas exponenciais para descrever todo o processo de envelhecimento cerebral. A figura 4.4 mostra a taxa de envelhecimento para todas as regiões cerebrais em três diferentes grupos: adultos jovens, adultos de meia idade e idosos. É possível notar que as maiores alterações ocorrem entre o grupo de adultos jovens e adultos de meia idade. Quase não há diferenças nas taxas de envelhecimento entre os grupos B e C.

Nos adultos jovens, as maiores taxas de decaimento de espessura cortical foram o giro pós central esquerdo, com 0,013 mm/ano e o cingulado rostral anterior direito, com 0,0096 mm/ano. Já nos adultos com meia idade, 


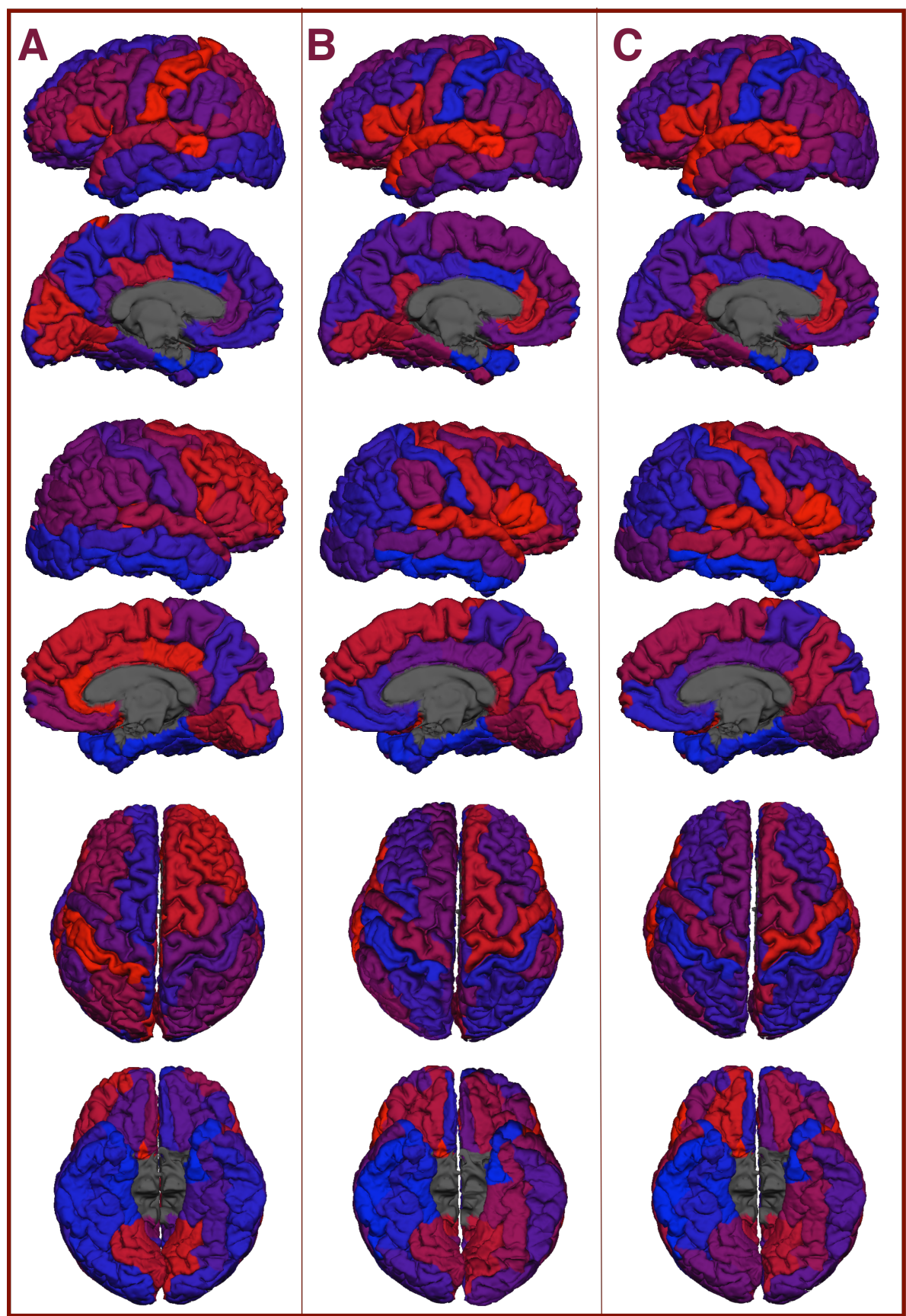

Figura 4.4: Taxa de envelhecimento em indivíduos saudáveis. A figura acima descreve as taxas de envelhecimento em indivíduos saudáveis. Regiões em azul perdem substância cinzenta mais lentamente enquanto regiões vermelhas perdem mais rapidamente, com relação à média do grupo em que se encontram. Em A. temos o grupo de adultos jovens (idades menores que 40 anos). Em $B$ podemos ver o grupo dos adultos de meia idade (entre 40 e 60 anos) e por fim em $C$ estão descritos os idosos (maiores que 60 anos). As regiões cinzas não foram estudadas pois são indefinidas pelo FreeSurfer e foram descartadas do presente estudo. 
as regiões com maior decaimento foram a parte triangular do giro frontal inferior direito, com 0,0059 mm/ano e o lobo temporal superior esquerdo, com 0,0058 mm/ano. Os mesmos valores se repetiram para o grupo dos idosos. Nota-se que as taxas de decaimento de espessura cortical obtidas em nosso estudo para adultos jovens estão bem acima dos valores obtidos por Lemaitre (LEMAITRE et al., 2012), conforme citado anteriormente. Entretanto, quando são analisados os adultos de meia idade e idosos, os valores se aproximam bastante em ambos os estudos. Tal diferença no primeiro grupo pode ser decorrente do modelo de regressão escolhido, visto que no caso dele, os dados foram modelados por uma reta, à qual pode se adequar melhor às fases finais do envelhecimento. Em nosso caso, identificamos uma queda inicial mais acentuada, encontrando nos adultos jovens uma taxa de decaimento 65\% maior que nos adultos de meia idade e idosos, indicando uma diminuição no potencial de queda de espessura com o passar dos anos, mais uma razão para utilização da modelagem exponencial para ilustrar tal comportamento.

\subsection{Montagem da rede de conectividade}

Conforme descrito no capítulo 3, para montagem da matriz de conectividade primeiramente retiramos o efeito da idade das medidas de espessura cortical e utilizamos os resíduos da regressão para calcular o coeficiente de correlação de Pearson entre todos os pares de regiões. Para ilustrar tal procedimento, na figura 4.5 é mostrado um gráfico cruzando informações de espessura das regiões temporais superiores direita e esquerda juntamente com o respectivo gráfico gerado após a retirada do efeito da idade. Nota-se uma diminuição do coeficiente de correlação (R) do primeiro caso para o segundo caso, indicando que o efeito da idade foi retirado e a significante correlação ainda encontrada é decorrente de outros fatores.

Na figura 4.6, pode ser visto um mapa dos coeficientes de correlação de Pearson calculados para todos os pares de regiões analisadas.

Uma vez montada a matriz de correlações, podemos montar a rede de 

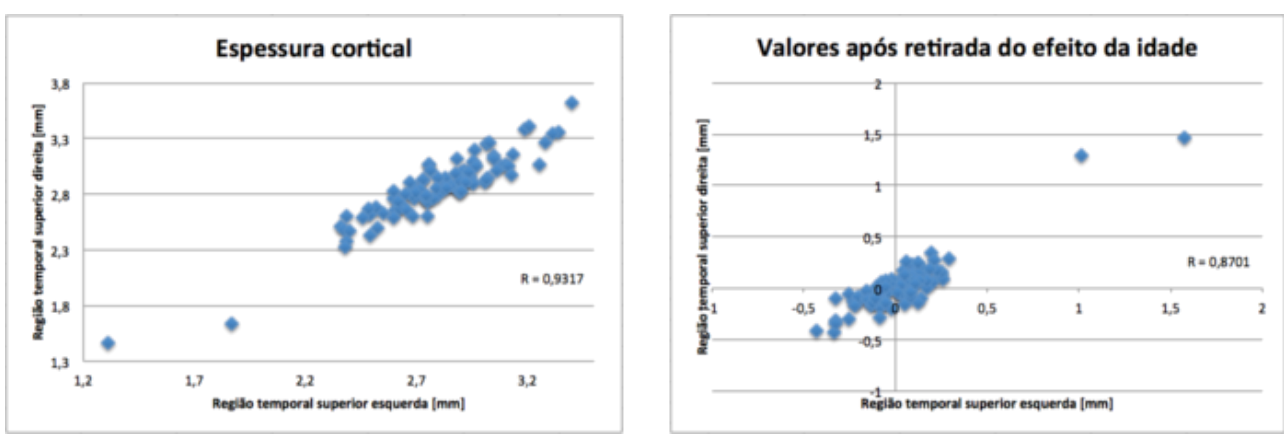

Figura 4.5: Impacto da retirada do efeito da idade no coeficiente de correlação. Nos gráficos acima é possível visualizar o coeficiente de correlação para as regiões temporais superiores esquerda e direita antes e depois da retirada do efeito da idade.

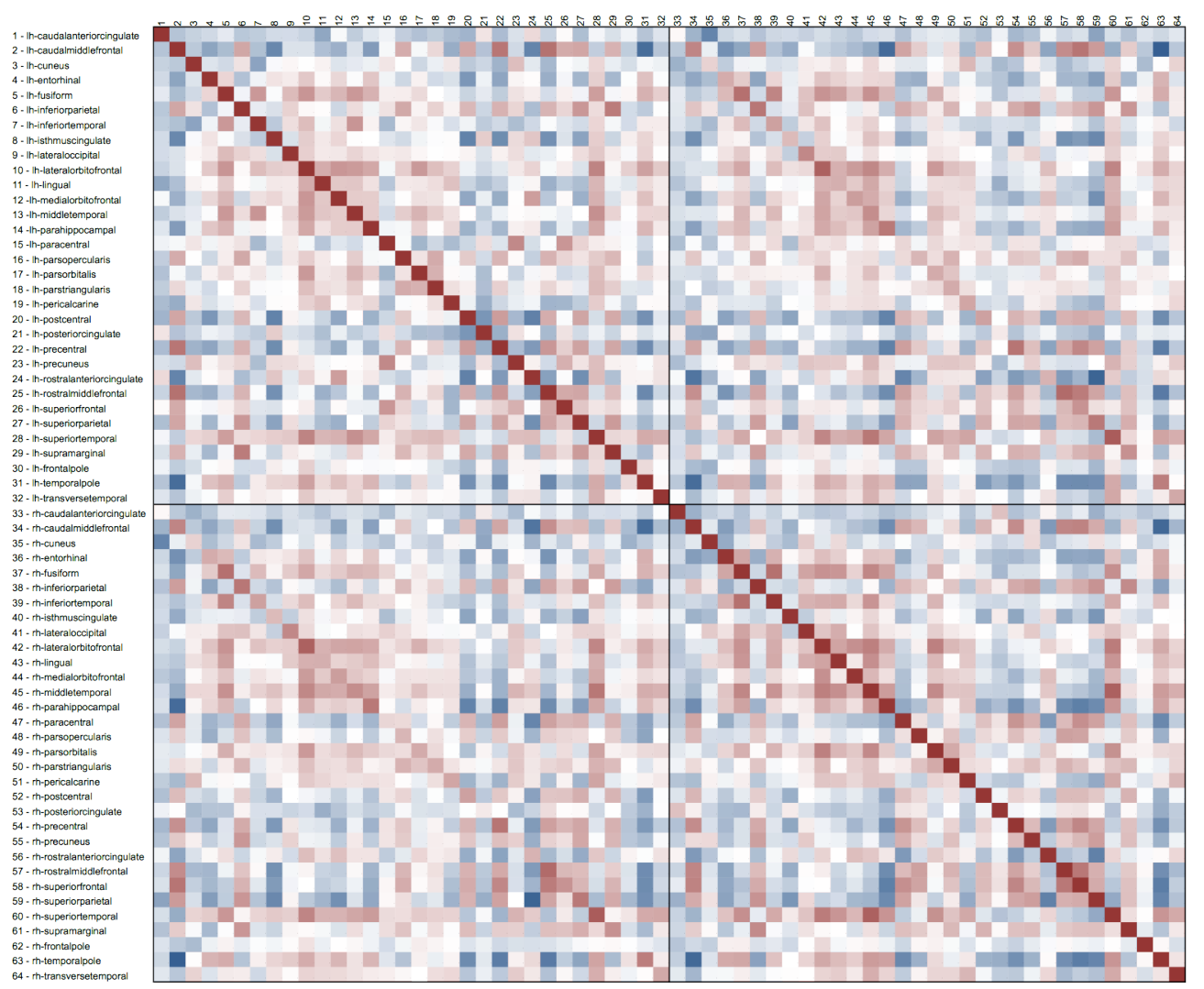

Figura 4.6: Matriz de correlações. Cores azuis indicam um coeficiente baixo, brancas significam um coeficiente intermediário enquanto vermelhas representam os maiores coeficientes calculados. O primeiro quadrante é referente às correlações intra-hemisfério esquerdo, o segundo e terceiro quadrantes referem-se à correlações inter-hemisférios e o quarto quadrante é relacionado às correlações intra-hemisfério direito. 
conectividade anatômica. Para isso, devemos escolher um valor limite para o coeficiente a partir do qual duas regiões serão consideradas conectadas. Utilizando o cálculo automático implementado no software construído no presente estudo (ver seção 3.2.4), o valor limite encontrado foi 0,45. Nesse contexto, o maior valor de $\mathrm{P}$ encontrado foi da ordem de $10^{-11}$, indicando uma confiabilidade estatística nas conexões propostas. A figura 4.7 ilustra a rede de conectividade encontrada.

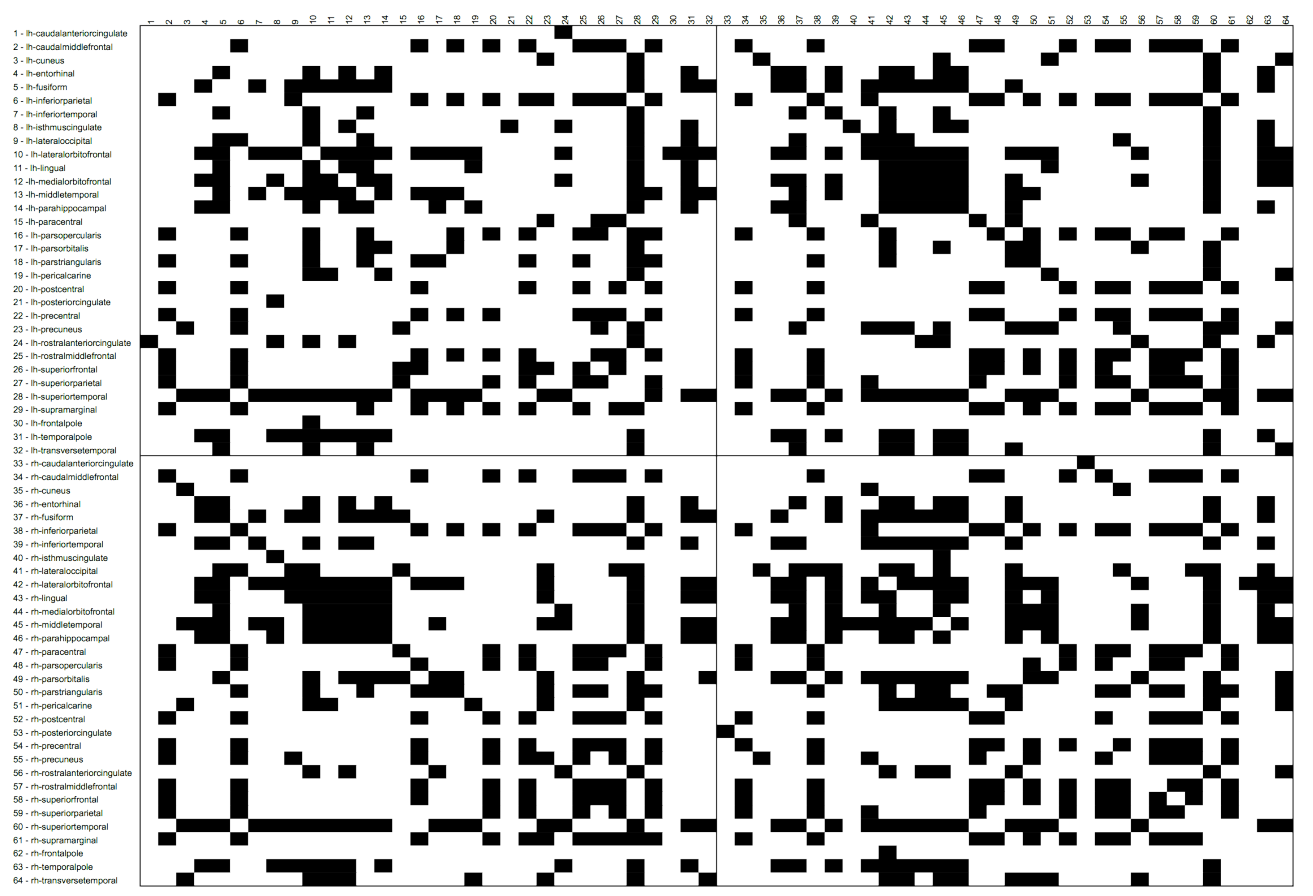

Figura 4.7: Rede de conectividade não ponderada. Os quadrados pretos indicam presença de conexão enquanto os brancos indicam ausência da mesma.

Ao todo, foram encontradas 244 conexões no hemisfério esquerdo, 300 conexões no hemisfério direito e 273 conexões entre os hemisférios. Quando comparamos nossa rede com uma rede encontrada pela da técnica de DTI (ITURRIA-MEDINA et al., 2008), encontramos uma similaridade nas conexões intra-hemisférios, com destaque para os pares envolvendo as regiões hipocampal e temporal esquerdas, ocipital e temporal esquerdas, cuneo e lingual direitas e temporal e parietal superiores direitas. Contudo há uma diferença significativa nas conexões inter-hemisférios. Em nossa análise, 
encontramos uma quantidade significativa dessas conexões, principalmente entre regiões análogas de ambos os hemisférios, no entanto, no estudo envolvendo DTI, nota-se poucas conexões, com destaque apenas para as regiões ocipitais e frontais esquerdas e direitas.

Comparamos também a rede encontrada em nosso software com estudos envolvendo conectividade calculada através de parâmetros morfológicos, para os quais encontramos resultados bastante semelhantes. He (HE; CHEN; EVANS, 2007) encontrou uma rede de conectividade cerebral com base em similaridade de espessura cortical e dentre os 15 pares de regiões mais fortemente conectadas, 8 envolviam áreas frontais, em linha com nosso estudo, com diferenças nos 7 pares restantes. As mesmas podem ter ocorrido devido ao modelo de regressão biexponencial, ferramenta de extração de espessura cortical e atlas considerado em nosso estudo, os quais foram diferentes. O maior coeficiente de correlação encontrado por ele foi 0,67 enquanto o nosso foi 0,83 . A tabela 4.2 mostra as 15 regiões mais fortemente conectadas encontradas em nossa análise.

$\mathrm{Na}$ rede de conectividade calculada no presente estudo, o coeficiente de agrupamento encontrado foi 0,67 enquanto o comprimento médio do caminho foi 0,52. Comparando esses valores com os mesmos valores calculados a partir de 500 redes aleatórias com a mesma distribuição de graus, encontramos um $\gamma$ $=1,89, \lambda=0,91$ e portanto $\sigma=2,07$. Medina (ITURRIA-MEDINA et al., 2008), realizou um estudo de conectividade cerebral baseado em DTI e encontrou $\gamma$ $=1,85, \lambda=1,12$ e $\sigma=1,64$. He (HE; CHEN; EVANS, 2007) realizou um estudo de conectividade cerebral baseado em espessura cortical e encontrou $\gamma=2,36, \lambda=1,15$ e $\sigma=2,04$. Nota-se portanto uma similaridade entre nosso estudo e demais análises presentes na literatura. De acordo com (WATTS; STROGATZ, 1998), como obtivemos um sigma maior que 1, podemos dizer que a nossa rede apresenta um comportamento de mundo pequeno, novamente em linha com estudos anteriores. (HE; CHEN; EVANS, 2007; CHEN et al., 2008; 


\begin{tabular}{llll}
\hline N. & Região 1 & Região 2 & $\begin{array}{c}\text { Coeficiente de } \\
\text { correlação }\end{array}$ \\
\hline \hline 1 & Temporal superior esquerda & Temporal superior direita & 0,8702 \\
2 & Orbito-frontal lateral esquerda & Orbito-frontal lateral direita & 0,8556 \\
3 & Temporal superior direita & Temporal média direita & 0,8548 \\
4 & Frontal média rostral esquerda & Frontal média rostral direita & 0,8227 \\
5 & Fusiform esquerda & Fusiform direita & 0,8052 \\
6 & Temporal inferior direita & Fusiform direita & 0,8033 \\
7 & Frontal média rostral esquerda & Frontal média caudal esquerda & 0,8001 \\
8 & Pré central esquerda & Pré central direita & 0,7890 \\
9 & Frontal média caudal esquerda & Frontal superior direita & 0,7887 \\
10 & Inferior parietal esquerda & Inferior parietal direita & 0,7823 \\
11 & Temporal superior esquerda & Temporal média direita & 0,7807 \\
12 & Temporal superior direita & Frontal média rostral direita & 0,7777 \\
13 & Parahipocampal esquerda & Parahipocampal direita & 0,7773 \\
14 & Parietal superior esquerda & Parietal superior direita & 0,7751 \\
\hline \hline
\end{tabular}

Tabela 4.2: Regiões mais fortemente conectadas em indivíduos saudáveis. $\mathrm{Na}$ tabela são descritas as 15 regiões com maior coeficiente de correção encontrados, sinalizando maior força em sua conexão.

HUMPHRIES; GURNEY; PRESCOTT, ; STAM, 2004; ACHARD et al., 2006; STAM et al., 2007; GUYE et al., 2010).

Visando ilustrar o comportamento dessas variáveis para cada coeficiente de correlação de corte testado pelo software, podemos visualizar o gráfico 4.8, que mostra uma diminuição do coeficiente de agrupamento à medida que o coeficiente de correlação de corte vai aumentando, além de um aumento no valor de sigma, evidenciando cada vez mais uma arquitetura de rede de mundo pequeno. Os coeficientes analisados partem de 0,1 até o coeficiente de correlação de corte calculado automaticamente para a rede. 

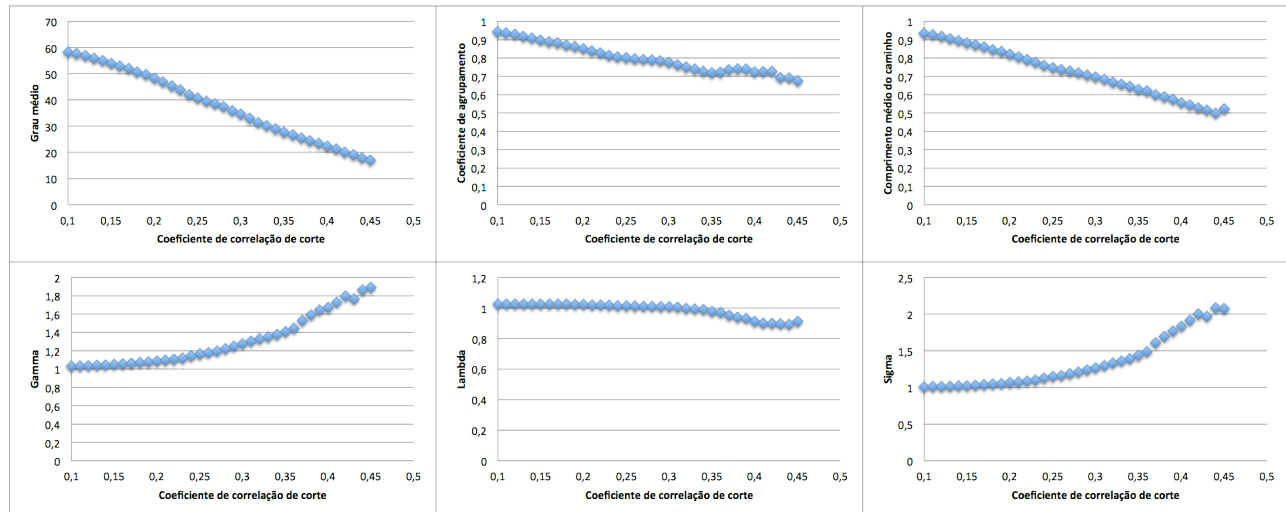

Figura 4.8: Propriedades de rede de mundo pequeno em função do coeficiente de correlação de corte. Nos gráficos pode ser visto que o grau médio da rede de conectividade cerebral decresce à medida que o coeficiente de correlação de corte aumenta, o mesmo ocorrendo com o coeficiente de agrupamento e comprimento médio do caminho. Efeito oposto ocorre com o parâmetro $\sigma$, indicando que a medida que os cortes vão sendo mais rígidos, a arquitetura da rede anatômica tende a apresentar um comportamento mais característico de rede de mundo pequeno.

\subsection{Detecção de comunidades}

Aplicando o algoritmo descrito na seção 3.2.5, identificamos nos indivíduos saudáveis 3 comunidades distintas. As mesmas podem ser vistas na figura 4.9. As comunidades encontradas coincidem com a rede dorsal atentiva (verde), rede ventral atentiva (azul) e a rede vermelha funcionando possivelmente como um pivô de integração. Tal arquitetura é afetada em pacientes, conforme veremos posteriormente. $\mathrm{O}$ fator de modularidade encontrado para essa divisão foi $Q=0,4$, pouco menor que o fator de modularidade $Q=0,5$ encontrado em um estudo recente (CHEN et al., 2008).

A arquitetura modular encontrada demonstra que houve um agrupamento de regiões bilaterais análogas, com uma divisão entre as áreas dorsal e ventral. Estudos prévios demonstraram fortes correlações funcionais entre tais regiões (LOWE; MOCK; SORENSON, 1998; HAMPSON et al., 2002; WANG et al., 2006) bem como um padrão similar de agrupamento (SALVADOR et al., 2005). Em um estudo recente, Chen (CHEN et al., 2008) também realizou uma análise modular de uma rede cerebral formada 


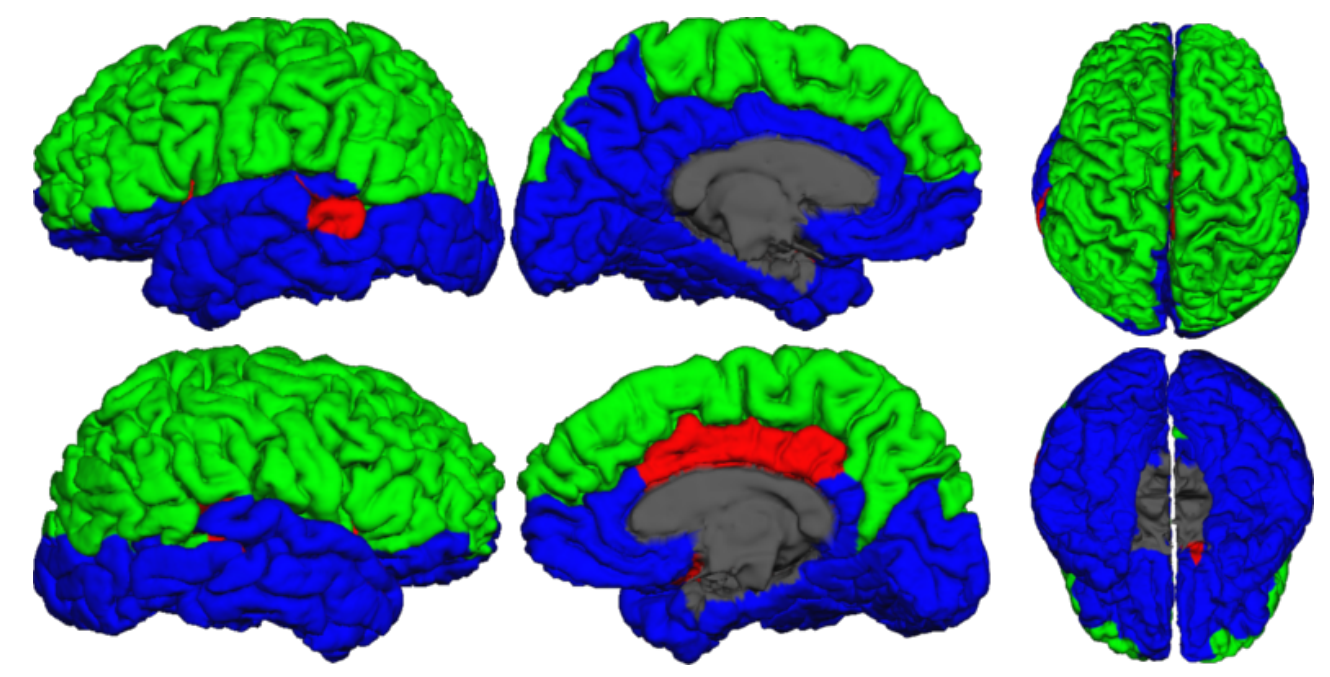

Figura 4.9: Comunidades encontradas nos indivíduos saudáveis. Na figura são mostradas as três comunidades encontradas nos indivíduos saudáveis. É possível identificar a rede dorsal atentiva, rede ventral atentiva e possivelmente a rede vermelha atuando como um pivô de integração. As regiões cinzas não foram estudadas pois são indefinidas pelo FreeSurfer e foram descartadas do presente estudo.

a partir de dados de espessura cortical e identificou 6 módulos em indivíduos saudáveis, associados à redes funcionais (módulo 1: estratégia; módulo 2: funções motoras; módulo 3: olfato; módulo 4: emoções; módulo 5: linguagem e audição; módulo 6: visual). Em nosso estudo, obtivemos um maior grau de agrupamento, encontrando 3 módulos. Em linhas gerais, houve um grupo contemplando os módulos 1 e 2 e outro grupo contemplando os módulos 3, 4, 5 e 6 . Nosso terceiro grupo, composto pelo cingulado direito, estava presente no módulo 1 do estudo do Chen. Tais diferenças podem ser atribuídas à alguns fatores tais como distinções nos atlas utilizados em ambos estudos; mecanismo para retirada do efeito da idade no cálculo da correlação; utilização de diferentes softwares para retirada da espessura cortical das imagens de ressonância e diferenças no algoritmo de detecção de comunidades. O algoritmo por nós implementado parte da rede completa e busca a melhor maneira de separar as comunidades, garantindo um maior valor para a modularidade enquanto o algoritmo implementado por Chen, utiliza a lógica inversa, partindo de uma rede onde cada região pertence 
à um módulo unitário e agrupando-as de forma à maximizar a função de modularidade. Futuras implementações em nosso software poderiam contemplar novos algoritmos de deteç̧ão de comunidades proporcionando um estudo comparativo das diversas técnicas existentes.

\subsection{Indivíduos saudáveis vs pacientes com epilepsia de lobo temporal}

Epilepsia de lobo temporal é a forma de epilepsia mais comum em adultos (BERNHARDT et al., 2011). Diversos estudos envolvendo análises da substância cinzenta por meio de imagens de ressonância magnética mostraram que as alterações estruturais se estendem às regiões temporal e frontal central (BERNASCONI et al., 2003; BERNHARDT et al., 2008; KELLER; ROBERTS, 2008). A introdução de métodos de análise de grafos nas redes cerebrais provê um mecanismo formal para quantificar as propriedades topológicas e organizacionais da rede cerebral e com isso possibilita um mecanismo para identificar o quanto tais propriedades são afetadas por determinadas patologias (BULLMORE; SPORNS, 2009; GUYE et al., 2010). Análises anteriores baseadas em espessura cortical revelaram alterações na arquitetura das redes cerebrais encontradas em indivíduos saudáveis e pacientes com Alzheimer (HE; CHEN; EVANS, 2008), esclerose múltipla (HE et al., 2009), esquisofrenia (BASSETT et al., 2008) e epilepsia (BERNHARDT et al., 2011).

O propósito dessa seção é discutir e comparar as características das redes complexas encontradas por meio de correlações de espessura cortical em indivíduos saudáveis e pacientes. Baseados no extenso dano estrutural causado por essa doença, nossa hipótese é que as propriedades das redes encontradas em ambos os casos serão diferentes, possivelmente apresentando menor eficiência nas redes formadas pelos pacientes.

Submetemos ao software dados de 93 indivíduos com confirmação clínica de epilepsia de lobo temporal, os quais foram obtidos a partir 
do pré-processamento de imagens adquiridas nas mesmas condições dos indivíduos saudáveis. Para esse grupo, foi aplicada apenas a regressão monoexponencial, visto que não havia indivíduos com idade menor que 21 anos, o que não justifica a utilização de uma exponencial para modelar o amadurecimento.

Na figura 4.10 pode ser visto um mapa da taxa de decaimento da espessura cortical. Tal como na figura 4.4, temos as três faixas etárias analisadas e podemos verificar uma alteração bastante difusa na velocidade de queda de espessura cortical em diversas regiões.

A tabela 4.3 mostra uma comparação entre as 8 regiões com maior taxa de decaimento de espessura cortical para cada faixa etária analisada em indivíduos saudáveis e pacientes. Nota-se que até 40 anos os pacientes com epilepsia apresentaram a região parahipocampal com maiores perdas, diferentemente dos indivíduos saudáveis, onde tal região nem aparece entre as 8 primeiras. Além disso, a taxa de decaimento encontrada nos pacientes é sempre maior que os indivíduos saudáveis. Comparando regiões com maiores perdas de ambos os grupos para a faixa etária até 40 anos, essa diferença chega à quase 500\%. Tal valor diminui para 72\% na faixa etária dos 40 à 60 anos e 69\% para os mais idosos, sugerindo que a maior perda de espessura cortical em pacientes com epilepsia ocorra na faixa até os 40 anos de idade, ainda que continuem a perder com uma velocidade maior que os indivíduos saudáveis ao longo de toda vida.

Para os pacientes, o coeficiente de correlação de corte encontrado automaticamente pelo software foi 0,41 (ver seção 3.2.4), menor portanto que os 0,45 encontrado para o grupo de indivíduos saudáveis, sugerindo uma queda global no grau de conectividade. A matriz de conectividade obtida também foi substancialmente diferente. A mesma pode ser vista na figura 4.11 .

Quando verificamos as diferenças entre um grupo e outro nos 


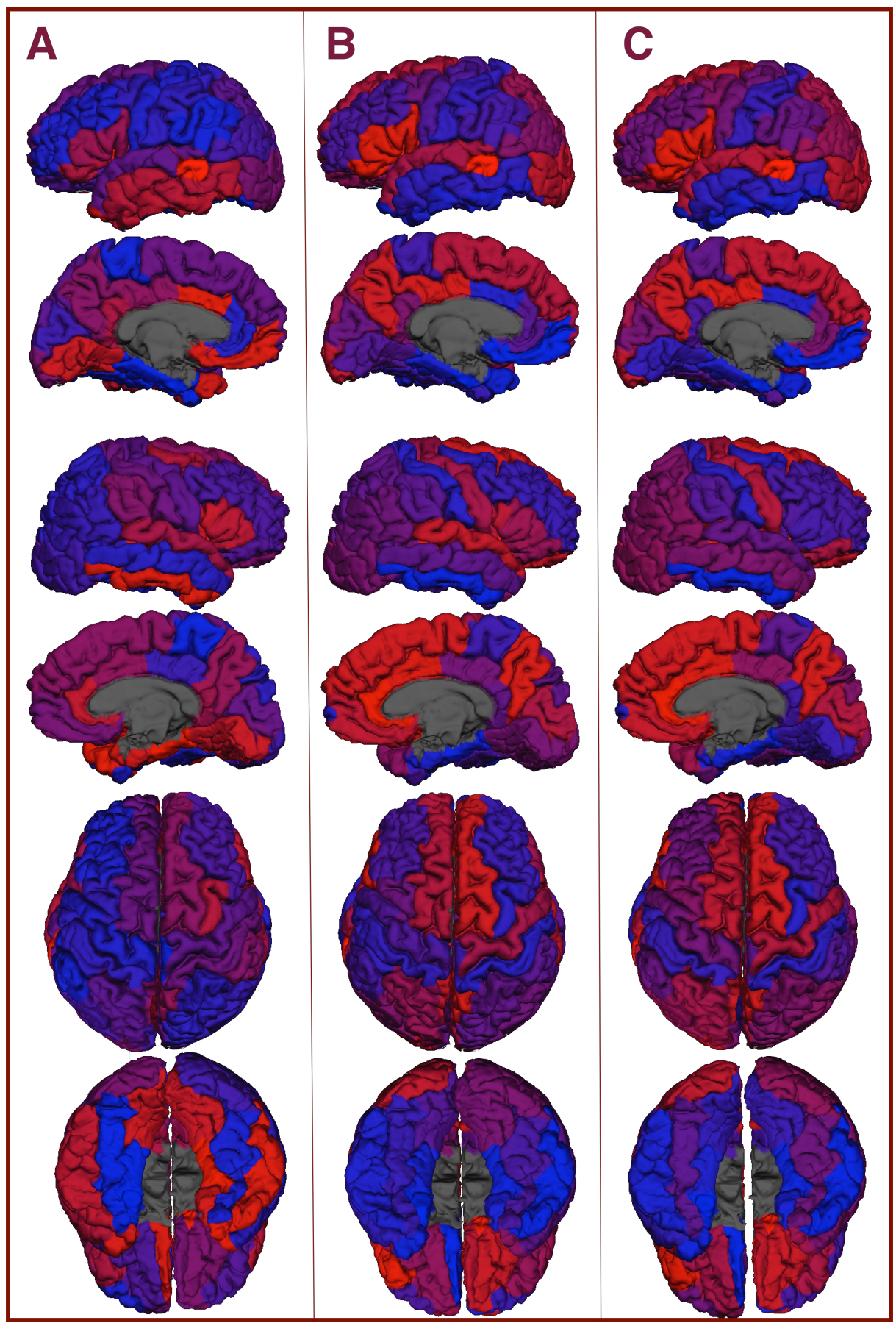

Figura 4.10: Taxa de envelhecimento em pacientes com epilepsia. Regiões em azul perdem substância cinzenta mais lentamente enquanto regiões vermelhas perdem mais rapidamente, com relação à média do grupo em que se encontram. Em A. temos o grupo de adultos jovens (idades menores que 40 anos). Em $B$ podemos ver o grupo dos adultos de meia idade (entre 40 e 60 anos) e por fim em $C$ estão descritos os idosos (maiores que 60 anos). 


A)
\begin{tabular}{|l|ll|ll|}
\hline & \multicolumn{2}{|c|}{ Indivíduos saudáveis } & \multicolumn{2}{c|}{ Pacientes } \\
\hline N. & Região & $\begin{array}{l}\text { Taxa de } \\
\text { decaimento }\end{array}$ & Região & $\begin{array}{l}\text { Taxa } \\
\text { decaimento }\end{array}$ \\
\hline 1 & Pós-central esquerda & 0,0131 & Para hipocampal direita & 0,0652 \\
2 & Cingulado anterior rostral direito & 0,00963 & Polo frontal direito & 0,0358 \\
3 & Temporal transversa esquerda & 0,00955 & Cingulado anterior caudal esquerdo & 0,0275 \\
4 & Temporal transversa direita & 0,00842 & Temporal inferior direita & 0,0272 \\
5 & Cingulado posterior direito & 0,00820 & Frontal orbital média esquerda & 0,0265 \\
6 & Cuneo esquerdo & 0,00808 & Polo temporal esquerdo & 0,0244 \\
7 & Parte opercular direita & 0,00758 & Interior do sulco rhinal direito & 0,0241 \\
8 & Frontal média rostral direita & 0,00751 & Temporal transversa direita & 0,0146 \\
\hline
\end{tabular}

\begin{tabular}{|c|c|c|c|c|}
\hline \multicolumn{5}{|l|}{ B) } \\
\hline & \multicolumn{2}{|l|}{ Indivíduos saudáveis } & \multicolumn{2}{|l|}{ Pacientes } \\
\hline N. & Região & $\begin{array}{l}\text { Taxa de } \\
\text { decaimento }\end{array}$ & Região & $\begin{array}{l}\text { Taxa de } \\
\text { decaimento }\end{array}$ \\
\hline 1 & Parte triangular direita & 0,00598 & Cingulado anterior rostral direito & 0,0103 \\
\hline 2 & Temporal superior esquerda & 0,00580 & Parte orbital esquerda & 0,00821 \\
\hline 3 & Temporal transversa esqueda & 0,00574 & Parte triangular esquerda & 0,00758 \\
\hline 4 & Parte triangular esquerda & 0,00570 & Parte opercular esquerda & 0,00709 \\
\hline 5 & Temporal superior direita & 0,00545 & Cingulado anterior caudal direito & 0,00696 \\
\hline 6 & Temporal transversa direita & 0,00545 & Précuneo direito & 0,00691 \\
\hline 7 & Parte opercular esquerda & 0,00536 & Cingulado posterior esquerdo & 0,00690 \\
\hline 8 & Parte opercular direita & 0,00472 & Frontal superior direita & 0,00609 \\
\hline \multicolumn{5}{|c|}{ 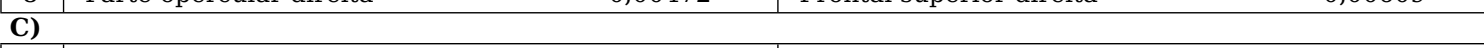 } \\
\hline & \multicolumn{2}{|l|}{ Indivíduos saudáveis } & \multicolumn{2}{|l|}{ Pacientes } \\
\hline $\mathbf{N}$. & Região & $\begin{array}{l}\text { Taxa de } \\
\text { decaimento }\end{array}$ & Região & $\begin{array}{l}\text { Taxa de } \\
\text { decaimento }\end{array}$ \\
\hline 1 & Parte triangular direita & 0,00562 & Cingulado anterior rostral direito & 0,00951 \\
\hline 2 & Temporal superior esquerda & 0,00550 & Parte orbital esquerda & 0,00760 \\
\hline 3 & Temporal superior direita & 0,00519 & Parte triangular esquerda & 0,00700 \\
\hline 4 & Parte opercular esquerda & 0,00508 & Parte opercular esquerda & 0,00660 \\
\hline 5 & Parte triangular esquerda & 0,00450 & Cingulado anterior caudal direito & 0,00651 \\
\hline 6 & Pré-central direita & 0,00388 & Cingulado posterior esquerdo & 0,00645 \\
\hline 7 & Cingulado anterior rostral esquerdo & 0,00388 & Precuneo direito & 0,00639 \\
\hline 8 & Cingulado istmo esquerdo & 0,00335 & Frontal superior direita & 0,00575 \\
\hline
\end{tabular}

Tabela 4.3: Regiões com maior taxa média de decaimento de espessura cortical em indivíduos saudáveis e pacientes com idades até 40 anos (A), entre 40 e 60 anos (B) e acima de 60 anos (C). Os valores estão expressos em milímetros por ano. 


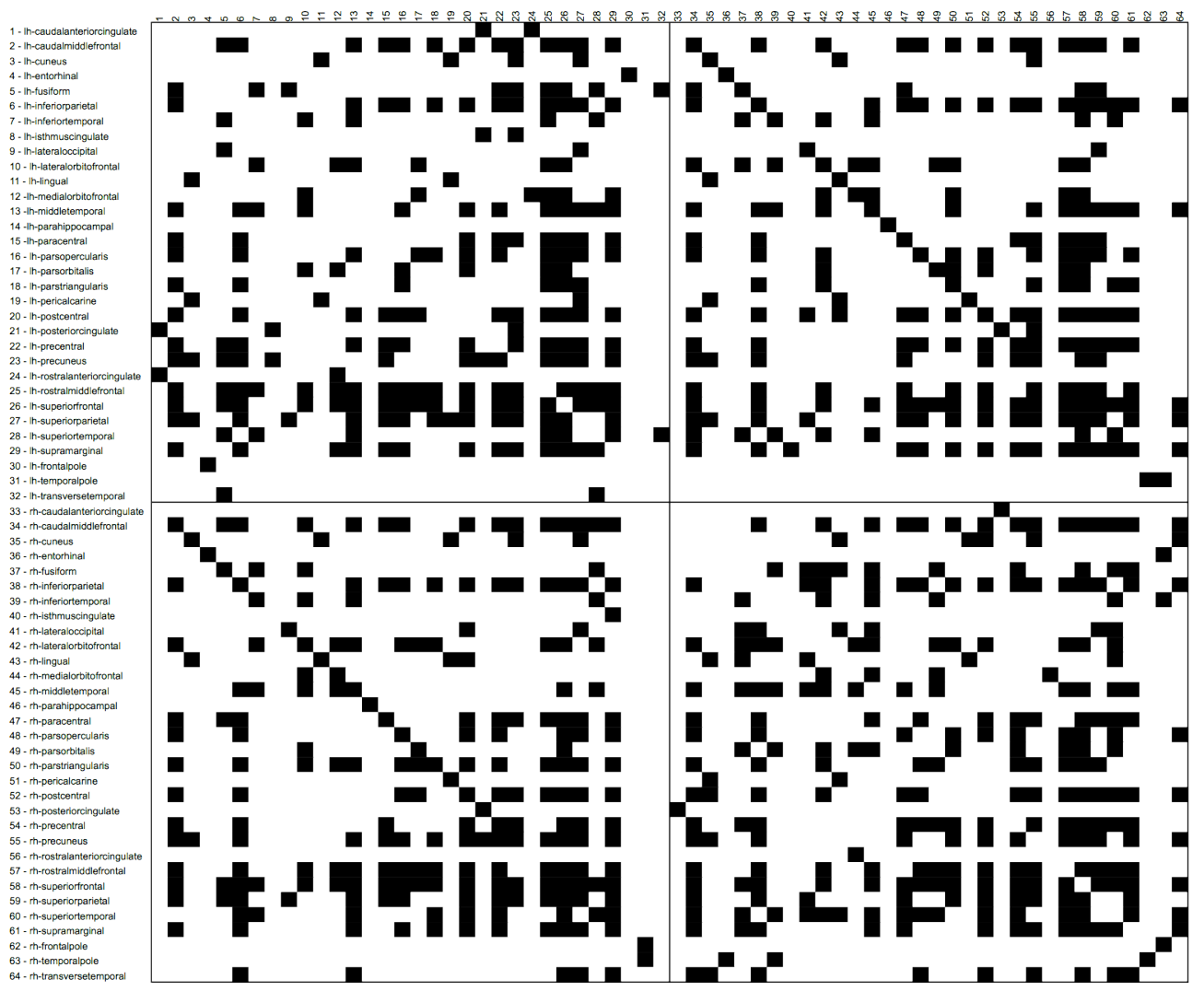

Figura 4.11: Rede de conectividade para pacientes com epilepsia. Na figura está descrita a rede de conectividade encontrada. Os quadrados pretos indicam presença de conexão enquanto os brancos indicam ausência da mesma.

deparamos com 375 conexões que existiam no grupo de indivíduos saudáveis e foram extintas nos pacientes com epilepsia, bem como 264 novas conexões passaram a existir nesse último. Das 375 conexões perdidas, 120 foram intrahemisfério esquerdo, 133 foram inter-hemisférios e 122 intrahemisfério direito. Em se tratando das novas conexões, 101 ocorreram intrahemisfério esquerdo, 79 interhemiférios e 84 intrahemisfério direito. A figura 4.12 ilustra a diferença entre as matrizes de conectividade e a tabela 4.4 ilustra as 15 regiões mais fortemente conectadas.

Quanto aos parâmetros de rede, também houveram alterações. O coeficiente de agrupamento encontrado para a rede formada pelos pacientes foi 0,57 e comprimento médio do caminho foi 0,44 , valores $15 \%$ menores 


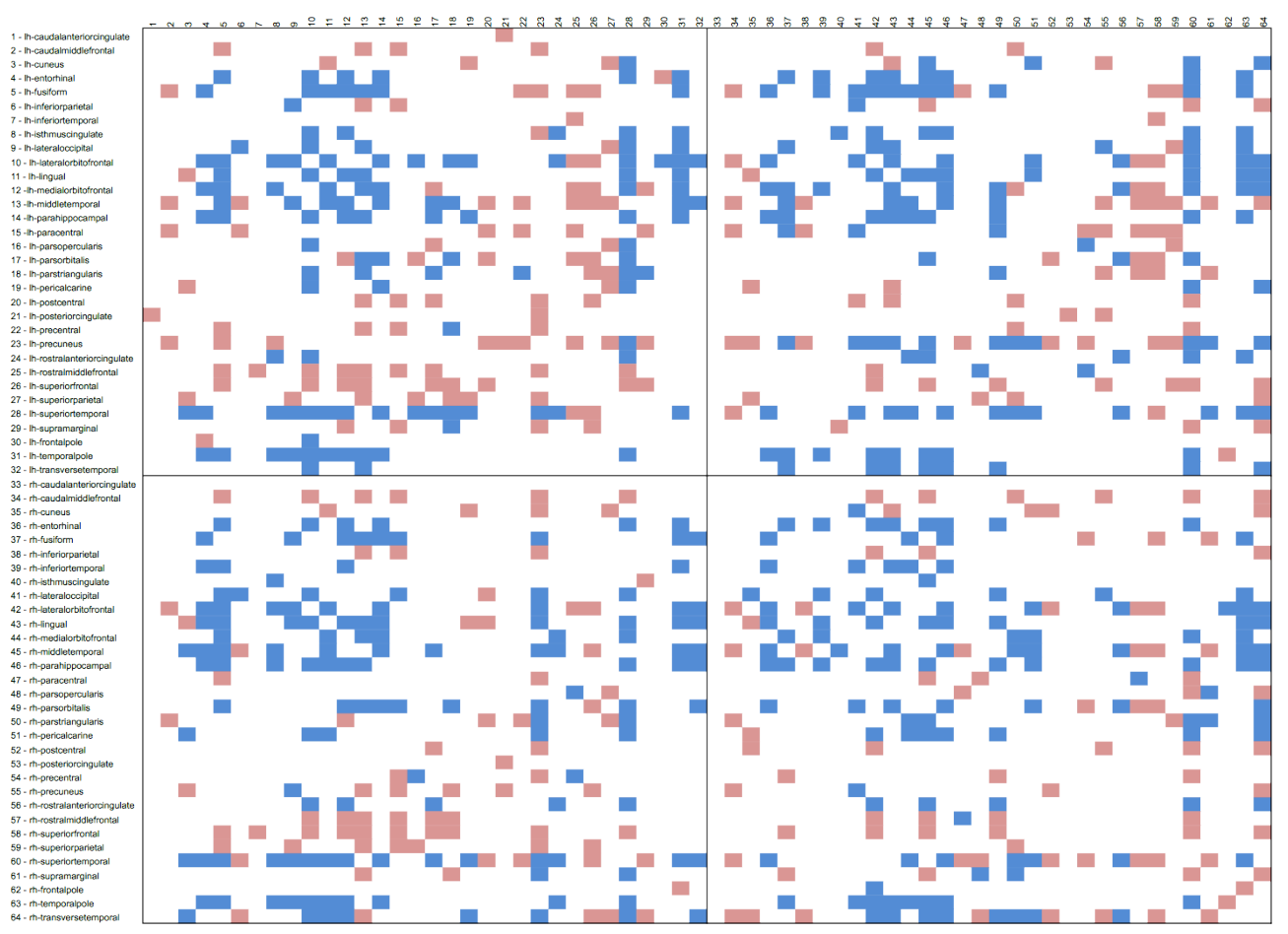

Figura 4.12: Diferenças nas conexões anatômicas de indivíduos saudáveis e pacientes com epilepsia. Pontos azuis indicam que a conexão existia nos indivíduos saudáveis e foi extinta nos pacientes enquanto pontos vermelhos indicam o oposto. As áreas brancas significam que não houve alterações.

que os calculados para a rede dos indivíduos saudáveis. Comparando esses valores com os dados de 500 redes aleatórias com a mesma distribuição de graus, encontramos $\gamma=1,38, \lambda=0,83$ e portanto $\sigma=1,66$. Bernhardt (BERNHARDT et al., 2011) realizou um estudo dessas métricas em redes de conectividade provenientes de pacientes com epilepsia e encontrou um coeficiente de agrupamento $=0,4$, comprimento médio do caminho $=2, \gamma$ $=1,05, \lambda=1,87$ e $\sigma=1,78$. Segundo ele, houve um aumento no valor de $\sigma$ dos pacientes quando comparados com os indivíduos saudáveis. Em nosso estudo, ocorreu o oposto, com uma queda no valor de $\sigma$ e nos parâmetros de rede de mundo pequeno de forma geral, sugerindo uma menor eficiência na rede formada pelos pacientes, possivelmente causada pela doença.

Nota-se portanto que a rede encontrada nos pacientes ainda mantém uma característica de rede de mundo pequeno porém apresenta uma quebra em sua arquitetura. O gráfico 4.13 mostra o comportamento dessas variáveis 


\begin{tabular}{llll}
\hline N. & Região 1 & Região 2 & $\begin{array}{c}\text { Coeficiente de } \\
\text { correlação }\end{array}$ \\
\hline \hline 1 & Frontal superior esquerda & Frontal superior direita & 0,8302 \\
2 & Parietal superior esquerda & Parietal superior direita & 0,7909 \\
3 & Parietal superior esquerda & Parietal inferior esquerda & 0,7857 \\
4 & Frontal média rostral esquerda & Caudal média frontal esquerda & 0,7714 \\
5 & Lateral orbito-frontal esquerda & Lateral orbito-frontal direita & 0,7662 \\
6 & Parietal superior esquerda & Precuneus Esquerda & 0,7642 \\
7 & Parietal superior direita & Parietal inferior direita & 0,7504 \\
8 & Frontal superior esquerda & Frontal média caudal esquerda & 0,7487 \\
9 & Pré-central esquerda & Pré-central direita & 0,7434 \\
10 & Frontal superior direita & Frontal caudal média direita & 0,7422 \\
11 & Parietal inferior esquerda & Parietal inferior direita & 0,7397 \\
12 & Temporal superior direita & Frontal média rostral direita & 0,7777 \\
13 & Frontal média rostral esquerda & Frontal média rostral direita & 0,7374 \\
14 & Parietal superior direita & Precuneus direita & 0,7370 \\
15 & Caudal frontal média esquerda & Superior frontal direita & 0,7317 \\
\hline \hline
\end{tabular}

Tabela 4.4: Regiões mais fortemente conectadas em pacientes com epilepsia. Na tabela são descritas as 15 regiões com maior coeficiente de correção encontrados para a rede dos pacientes com epilepsia, sinalizando maior força em sua conexão.

com a alteração do coeficiente de correlação de corte até o valor utilizado para montagem da rede $(0,41)$, comparando-os com os valores obtidos nos indivíduos saudáveis. Para pequenos valores do coeficiente de correlação de corte. ambos os grupos são semelhantes, porém quando consideramos conexões mais intensas notamos uma diferenciação no comportamento dos grupos. O grupo de pacientes apresenta valores menores em todos os parâmetros analisados, possivelmente refletindo de forma quantitativa uma diminuição da eficiência na rede cerebral causada pela patologia.

Em nossas pesquisas, não encontramos nenhum estudo anterior analisando uma divisão modular de pacientes com epilepsia. Aplicando nosso algoritmo de deteç̧ão de comunidades explicado na seção 3.2.5, verificamos que nos pacientes foram encontradas 6 comunidades ao invés das 


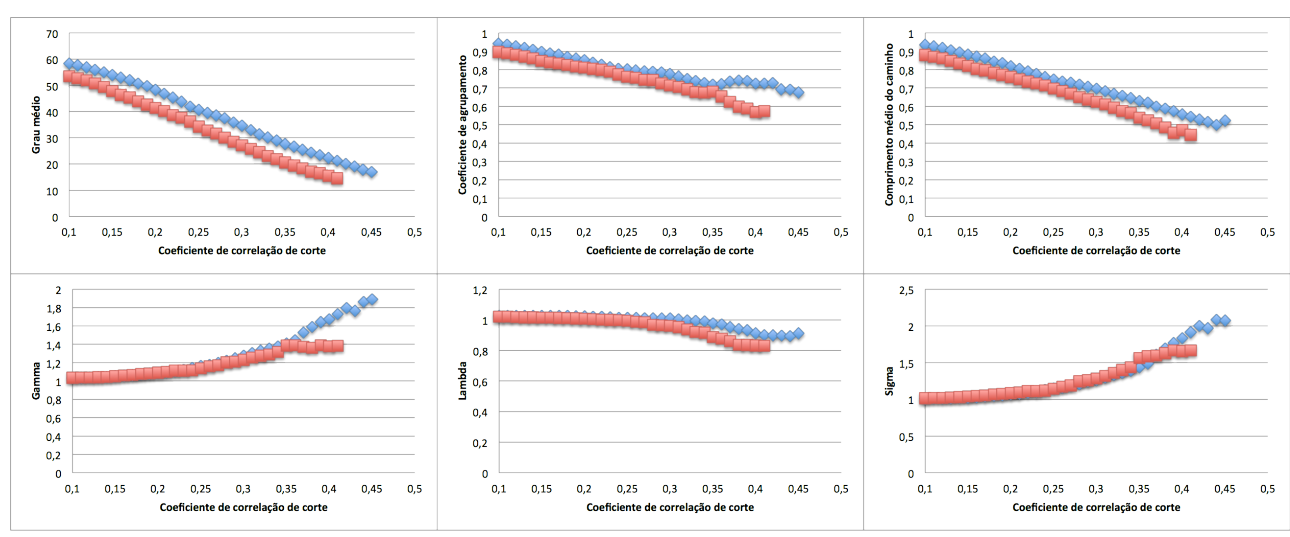

Figura 4.13: Comparação dos parâmetros de rede para indivíduos saudáveis e pacientes com epilepsia. Os pontos azuis indicam valores encontrados para os indivíduos saudáveis enquanto os vermelhos indicam valores encontrados para os pacientes. Nos gráficos pode ser visto que há uma quebra na arquitetura de redes encontradas para os pacientes, evidenciando uma possível consequência da doença. Em todos os parâmetros analisados, as redes formadas pelos pacientes apresentaram menores valores.

3 encontradas nos indivíduos saudáveis. Tal fato pode ser decorrente de uma quebra de organização estrutural causada pela patologia refletindo em uma diminuição no fator de agrupamento e consequentemente uma maior divisão modular das áreas cerebrais. Tal divisão pode ser vista na figura 4.14. 


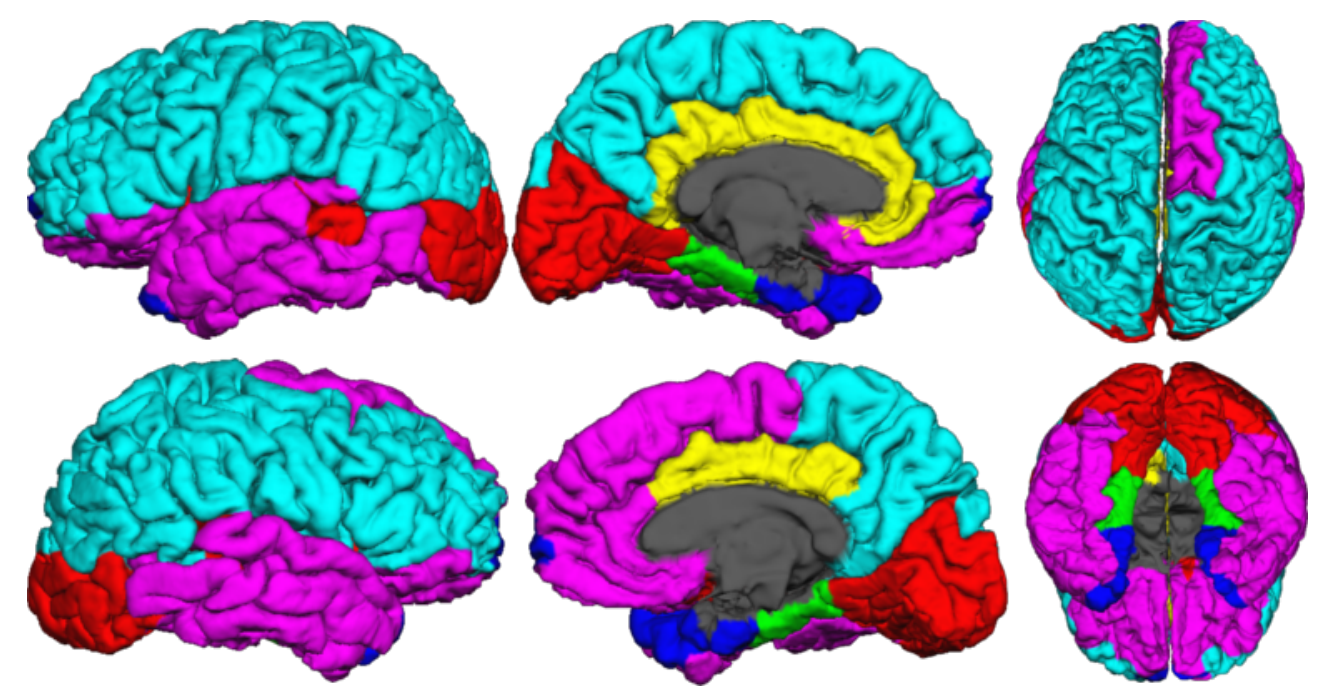

Figura 4.14: Comunidades encontradas nos pacientes com epilepsia. $\mathrm{Na}$ figura são mostradas as seis comunidades encontradas nos pacientes com epilepsia, decorrentes possivelmente de uma quebra de organização estrutural, resultando em um menor coeficiente de agrupamento e consequentemente uma maior divisão da rede de conectividade anatômica cerebral. 


\section{Capítulo}

\section{Conclusão}

No presente estudo, nosso objetivo foi criar um software capaz de realizar a montagem de uma rede de conectividade cerebral baseada não em DTI ou fMRI, mas sim em semelhanças estatísticas de uma determinada característica morfológica. Para isso, implementamos alguns algoritmos de regressão linear e não linear de dados, propusemos um ajuste bi-exponencial para retirada do efeito da idade, bem como mecanismos de cálculo de correlações e montagem da rede de conectividade. Além disso, foi implementado um algoritmo de cálculo de comunidades, permitindo uma divisão modular da rede cerebral encontrada.

Para testar as implementações, submetemos ao software dados de espessura cortical de um grupo de indivíduos saudáveis e um grupo de pacientes com epilepsia de lobo temporal. Para o grupo de indivíduos saudáveis definimos as idades de término de amadurecimento e início do envelhecimento para cada região cerebral analisada, verificamos que a rede de conectividade encontrada possuía uma característica de rede de mundo pequeno e encontramos 3 comunidades. Ja no grupo dos pacientes, encontramos maiores taxas de decaimento de espessura cortical quando comparados aos controles, com uma diferença chegando à 500\% em alguns casos, além de apresentarem uma diminuição na quantidade de conexões encontradas e uma queda média de $15 \%$ nos parâmetros de rede de mundo pequeno, sugerindo uma diminuição global na eficiência da rede encontrada, possivelmente em decorrência da patologia. Além disso, para os pacientes 
foram identificadas 6 comunidades ao invés das 3 encontradas nos indivíduos saudáveis, consequencia do menor coeficiente de agrupamento encontrado nesse grupo.

O software permite análises posteriores de diversas massas de dados, incluindo novas imagens, diferentes patologias e também diferentes características morfológicas. O mesmo será licenciado pelos termos da GNU Public License e incluído em um repositório de código aberto onde mais pessoas poderão contribuir para seu crescimento e amadurecimento. Como trabalhos futuros, é possível pensar na implementação de uma análise de redes complexas com base em DTI e fMRI e principalmente na montagem de uma base de dados contendo redes montadas a partir de grupos de pacientes com diferentes doenças, permitindo o desenvolvimento de um algoritmo comparativo e culminando com um software de suporte ao diagnóstico, mais uma ferramenta para auxiliar os médicos e profissionais de saúde na tarefa de detecção e tratamento de doenças. 


\section{Referências Bibliográficas}

ACHARD, S. et al. A resilient, low-frequency, small-world human brain functional network with highly connected association cortical hubs. The Journal of Neuroscience, v. 26, n. 1, p. 63-72, 2006.

AERTSEN, A. M. et al. Dynamics of neuronal firing correlation: modulation of "effective connectivity". J Neurophysiol, v. 61, n. 5, p. 900-917, maio 1989. Disponível em: <http://jn.physiology.org/content/61/5/900.abstract $>$.

AGANJ, I. et al. Measurement of cortical thickness from MRI by minimum line integrals on soft-classified tissue. Human Brain Mapping, Wiley Subscription Services, Inc., A Wiley Company, v. 30, n. 10, p. 3188-3199, 2009. ISSN 1097-0193. Disponível em: <http://dx.doi.org/10.1002/hbm.20740>.

BASSER, P.; MATTIELLO, J.; LEBIHAN, D. Estimation of the effective self-diffusion tensor from the nmr spin echo. Journal of Magnetic Resonance, Series B, v. 103, n. 3, p. 247-254, 1994.

BASSETT, D.; BULLMORE, E. Small-world brain networks. Neuroscientist, v. 12, n. 6, p. 512-523, 2006.

BASSETT, D. et al. Hierarchical organization of human cortical networks in health and schizophrenia. Journal of Neuroscience, v. 28, n. 37, p. 9239-9248, 2008.

BASTIANI, M. et al. Human cortical connectome reconstruction from diffusion weighted MRI: The effect of tractography algorithm. NeuroImage, v. 62, n. 3, p. 1732-1749, 2012.

BELLIS, M. D. D. et al. Sex differences in brain maturation during childhood and adolescence. Cerebral Cortex, v. 11, n. 6, p. 552-557, 2001.

BERNASCONI, N. et al. Mesial temporal damage in temporal lobe epilepsy: a volumetric MRI study of the hippocampus, amygdala and parahippocampal region. Brain, v. 126, n. 2, p. 462-469, 2003. Disponível em: $<$ http://brain.oxfordjournals.org/content/126/2/462.abstract $>$. 
BERNHARDT, B. C. et al. Graph-theoretical analysis reveals disrupted small-world organization of cortical thickness correlation networks in temporal lobe epilepsy. Cerebral cortex (New York, N.Y. : 1991), v. 21, n. 9, p. 2147-2157, set. 2011. ISSN 1460-2199. Disponível em: $<$ http://dx.doi.org/10.1093/cercor/bhq291>.

BERNHARDT, B. C. et al. Mapping limbic network organization in temporal lobe epilepsy using morphometric correlations: Insights on the relation between mesiotemporal connectivity and cortical atrophy. NeuroImage, v. 42, n. 2, p. 515 - 524, 2008. ISSN 1053-8119. Disponível em: $<$ http://www.sciencedirect.com/science/article/pii/S1053811908006058>.

BIHAN, D. L.; JOHANSEN-BERG, H. Diffusion MRI at 25: Exploring brain tissue structure and function. NeuroImage, v. 61, n. 2, p. 324-341, 2012.

BLOCH, F. Nuclear induction. Phys. Rev., American Physical Society, v. 70, p. 460-474, Oct 1946. Disponível em: $<$ http://link.aps.org/doi/10.1103/PhysRev.70.460>.

BULLMORE, E.; SPORNS, O. Complex brain networks: graph theoretical analysis of structural and functional systems. Nature Reviews Neuroscience, Nature Publishing Group, v. 10, n. 3, p. 186-198, 2009.

BULLMORE, E.; SPORNS, O. The economy of brain network organization. Nat Rev Neurosci, Nature Publishing Group, a division of Macmillan Publishers Limited. All Rights Reserved., v. 13, n. 5, p. 336-349, maio 2012. ISSN 1471-003X. Disponível em: <http://dx.doi.org/10.1038/nrn3214>.

BUSHBERG, J. T. et al. The Essential Physics of Medical Imaging. [S.l.]: Lippincott Williams and Wilkins, 2012.

CHEN, K.-C.; CHIANG, M.; POOR, H. V. From technological networks to social networks. IEEE Journal on Selected Areas in Communications, v. 31, n. 9-Supplement, p. 548-572, 2013.

CHEN, Z. et al. Revealing modular architecture of human brain structural networks by using cortical thickness from MRI. Cerebral Cortex, v. 18, n. 10, p. 2374-2381, 2008.

CHO, M. W.; CHOI, M. Y. Brain networks: Graph theoretical analysis and development models. Int. J. Imaging Syst. Technol., John Wiley \& Sons, Inc., New York, NY, USA, v. 20, n. 2, p. 108-116, jun. 2010. ISSN 0899-9457. Disponível em: <http://dx.doi.org/10.1002/ima.v20:2>.

CLARKSON, M. J. et al. A comparison of voxel and surface based cortical thickness estimation methods. NeuroImage, v. 57, n. 3, p. 856 - 865, 2011. ISSN 1053-8119. <ce:title>Special 
Issue: Educational Neuroscience</ce:title>. Disponível em:

$<$ http://www.sciencedirect.com/science/article/pii/S1053811911005611>.

COFFEY, C. et al. Sex differences in brain aging: A quantitative magnetic resonance imaging study. Archives of Neurology, v. 55, n. 2, p. 169-179, 1998. Disponível em: $<+$ http://dx.doi.org/10.1001/archneur.55.2.169>.

CRICK, F.; JONES, E. Backwardness of human neuroanatomy. Nature, v. 361, p. 109-110, 1993.

DALE, A. M.; FISCHL, B.; SERENO, M. I. Cortical surface-based analysis: I. segmentation and surface reconstruction. NeuroImage, v. 9, n. 2, p. 179 - 194, 1999. ISSN 1053-8119. Disponível em: $<$ http://www.sciencedirect.com/science/article/pii/S1053811998903950>.

DALE, A. M.; SERENO, M. I. Improved localizadon of cortical activity by combining eeg and meg with MRI cortical surface reconstruction: A linear approach. J. Cognitive Neuroscience, MIT Press, Cambridge, MA, USA, v. 5, n. 2, p. 162-176, abr. 1993. ISSN 0898-929X. Disponível em: $<$ http://dx.doi.org/10.1162/jocn.1993.5.2.162>.

DECARLI, C. et al. Measures of brain morphology and infarction in the framingham heart study: establishing what is normal. Neurobiology of Aging, v. 26, n. 4, p. 491-510, 2005.

DESIKAN, R. S. et al. An automated labeling system for subdividing the human cerebral cortex on MRI scans into gyral based regions of interest. NeuroImage, v. 31, n. 3, p. 968 - 980, 2006. ISSN 1053-8119. Disponível em: $<$ http://www.sciencedirect.com/science/article/pii/S1053811906000437>.

DOUGHERTY, R. F. et al. Functional organization of human occipital-callosal fiber tracts. Proceedings of the National Academy of Sciences of the United States of America, v. 102, n. 20, p. 7350-7355, 2005. Disponível em: $<$ http://dx.doi.org/10.1073/pnas.0500003102>.

EGUíLUZ, V. M. et al. Scale-free brain functional networks. Phys. Rev. Lett., American Physical Society, v. 94, p. 018102, Jan 2005. Disponível em: $<$ http://link.aps.org/doi/10.1103/PhysRevLett.94.018102>.

ESSEN, D. V. Computerized Anatomical Reconstruction Toolkit. 2013. Disponível em: <http://brainvis.wustl.edu/wiki/index.php/Caret:Download $>$.

EVANS, A. C. Networks of anatomical covariance. NeuroImage, v. 80 , n. 0, p. 489 - 504, 2013. ISSN 1053-8119. Disponível em: $<$ http://www.sciencedirect.com/science/article/pii/S105381191300548X >.

FISCHL, B. FreeSurfer Software Suite. 2013. Disponível em: $<$ http://surfer.nmr.mgh.harvard.edu $>$. 
FISCHL, B.; DALE, A. M. Measuring the thickness of the human cerebral cortex from magnetic resonance images. Proceedings of the National Academy of Sciences, v. 97, n. 20, p. 11050-11055, 2000. Disponível em: $<$ http://www.pnas.org/content/97/20/11050.abstract $>$.

FISCHL, B. et al. Automatically parcellating the human cerebral cortex. Cerebral Cortex, v. 14, n. 1, p. 11-22, 2004. Disponível em: $<$ http://cercor.oxfordjournals.org/content/14/1/11.abstract $>$.

FISCHL, B. et al. Whole brain segmentation: Automated labeling of neuroanatomical structures in the human brain. Neuron, v. 33, n. 3, p. 341 - 355, 2002. ISSN 0896-6273. Disponível em: $<$ http://www.sciencedirect.com/science/article/pii/S089662730200569X >.

FJELL, A. M. et al. High consistency of regional cortical thinning in aging across multiple samples. Cerebral Cortex, v. 19, n. 9, p. 2001-2012, 2009. Disponível em: $<$ http://cercor.oxfordjournals.org/content/19/9/2001.abstract $>$.

FLANAGAN, M. T. Java Scientific Library. 2013. Disponível em: $<$ http://www.ee.ucl.ac.uk/ ${ }^{2}$ flanaga/java/>.

FORTUNATO, S.; BARTHELEMY, M. Resolution limit in community detection. Proceedings of the National Academy of Sciences, jan. 2007. Disponível em: $<$ http://www.pnas.org/cgi/content/abstract/104/1/36>.

FRISTON, K. J. et al. Functional connectivity: the principal-component analysis of large (PET) data sets. J Cereb Blood Flow Metab, v. 13, n. 1, p. 5-14, jan. 1993. Disponível em: <http://view.ncbi.nlm.nih.gov/pubmed/8417010>.

GFELLER, D. Simplifying Complex networks: from a Clustering to a Coarse graining strategy. Tese (Doutorado) - École Polytechnique Fédérale de Lausane, 2007.

GIEDD, J. N. et al. Brain development during childhood and adolescence: a longitudinal MRI study. 1999. 861 ?863 p. Disponível em: <http://www.nature.com/neuro/journal/v2/n10/full/nn1099_861.html>.

GONG, G. et al. Convergence and divergence of thickness correlations with diffusion connections across the human cerebral cortex. NeuroImage, v. 59, n. 2, p. 1239-1248, 2012.

GONG, G. et al. Mapping anatomical connectivity patterns of human cerebral cortex using in vivo diffusion tensor imaging tractography. Cerebral Cortex, v. 19, n. 3, p. 524-536, 2009.

GONG, G. et al. Age- and gender-related differences in the cortical anatomical network. Journal of Neuroscience, v. 29, n. 50, p. 15684-15693, 2009. 
GREICIUS, M. et al. Functional connectivity in the resting brain: A network analysis of the default mode hypothesis. Proceedings of the National Academy of Sciences of the United States of America, v. 100, n. 1, p. 253-258, 2003.

GUYE, M. et al. Graph theoretical analysis of structural and functional connectivity MRI in normal and pathological brain networks. Magnetic Resonance Materials in Physics, Biology and Medicine, Springer-Verlag, v. 23, n. 5-6, p. 409-421, 2010. ISSN 0968-5243. Disponível em: $<$ http://dx.doi.org/10.1007/s10334-010-0205-z>.

HAIDAR, H.; SOUL, J. S. Measurement of cortical thickness in 3d brain MRI data: Validation of the laplacian method. Journal of Neuroimaging, Blackwell Publishing Inc, v. 16, n. 2, p. 146-153, 2006. ISSN 1552-6569. Disponível em: $<$ http://dx.doi.org/10.1111/j.1552-6569.2006.00036.x $>$.

HAMPSON, M. et al. Detection of functional connectivity using temporal correlations in MR images. Hum. Brain Mapp., Wiley Subscription Services, Inc., A Wiley Company, v. 15, n. 4, p. 247-262, 2002. Disponível em: $<$ http://dx.doi.org/10.1002/hbm.10022>.

HARGREAVES, B. Rapid gradient-echo imaging. Journal of Magnetic Resonance Imaging, Wiley Subscription Services, Inc., A Wiley Company, v. 36, n. 6, p. 1300-1313, 2012. ISSN 1522-2586. Disponível em: $<$ http://dx.doi.org/10.1002/jmri.23742>.

HARTWELL, L. H. et al. From molecular to modular cell biology. Nature, v. 402, n. 6761 Suppl, p. C47-C52, 1999.

HE, Y.; CHEN, Z.; EVANS, A. Structural insights into aberrant topological patterns of large-scale cortical networks in alzheimer's disease. Journal of Neuroscience, v. 28, n. 18, p. 4756-4766, 2008.

HE, Y.; CHEN, Z. J. J.; EVANS, A. C. C. Small-World anatomical networks in the human brain revealed by cortical thickness from MRI. Cereb Cortex, 2007. Disponível em: <http://dx.doi.org/10.1093/cercor/bhl149>.

HE, Y. et al. Impaired small-world efficiency in structural cortical networks in multiple sclerosis associated with white matter lesion load. Brain, v. 132, n. 12, p. 3366-3379, dez. 2009. ISSN 1460-2156. Disponível em: $<$ http://dx.doi.org/10.1093/brain/awp089>.

HUMPHRIES, M. D.; GURNEY, K.; PRESCOTT, T. J. The brainstem reticular formation is a small-world, not scale-free, network. The Royal Society of London Proceedings: Biological Sciences.

ITURRIA-MEDINA, Y. et al. Studying the human brain anatomical network via diffusion-weighted MRI and Graph Theory. NeuroImage, Brain 
Dynamics Department, Cuban Neuroscience Center, Havana, Cuba, v. 40, n. 3, p. 1064-1076, abr. 2008. ISSN 10538119. Disponível em: $<$ http://dx.doi.org/10.1016/j.neuroimage.2007.10.060>.

JOHANSEN-BERG, H.; RUSHWORTH, M. F. Using diffusion imaging to study human connectional anatomy. Annual review of neuroscience, v. 32, n. 1, p. 75-94, 2009. Disponível em: $<$ http://dx.doi.org/10.1146/annurev.neuro.051508.135735>.

JONES, S. E.; BUCHBINDER, B. R.; AHARON, I. Three-dimensional mapping of cortical thickness using laplace?s equation. Human Brain Mapping, v. 11, p. 12-32, 2000.

KELLER, S. S.; ROBERTS, N. Voxel-based morphometry of temporal lobe epilepsy: An introduction and review of the literature. Epilepsia, Blackwell Publishing Inc, v. 49, n. 5, p. 741-757, 2008. ISSN 1528-1167. Disponível em: $<$ http://dx.doi.org/10.1111/j.1528-1167.2007.01485.x >.

KNIGHT, W. et al. Acceleration of cortical thinning in familial alzheimer's disease. Neurobiology of Aging, v. 32, n. 10, p. 1765 - 1773, 2011. ISSN 0197-4580. Disponível em: $<$ http://www.sciencedirect.com/science/article/pii/S019745800900373X >.

LATORA, V.; MARCHIORI, M. Efficient behavior of small-world networks. Phys. Rev. Lett., American Physical Society, v. 87, p. 198701, Oct 2001. Disponível em: <http://link.aps.org/doi/10.1103/PhysRevLett.87.198701>.

LEMAITRE, H. et al. Normal age-related brain morphometric changes: nonuniformity across cortical thickness, surface area and gray matter volume? Neurobiol Aging, E1-9, n. 617, 2012.

LEO, V. D. et al. Community core detection in transportation networks. Phys. Rev. E, American Physical Society, v. 88, n. 4, p. 042810, out. 2013. Disponível em: <http://link.aps.org/doi/10.1103/PhysRevE.88.042810>.

LERCH, J. P.; EVANS, A. C. Cortical thickness analysis examined through power analysis and a population simulation. NeuroImage, v. 24 , n. 1, p. 163 - 173, 2005. ISSN 1053-8119. Disponível em: $<$ http://www.sciencedirect.com/science/article/pii/S1053811904004185>.

LERCH, J. P. et al. Focal decline of cortical thickness in alzheimer's disease identified by computational neuroanatomy. Cerebral Cortex, v. 15, n. 7, p. 995-1001, 2005. Disponível em: $<$ http://cercor.oxfordjournals.org/content/15/7/995.abstract $>$.

LOHMANN, G.; PREUL, C.; HUND-GEORGIADIS, M. Morphology-based cortical thickness estimation. Springer, v. 2732, p. $89-100,2003$. ISSN 1053-8119. 
LOWE, M.; MOCK, B.; SORENSON, J. Functional connectivity in single and multislice echoplanar imaging using resting-state fluctuations. 1998.

MACDONALD, D. et al. Automated 3-d extraction of inner and outer surfaces of cerebral cortex from MRI. NeuroImage, v. 12, n. 3, p. 340 - 356, 2000. ISSN 1053-8119. Disponível em: $<$ http://www.sciencedirect.com/science/article/pii/S1053811999905347>.

MASLOV, S.; SNEPPEN, K. Specificity and Stability in Topology of Protein Networks. Science, American Association for the Advancement of Science, v. 296, n. 5569, p. 910-913, maio 2002. ISSN 1095-9203. Disponível em: $<$ http://dx.doi.org/10.1126/science.1065103>.

MAZZOLA, A. A. Ressona?ncia magne?tica: princi?pios de formac?a?o da imagem e aplicac?o?es em imagem funcional. Revista Brasileira de Física Médica, Revista Brasileira de Física Médica, v. 3, p. 117-129, 2009.

MECHELLI, A. et al. Structural covariance in the human cortex. Journal of Neuroscience, v. 25, n. 36, p. 8303-8310, 2005.

MICHELOYANNIS, S. et al. Using graph theoretical analysis of multi channel eeg to evaluate the neural efficiency hypothesis. Neuroscience Letters, v. 402, n. 3, p. 273-277, 2006.

MILLER, M. I. et al. Bayesian construction of geometrically based cortical thickness metrics. NeuroImage, v. 12, n. 6, p. 676 - 687, 2000. ISSN 1053-8119. Disponível em: $<$ http://www.sciencedirect.com/science/article/pii/S1053811900906669>.

MORECRAFT, R. J. et al. Diffusion MRI: From quantitative measurement to in-vivo neuroanatomy. In: . [S.1.]: Elsevier Inc, 2009. cap. Classic and Contemporary Neural Tract Tracing Techniques.

NEWMAN, M. E. Modularity and community structure in networks. Proc Natl Acad Sci U S A, v. 103, n. 23, p. 8577-8582, jun. 2006.

PENG, X.-L. et al. Temporal prediction of epidemic patterns in community networks. New Journal of Physics, v. 15, n. 11, p. 113033, 2013. Disponível em: <http://stacks.iop.org/1367-2630/15/i=11/a=113033>.

PETERS, A. et al. Are neurons lost from the primate cerebral cortex during normal aging? Cerebral Cortex, v. 8, p. 295-300, 1998.

PIZER, S. M. et al. Zoom-invariant vision of figural shape: The mathematics of cores. Computer Vision and Image Understanding, v. 69, n. 1, p. 55 - 71, 1998. ISSN 1077-3142. Disponível em: $<$ http://www.sciencedirect.com/science/article/pii/S1077314297905634>. 
PLEWES, D. B. The aapm/rsna physics tutorial for residents. contrast mechanisms in spin-echo $\mathrm{mr}$ imaging. Radiographics, v. 14, n. 6, p. 1389-1404, 1994. Disponível em: $<$ http://radiographics.rsna.org/content/14/6/1389.abstract $>$.

POOLEY, R. A. Fundamental physics of $\mathrm{mr}$ imaging1.

Radiographics, v. 25, n. 4, p. 1087-1099, 2005. Disponível em: $<$ http://radiographics.rsna.org/content/25/4/1087.abstract>.

PRICE, R. R. The aapm/rsna physics tutorial for residents. contrast mechanisms in gradient-echo imaging and an introduction to fast imaging. Radiographics, v. 15, n. 1, p. 165-178, 1995. Disponível em: $<$ http://radiographics.rsna.org/content/15/1/165.abstract $>$.

PURCELL, E. M.; TORREY, H. C.; POUND, R. V. Resonance absorption by nuclear magnetic moments in a solid. Phys. Rev., American Physical Society, v. 69, p. 37-38, Jan 1946. Disponível em: $<$ http://link.aps.org/doi/10.1103/PhysRev.69.37>.

RAMNANI, N. et al. New approaches for exploring anatomical and functional connectivity in the human brain. Biological Psychiatry, v. 56, n. 9, p. 613-619, 2004.

RAZ, N. Ageing and the brain. In: . eLS. John Wiley and Sons, Ltd, 2001. ISBN 9780470015902. Disponível em: $<$ http://dx.doi.org/10.1038/npg.els.0004063>.

RAZ, N. et al. Aging, sexual dimorphism, and hemispheric asymmetry of the cerebral cortex: replicability of regional differences in volume. Neurobiol Aging, v. 25, n. 3, p. 377-396, 2004.

RINCK, P. Magnetic Resonance in Medicine. The Basic Textbook of the European Magnetic Resonance Forum. 2013. Disponível em: $<$ http://www.magnetic-resonance.org $>$.

ROHRER, J. D. et al. Patterns of cortical thinning in the language variants of frontotemporal lobar degeneration. Neurology, v. 72, n. 18, p. 1562-1569, maio 2009. ISSN 1526-632X. Disponível em: $<$ http://dx.doi.org/10.1212/wnl.0b013e3181a4124e $>$.

ROSAS, H. D. et al. Cerebral cortex and the clinical expression of huntington's disease: complexity and heterogeneity. Brain, v. 131, n. 4, p. 1057-1068, 2008. Disponível em: $<$ http://brain.oxfordjournals.org/content/131/4/1057.abstract $>$.

RUBINOV, M.; SPORNS, O. Complex network measures of brain connectivity: Uses and interpretations. NeuroImage, 
v. 52, n. 3, p. 1059 - 1069, 2010. ISSN 1053-8119.

$<$ ce:title>Computational Models of the Brain</ce:title>. Disponível em:

$<$ http://www.sciencedirect.com/science/article/pii/S105381190901074X >.

SAILER, M. et al. Focal thinning of the cerebral cortex in multiple sclerosis. Brain, v. 126, n. 8, p. 1734-1744, 2003. Disponível em: $<$ http://brain.oxfordjournals.org/content/126/8/1734.abstract $>$.

SALAT, D. H. et al. Thinning of the cerebral cortex in aging. Cerebral Cortex, v. 14, n. 7, p. 721-730, 2004. Disponível em: $<$ http://cercor.oxfordjournals.org/content/14/7/721.abstract $>$.

SALVADOR, R. et al. Neurophysiological architecture of functional magnetic resonance images of human brain. Cerebral Cortex, v. 15, n. 9, p. 1332-1342, 2005.

SEGONNE, F. et al. A hybrid approach to the skull stripping problem in MRI. NeuroImage, v. 22, n. 3, p. 1060 - 1075, 2004. ISSN 1053-8119. Disponível em: $<$ http://www.sciencedirect.com/science/article/pii/S1053811904001880>.

SOWELL, E. R. et al. Sex differences in cortical thickness mapped in 176 healthy individuals between 7 and 87 years of age. Cerebral cortex (New York, N.Y. : 1991), v. 17, p. 1550-60, 2007 Jul 2007. ISSN 1047-3211.

SPORNS, O. From simple graphs to the connectome: Networks in neuroimaging. NeuroImage, v. 62, n. 2, p. 881 - 886, 2012. ISSN 1053-8119. Disponível em: <http://www.sciencedirect.com/science/article/pii/S1053811911010172>.

SPORNS, O. et al. Organization, development and function of complex brain networks. Trends in Cognitive Sciences, Elsevier Inc., v. 8, p. 418-425, 2004.

STAM, C. Functional connectivity patterns of human magnetoencephalographic recordings: a śmall-worldńetwork? Neuroscience Letters, Elsevier Inc., v. 355, p. 25-28, 2004.

STAM, C. et al. Small-world networks and functional connectivity in alzheimer's disease. Cereb Cortex, v. 17, n. 1, p. 92-9, 2007.

STANISZ, G. J. et al. T1, t2 relaxation and magnetization transfer in tissue at 3t. Magnetic Resonance in Medicine, Wiley Subscription Services, Inc., A Wiley Company, v. 54, n. 3, p. 507-512, 2005. ISSN 1522-2594. Disponível em: <http://dx.doi.org/10.1002/mrm.20605>.

SULLIVAN, E. et al. Effects of age and sex on volumes of the thalamus, pons, and cortex. Neurobiology of Aging, v. 25, n. 2, p. 185-192, 2004. 
THAMBISETTY, M. et al. Longitudinal changes in cortical thickness associated with normal aging. NeuroImage, v. 52, n. 4, p. $1215-1223,2010$. ISSN 1053-8119.

TUCH, D. et al. High angular resolution diffusion imaging reveals intravoxel white matter fiber heterogeneity. Magnetic Resonance in Medicine, v. 48, n. 4, p. 577-582, 2002.

TUCH, D. et al. Q-ball imaging of macaque white matter architecture. Philos Trans R Soc Lond B Biol Sci, v. 360, n. 1457, p. 869-879, 2005.

VANDENBERGHE, R. et al. The associative-semantic network for words and pictures: Effective connectivity and graph analysis. Brain and Language, v. 127, n. 2, p. 264 - 272, 2013. ISSN 0093-934X. Disponível em: $<$ http://www.sciencedirect.com/science/article/pii/S0093934X12001678>.

VELASCO, T. R.; TERRA-BUSTAMANTE, V. C. Video-eletrencefalografia: Fundamentos e aplicação na investigação das epilepsias. In: [S.l.]: Lemos Editorial, 1999. cap. Epilepsias do Lobo Parietal e Occipital: Características Clínicas e Semiologia ictal ao Vídeo-EEG.

VERTES, P. et al. Simple models of human brain functional networks. Proceedings of the National Academy of Sciences of the United States of America, v. 109, n. 15, p. 5868-5873, 2012.

WANG, L. et al. Changes in Hippocampal Connectivity in the Early Stages of Alzheimer's Disease: Evidence from Resting State fMRI. NeuroImage, Academic Press, v. 31, n. 2, p. 496-504, 2006. Disponível em: $<$ http://hal.inria.fr/inria-00123587>.

WATTS, D.; STROGATZ, S. Collective dynamics of 'small-world' networks. Nature, n. 393, p. 440-442, 1998.

$\mathrm{XU}$, J. et al. Gender effects on age-related changes in brain structure. American Journal of Neuroradiology, v. 21, n. 1, p. 112-118, 2000. Disponível em: <http://www.ajnr.org/content/21/1/112.abstract $>$.

YEZZI, A.; PRINCE, J. An eulerian pde approach for computing tissue thickness. Medical Imaging, IEEE Transactions on, v. 22, n. 10, p. 1332-1339, 2003. ISSN 0278-0062. 


\section{Planilha de entrada de dados}

A figura abaixo mostra uma parte da planilha utilizada como entrada para o software implementado no presente estudo. As colunas de identificação e nome foram alteradas para manter o sigilo das informações. Em cada linha estão presentes as informações de um indivíduo e em cada coluna a região cerebral e o valor da característica morfológica analisada. Nesse caso, espessura cortical. 


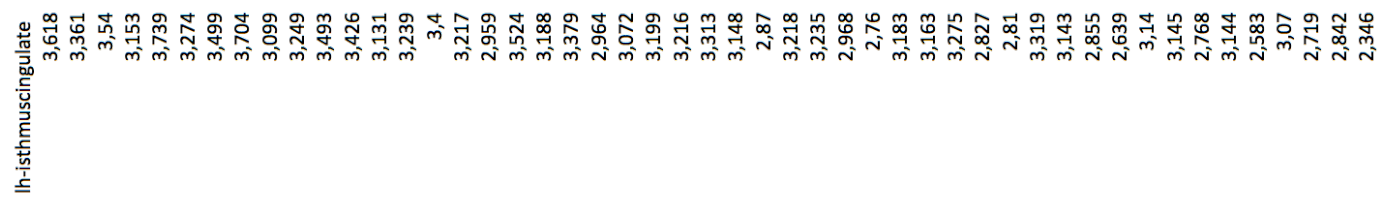

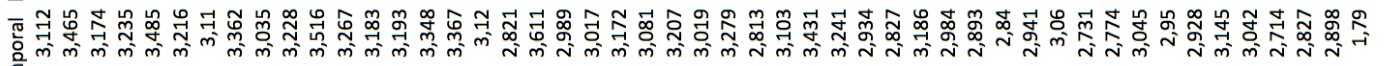
童

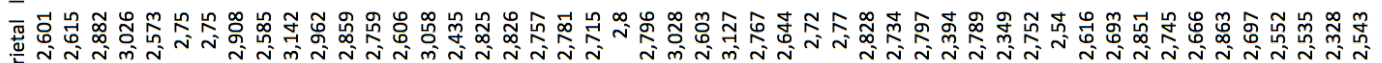
要

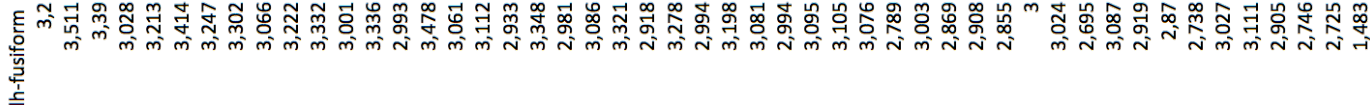

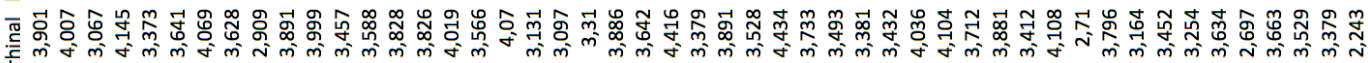
突

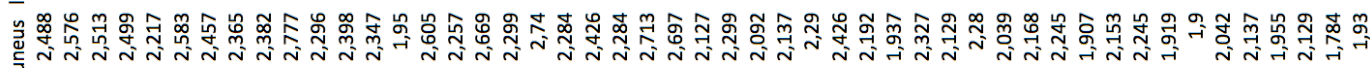
疍

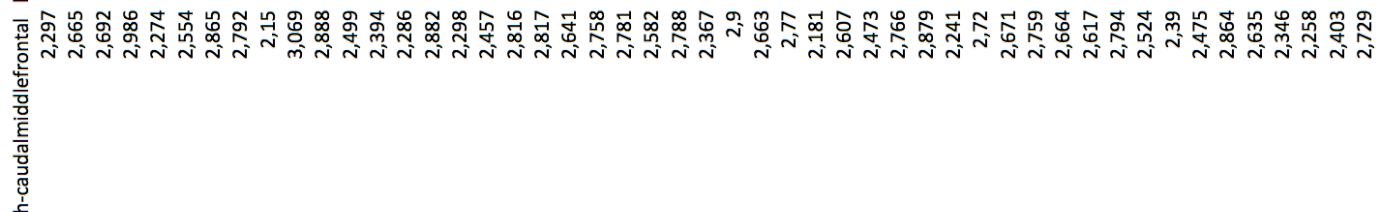

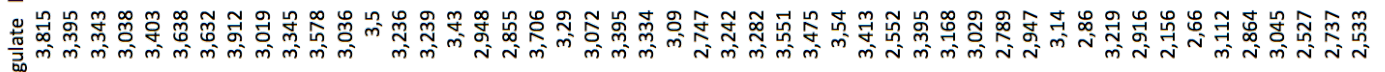

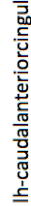

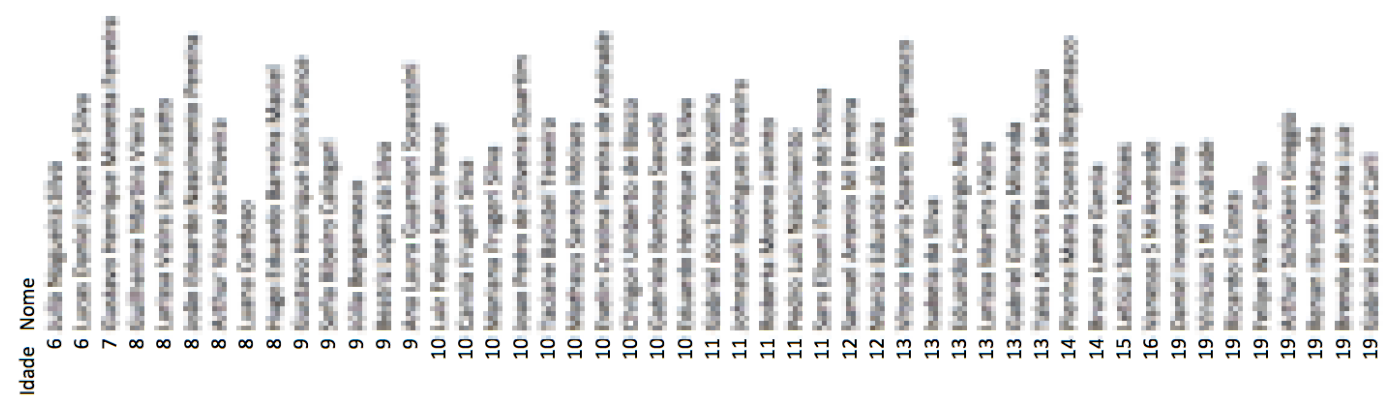

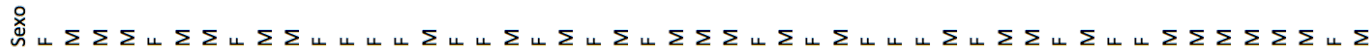

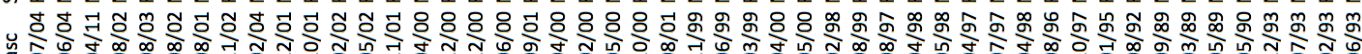

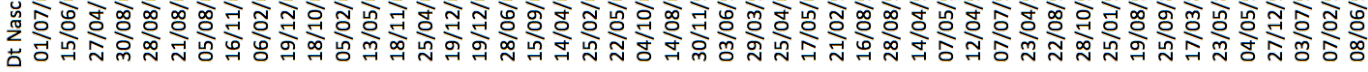

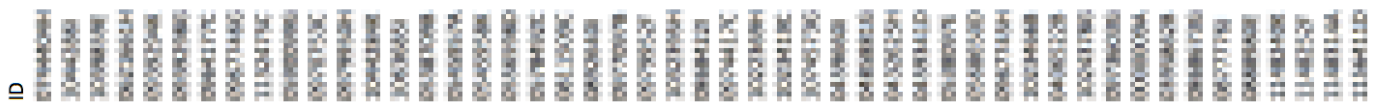

Figura A.1: Planilha de dados utilizada para execução do software. Na figura é mostrada apenas uma parte da planilha completa à qual possui 70 colunas e 192 linhas no caso dos indivíduos saudáveis. 


\section{Anexo}

B

\section{Planilha de saída de dados}

Cada figura do presente anexo mostra uma folha da planilha gerada como resultado da execução do software implementado no presente estudo. Quando todas as opções ilustradas na seção 3.2.6 estiverem selecionadas, teremos uma planilha com 6 folhas, ilustradas a seguir. 


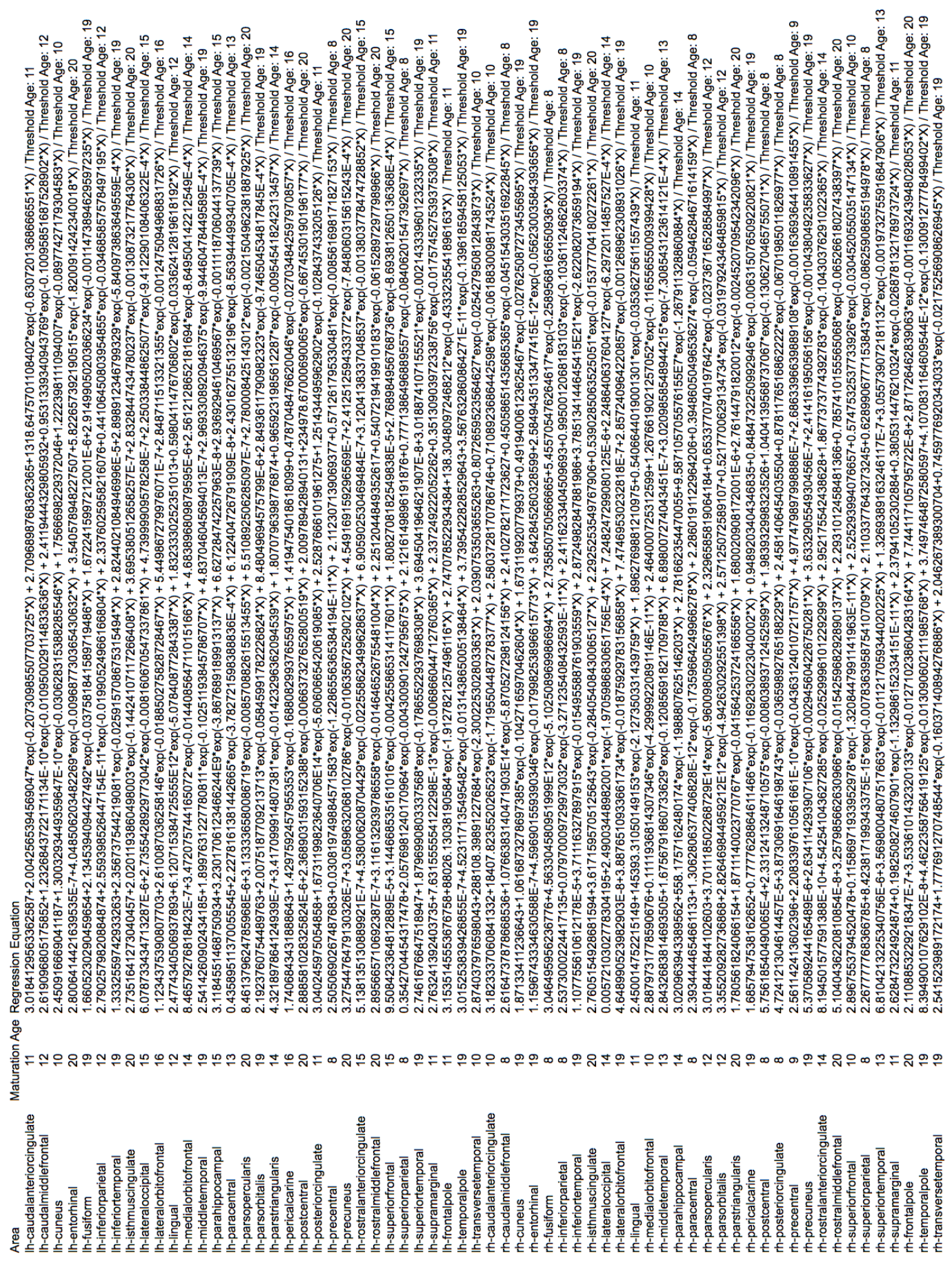

Figura B.1: Folha contendo as idades de amadurecimento e equações bi-exponenciais de regressão encontradas para cada região na análise dos indivíduos saudáveis. 
Area

Ih-caudalanteriorcingulate

Ih-caudalmiddlefrontal

Ih-cuneus

Ih-entorhinal

Ih-fusiform

Ih-inferiorparietal

Ih-inferiortemporal

Ih-isthmuscingulate

Ih-lateraloccipital

Ih-lateralorbitofrontal

Ih-lingual

Ih-medialorbitofrontal

Ih-middletemporal

Ih-parahippocampal

Ih-paracentral

Ih-parsopercularis

Ih-parsorbitalis

Ih-parstriangularis

Ih-pericalcarine

Ih-postcentral

Ih-posteriorcingulate

Ih-precentral

Ih-precuneus

Ih-rostralanteriorcingulate

Ih-rostralmiddlefrontal

Ih-superiorfrontal

Ih-superiorparietal

Ih-superiortemporal

Ih-supramarginal

Ih-frontalpole

Ih-temporalpole

Ih-transversetemporal

rh-caudalanteriorcingulate

rh-caudalmiddlefrontal

rh-cuneus

rh-entorhinal

rh-fusiform

rh-inferiorparietal

rh-inferiortemporal

rh-isthmuscingulate

rh-lateraloccipital

rh-lateralorbitofrontal

rh-lingual

rh-medialorbitofrontal

rh-middletemporal

rh-parahippocampal

rh-paracentral

rh-parsopercularis

rh-parsorbitalis

rh-parstriangularis

rh-pericalcarine

rh-postcentral

rh-posteriorcingulate

rh-precentral

rh-precuneus

rh-rostralanteriorcingulate

rh-rostralmiddlefrontal

rh-superiorfrontal

rh-superiorparietal

rh-superiortemporal

rh-supramarginal

rh-frontalpole

rh-temporalpole

rh-transversetemporal
Average Derived Lower 40 Average Derived 4060 Average Derived Greater 60 $-4,94897 \mathrm{E}-05 \quad-5,22676 \mathrm{E}-10$ $-0,000692347$ $-0,00721683 \quad-0,001343215 \quad-0,000166233$ $-4,63685 \mathrm{E}-19 \quad-2,46754 \mathrm{E}-33 \quad-2,55305 \mathrm{E}-49$ $-0,003225961 \quad-0,003156408 \quad-0,003067237$ $-0,005213768-0,002707577 \quad-0,001166085$ $-0,001662385-0,00164404 \quad-0,001620219$ $-0,003557785-0,003470427 \quad-0,003358838$ $-0,002056232 \quad-0,002019792 \quad-0,001972856$ $-0,003416923 \quad-0,003336901 \quad-0,003234542$ $-0,007079176 \quad-0,003750372 \quad-0,001656194$ $-0,0021558 \quad-0,002120666 \quad-0,002075334$ $-0,002861854 \quad-0,002808296 \quad-0,002739395$ $-0,003153148 \quad-0,003087246 \quad-0,00300269$ $-0,002025806 \quad-0,001993114 \quad-0,001950925$ $-0,005587177 \quad-0,005363568 \quad-0,005083314$

$-0,002693199 \quad-0,002643792 \quad-0,002580203$

$-0,006834174 \quad-0,005702251 \quad-0,0045002$

$-0,005577134 \quad-0,0033445 \quad-0,00172729$

$-0,003851416 \quad-2,09983 E-08 \quad-2,23188 E-14$

$-0,005791555 \quad-0,000846965 \quad-7,89901 \mathrm{E}-05$

$-0,003738497 \quad-0,003177973 \quad-0,00256954$

$-0,001847137 \quad-0,001819802 \quad-0,001784468$

$-0,004124178-0,004017442 \quad-0,003881322$

$-0,00503762-0,001583451 \quad-0,000366853$

$-0,002342297 \quad-0,002303929 \quad-0,00225443$

$-0,005077456 \quad-0,001050336 \quad-0,000147291$

$-0,006048412 \quad-0,005807132 \quad-0,005504682$

$-0,00356412 \quad-0,002554809 \quad-0,001657031$

$-0,000444343 \quad-1,63924 \mathrm{E}-07 \quad-1,88289 \mathrm{E}-11$

$-7,86617 \mathrm{E}-14 \quad-5,85861 \mathrm{E}-15 \quad-2,51082 \mathrm{E}-16$

$-0,009294782 \quad-0,005745182 \quad-0,003083422$

$-0,00659104-0,002058113 \quad-0,000473018$

$-0,005042037 \quad-0,002151697 \quad-0,0007254$

$-0,005751066-0,003410688 \quad-0,00173682$

$-2,5793 \mathrm{E}-14 \quad-8,94915 \mathrm{E}-15 \quad-2,33855 \mathrm{E}-15$

$-0,000882695 \quad-7,54019 \mathrm{E}-06 \quad-2,84636 \mathrm{E}-08$

$-0,004537501 \quad-0,000654255 \quad-6,00195 \mathrm{E}-05$

$-3,82674 \mathrm{E}-06 \quad-1,09514 \mathrm{E}-26 \quad-1,22535 \mathrm{E}-49$

$-0,005122869 \quad-0,003827784 \quad-0,002618908$

$-0,00138821 \quad-0,001371701 \quad-0,001350287$

$-0,003483736 \quad-0,003400764 \quad-0,003294682$

$-0,006382432 \quad-0,003272608 \quad-0,001387114$

$-0,004484216 \quad-0,000509591 \quad-3,54628 \mathrm{E}-05$

$-0,002157667 \quad-0,002127915 \quad-0,002089412$

-2,03306E-06 -2,24258E-16 -1,45117E-27

$-0,003781755 \quad-0,001235356 \quad-0,000299926$

$-0,007398572-0,004721221 \quad-0,00263878$

$-0,006177651 \quad-0,003375526 \quad-0,001549827$

$-0,006268448 \quad-0,005983218 \quad-0,005628157$

$-0,004393978 \quad-0,003897653 \quad-0,003331185$

$-0,002765137 \quad-0,00024277 \quad-1,25563 \mathrm{E}-05$

$-0,007565665 \quad-0,002147052 \quad-0,000439521$

$-0,004176521 \quad-0,004048657 \quad-0,003886534$

$-0,002438443 \quad-0,002390568 \quad-0,002329045$

$-0,008404741 \quad-0,001196509 \quad-0,000108144$

$-0,006945835 \quad-0,002036514 \quad-0,000433656$

$-0,006790662 \quad-0,003818584 \quad-0,001817944$

$-0,003954087 \quad-0,000785366 \quad-0,000104954$

$-0,005666721 \quad-0,005458264 \quad-0,005195952$

$-0,00442898 \quad-0,002663823 \quad-0,001380911$

$-0,003236603 \quad-0,003165501 \quad-0,003074391$

$-1,10367 \mathrm{E}-14 \quad-9,78538 \mathrm{E}-16 \quad-5,11829 \mathrm{E}-17$

$-0,008230332 \quad-0,005452213 \quad-0,003196368$

Figura B.2: Folha contendo as médias das derivadas encontradas para a função de regressão que modela o envelhecimento, divididas em 3 grupos: adultos jovens (até 40 anos), meia idade (entre 40 e 60 anos) e idosos (acima de 60 anos). 

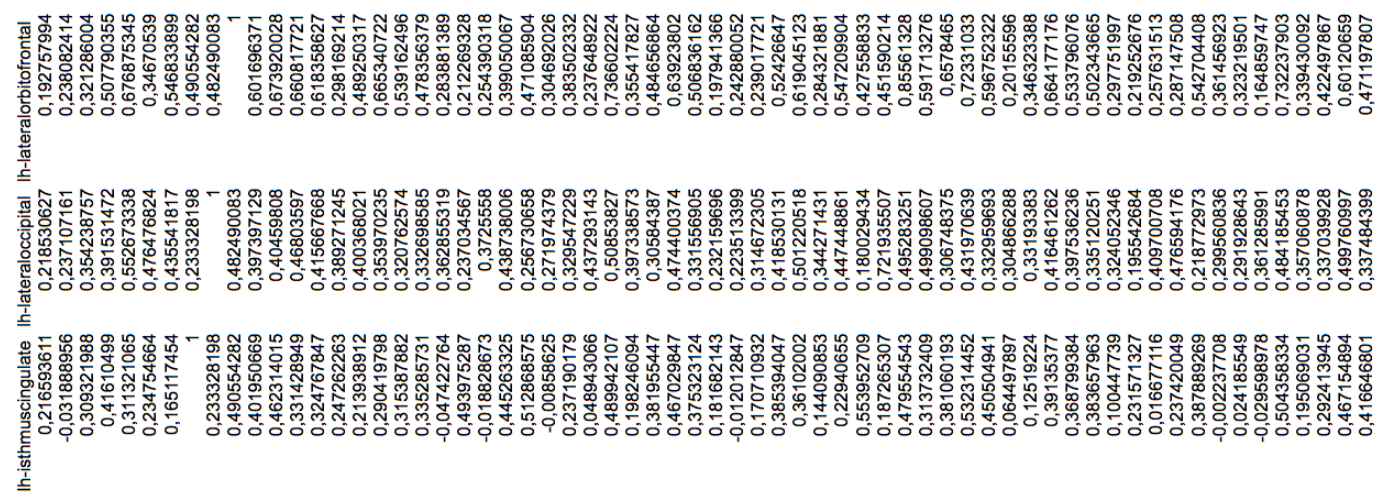

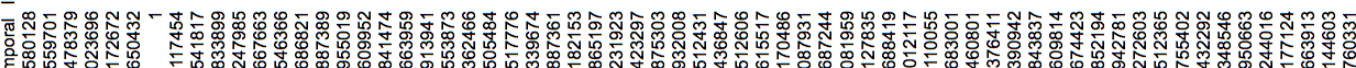

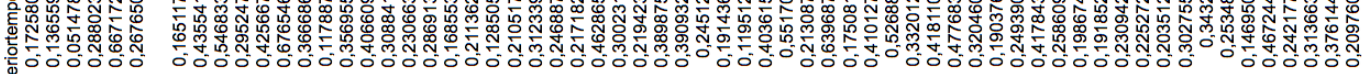
旁

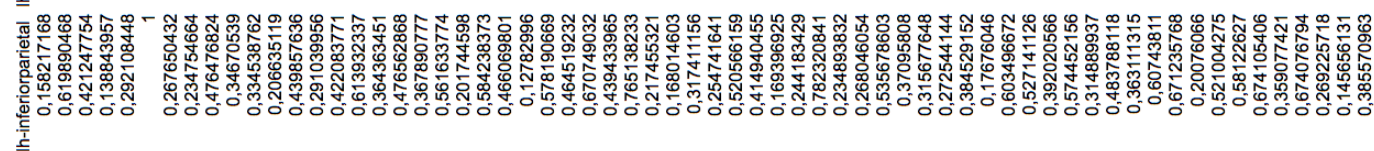

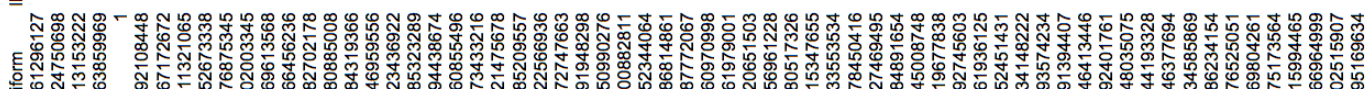
MUH

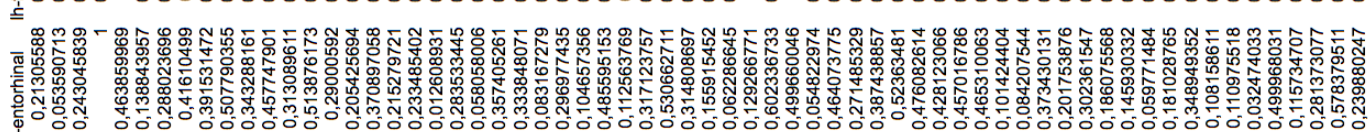

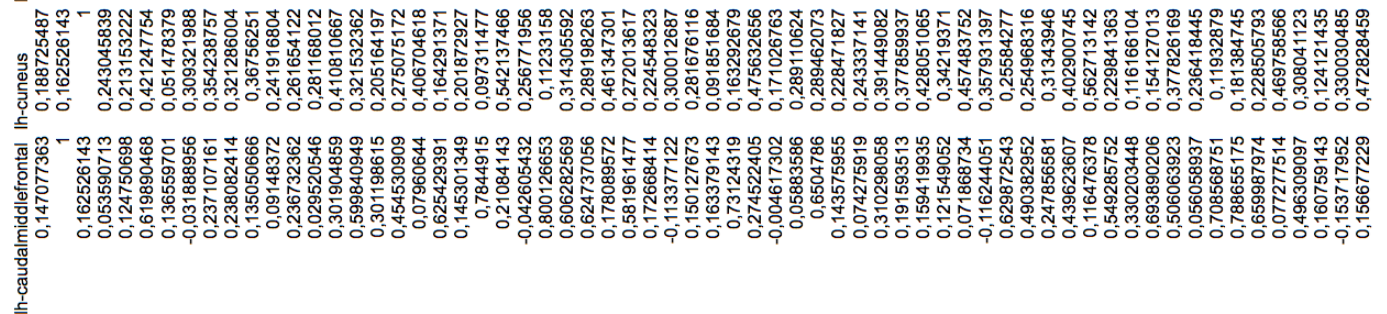

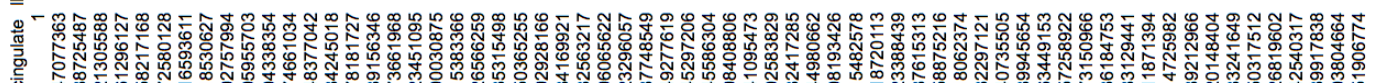

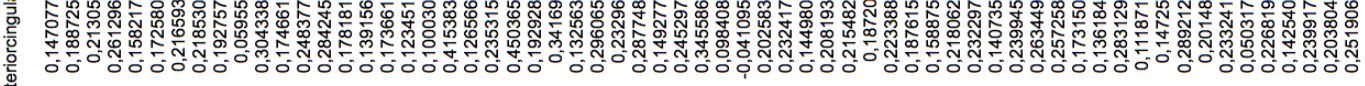

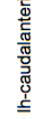

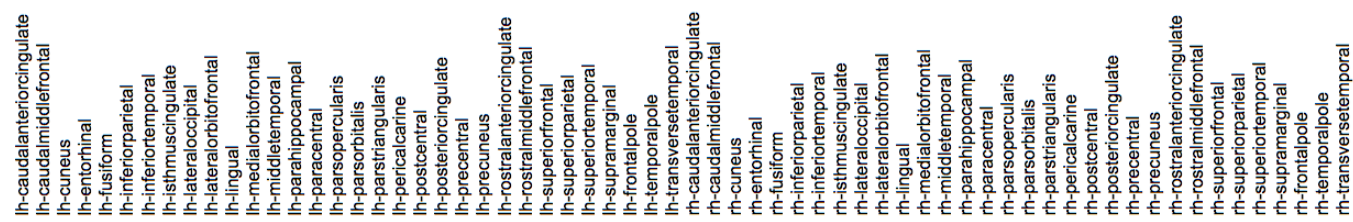

Figura B.3: Folha contendo a matrix de correlações encontrada. A figura não contém os dados de todas as regiões e visa apenas ilustrar o formato no qual os mesmos são gerados. 


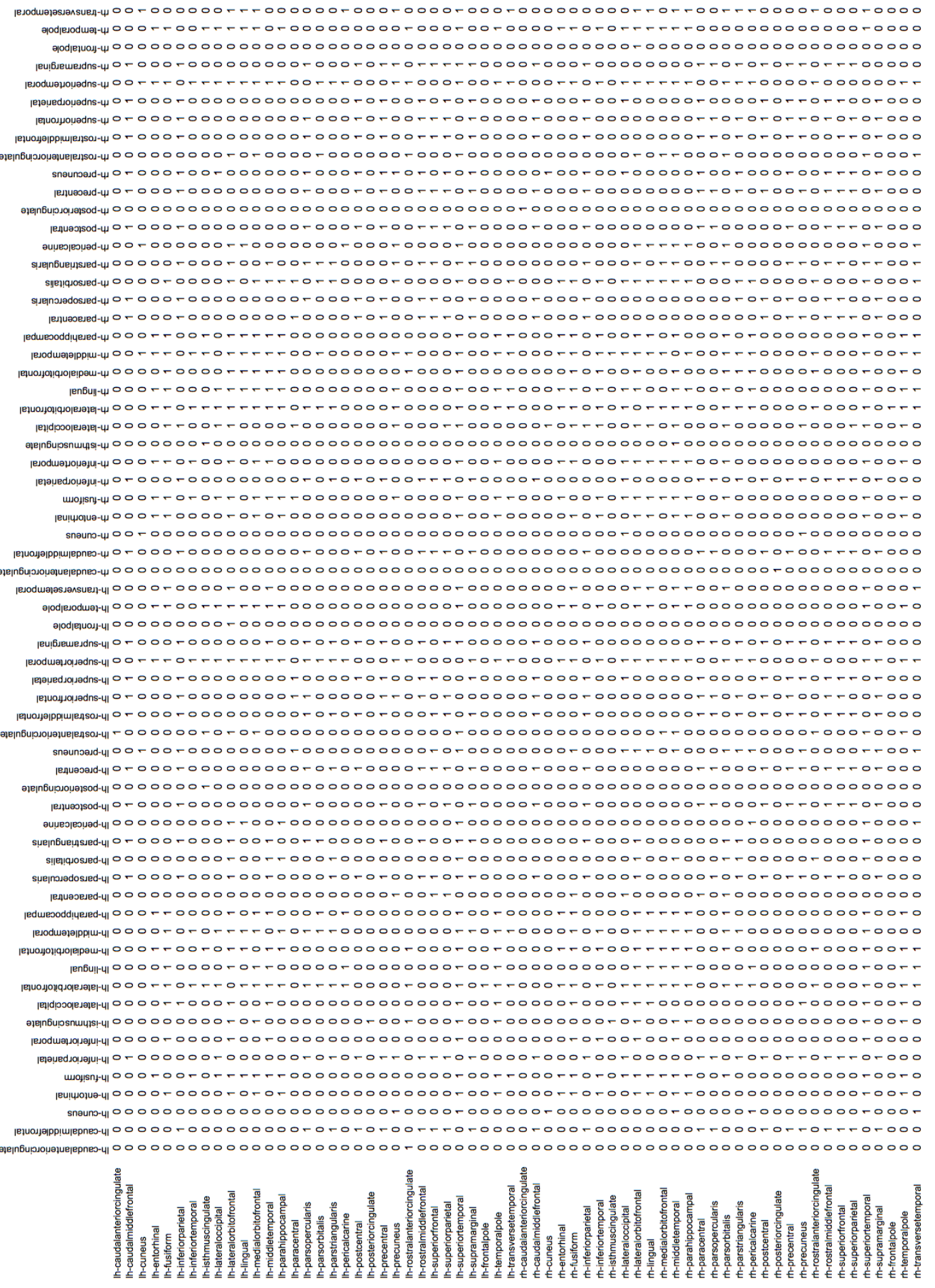

Figura B.4: Folha contendo a matriz de conectividade encontrada após o cálculo do coeficiente de correlação de corte. $O$ valor zero indica ausência de conexão enquanto valor 1 indica presença de conexão. 


\begin{tabular}{|c|c|c|c|c|c|c|}
\hline Threshold & Mean Degree & Clustering Coeficient & Characteristic Path Lengh & Gama & Lambda & Sigma \\
\hline 0,1 & 58,25 & 0,943570479 & 0,935189199 & 1,033178815 & 1,024960003 & 1,008018667 \\
\hline 0,11 & 57,65625 & 0,937388292 & 0,927646416 & 1,03641692 & 1,025851604 & 1,010299069 \\
\hline 0,12 & 56,875 & 0,929076763 & 0,917805742 & 1,039083265 & 1,026020273 & 1,012731709 \\
\hline 0,13 & 55,875 & 0,917837932 & 0,905303862 & 1,04113778 & 1,025486082 & 1,015262711 \\
\hline 0,14 & 55 & 0,908233019 & 0,894639429 & 1,043852716 & 1,025093988 & 1,01829952 \\
\hline 0,15 & 53,90625 & 0,897449369 & 0,881801615 & 1,050200725 & 1,025674405 & 1,023912384 \\
\hline 0,16 & 52,96875 & 0,889120884 & 0,871075221 & 1,056479071 & 1,025975726 & 1,029731059 \\
\hline 0,17 & 52,03125 & 0,882474917 & 0,8607322 & 1,062350931 & 1,025065366 & 1,036373841 \\
\hline 0,18 & 50,65625 & 0,870384934 & 0,845498092 & 1,072320958 & 1,024846418 & 1,046323565 \\
\hline 0,19 & 49,75 & 0,862651274 & 0,835677502 & 1,077168544 & 1,023740456 & 1,052189095 \\
\hline 0,2 & 48,3125 & 0,851900774 & 0,82067806 & 1,089516924 & 1,022962377 & 1,065060602 \\
\hline 0,21 & 46,875 & 0,838493025 & 0,805804068 & 1,096373197 & 1,020583767 & 1,074260862 \\
\hline 0,22 & 45,40625 & 0,827845028 & 0,791373926 & 1,10805375 & 1,018979763 & 1,087414873 \\
\hline 0,23 & 43,84375 & 0,814002089 & 0,776213048 & 1,120090818 & 1,017261905 & 1,101084011 \\
\hline 0,24 & 42,03125 & 0,80691104 & 0,759669003 & 1,142788146 & 1,014420454 & 1,126542886 \\
\hline 0,25 & 40,6875 & 0,801075132 & 0,747752489 & 1,165889753 & 1,014386405 & 1,149354671 \\
\hline 0,26 & 39,46875 & 0,794703154 & 0,737177074 & 1,177490364 & 1,01188635 & 1,163658709 \\
\hline 0,27 & 38,5625 & 0,792269583 & 0,729306179 & 1,197705022 & 1,010613816 & 1,18512631 \\
\hline 0,28 & 37,375 & 0,788442521 & 0,719537121 & 1,220985673 & 1,009979412 & 1,208921349 \\
\hline 0,29 & 35,90625 & 0,784231653 & 0,707654224 & 1,250499191 & 1,008824047 & 1,239561245 \\
\hline 0,3 & 34,5625 & 0,776383746 & 0,696858668 & 1,276013218 & 1,007686418 & 1,26628006 \\
\hline 0,31 & 32,9375 & 0,76237468 & 0,683007286 & 1,304655435 & 1,004840051 & 1,298371252 \\
\hline 0,32 & 31,34375 & 0,750195146 & 0,667608658 & 1,329419675 & 0,997788971 & 1,332365573 \\
\hline 0,33 & 30,1875 & 0,739926015 & 0,657139047 & 1,350330248 & 0,99374867 & 1,35882471 \\
\hline 0,34 & 28,9375 & 0,727177937 & 0,645552734 & 1,37639645 & 0,989090469 & 1,391577912 \\
\hline 0,35 & 27,625 & 0,719031112 & 0,629698527 & 1,40748016 & 0,977719748 & 1,439553781 \\
\hline 0,36 & 26,71875 & 0,7223835 & 0,620255386 & 1,445998237 & 0,971159534 & 1,488939959 \\
\hline 0,37 & 25,5 & 0,736780626 & 0,600462321 & 1,530035244 & 0,951921533 & 1,607312358 \\
\hline 0,38 & 24,4375 & 0,740542432 & 0,586690884 & 1,590991738 & 0,940188002 & 1,692205958 \\
\hline 0,39 & 23,375 & 0,739364199 & 0,574580313 & 1,64497264 & 0,931422443 & 1,766086541 \\
\hline 0,4 & 22,28125 & 0,723968585 & 0,555912226 & 1,670283244 & 0,911418285 & 1,832619853 \\
\hline 0,41 & 21,28125 & 0,725729268 & 0,543701213 & 1,727599028 & 0,901330652 & 1,9167206 \\
\hline 0,42 & 20,09375 & 0,726813253 & 0,528817702 & 1,796161727 & 0,8978943 & 2,000415558 \\
\hline 0,43 & 19,0625 & 0,692647583 & 0,515828778 & 1,765907735 & 0,8976545 & 1,967246568 \\
\hline 0,44 & 17,90625 & 0,690928706 & 0,498719062 & 1,862732201 & 0,893082 & 2,085734794 \\
\hline 0,45 & 17,03125 & 0,675421988 & 0,521721733 & 1,892073287 & 0,912456 & 2,07360496 \\
\hline
\end{tabular}

Figura B.5: Folha contendo os parâmetros de rede calculados para o intervalo de análise solicitado. 


\begin{tabular}{|c|c|}
\hline $\begin{array}{ll}\text { RAA } \\
\text { Color: } 255000 \\
\text { rh-caudalanterior I } \\
\text { rh-posteriorcingul I }\end{array}$ & $\begin{array}{l}\text { RAB } \\
\text { Color: } 025500 \\
\text { Ih-caudalmiddlefrontal } \\
\text { Ih-inferiorparietal } \\
\text { Ih-parsopercularis } \\
\text { Ih-parstriangularis } \\
\text { Ih-postcentral } \\
\text { Ih-precentral } \\
\text { Ih-rostralmiddlefrontal } \\
\text { Ih-superiorfrontal } \\
\text { Ih-superiorparietal } \\
\text { Ih-supramarginal } \\
\text { rh-caudalmiddlefrontal } \\
\text { rh-inferiorparietal } \\
\text { rh-paracentral } \\
\text { rh-parsopercularis } \\
\text { rh-postcentral } \\
\text { rh-precentral } \\
\text { rh-precuneus } \\
\text { rh-rostralmiddlefrontal } \\
\text { rh-superiorfrontal } \\
\text { rh-superiorparietal } \\
\text { rh-supramarginal } \\
\text { rh-parstriangularis } \\
\text { Ih-paracentral }\end{array}$ \\
\hline
\end{tabular}

RB

Color: 002550

Ih-caudalanteriorcingulate

Ih-rostralanteriorcingulate

Ih-cuneus

Ih-precuneus

Ih-superiortemporal

rh-cuneus

rh-middletemporal

rh-pericalcarine

rh-superiortemporal

rh-transversetemporal

Ih-entorhinal

Ih-fusiform

Ih-lateralorbitofrontal

Ih-medialorbitofrontal

Ih-parahippocampal

Ih-temporalpole

rh-entorhinal

rh-fusiform

rh-inferiortemporal

rh-lateralorbitofrontal

rh-lingual

rh-parahippocampal

rh-temporalpole

Ih-inferiortemporal

Ih-lateraloccipital

Ih-lingual

Ih-middletemporal

Ih-transversetemporal

rh-lateraloccipital

rh-medialorbitofrontal

rh-parsorbitalis

Ih-isthmuscingulate

Ih-posteriorcingulate

rh-isthmuscingulate

Ih-parsorbitalis

Ih-pericalcarine

Ih-frontalpole

rh-rostralanteriorcingulate

rh-frontalpole

Figura B.6: Folha contendo as comunidades encontradas segundo o algoritmo explicado na seção 3.2.5. 


\section{Anexo}

\section{Outros arquivos de saída}

Além da planilha, um arquivo em formato textual contendo todas as conexões encontradas também é gerado automaticamente em qualquer execução do software implementado no presente trabalho. Tal arquivo contem, em cada linha, os nomes de duas regiões conectadas separadas por um espaçamento. O mesmo pode ser visto na figura abaixo:

Caso o usuário esteja utilizando um atlas presente no FreeSurfer, ele poderá, conforme já visto na seção 3.2.6, solicitar a geração de mapas de cores para serem utilizados na montagem de mapas tal como os mostrados nas figuras 4.2 e 4.3. Nesse caso, será gerado um arquivo para cada hemisfério tal como mostrado na figura abaixo, para o hemisfério esquerdo: 
lh-caudalanteriorcingulate lh-rostralanteriorcingulate

lh-caudalmiddlefrontal lh-inferiorparietal

lh-caudalmiddlefrontal lh-parsopercularis

lh-caudalmiddlefrontal lh-parstriangularis

lh-caudalmiddlefrontal lh-postcentral

lh-caudalmiddlefrontal lh-precentral

lh-caudalmiddlefrontal lh-rostralmiddlefrontal

lh-caudalmiddlefrontal lh-superiorfrontal

lh-caudalmiddlefrontal lh-superiorparietal

lh-caudalmiddlefrontal lh-supramarginal

lh-caudalmiddlefrontal rh-caudalmiddlefrontal

lh-caudalmiddlefrontal rh-inferiorparietal

lh-caudalmiddlefrontal rh-paracentral

lh-caudalmiddlefrontal rh-parsopercularis

lh-caudalmiddlefrontal rh-postcentral

lh-caudalmiddlefrontal rh-precentral

lh-caudalmiddlefrontal rh-precuneus

lh-caudalmiddlefrontal rh-rostralmiddlefrontal

lh-caudalmiddlefrontal rh-superiorfrontal

lh-caudalmiddlefrontal rh-superiorparietal

lh-caudalmiddlefrontal rh-supramarginal

lh-cuneus lh-precuneus

lh-cuneus lh-superiortemporal

lh-cuneus rh-cuneus

lh-cuneus rh-middletemporal

lh-cuneus rh-pericalcarine

lh-cuneus rh-superiortemporal

lh-cuneus rh-transversetemporal

lh-entorhinal lh-fusiform

lh-entorhinal lh-lateralorbitofrontal

lh-entorhinal lh-medialorbitofrontal

lh-entorhinal lh-parahippocampal

lh-entorhinal lh-superiortemporal

lh-entorhinal lh-temporalpole

lh-entorhinal rh-entorhinal

lh-entorhinal rh-fusiform

lh-entorhinal rh-inferiortemporal

lh-entorhinal rh-lateralorbitofrontal

lh-entorhinal rh-lingual

lh-entorhinal rh-middletemporal

lh-entorhinal rh-parahippocampal

lh-entorhinal rh-superiortemporal

lh-entorhinal rh-temporalpole

Figura C.1: Arquivo TSV gerado na execução do software. Na figura estão apenas partes das conexões calculadas para os indivíduos saudáveis em caráter ilustrativo para demonstração do formato no qual o arquivo é gerado. 
3 caudalmiddlefrontal 025500

8 inferiorparietal 025500

18 parsopercularis 025500

20 parstriangularis 025500

22 postcentral 025500

24 precentral 025500

27 rostralmiddlefrontal 025500

28 superiorfrontal 025500

29 superiorparietal 025500

31 supramarginal 025500

17 paracentral 025500

2 caudalanteriorcingulate 002550

26 rostralanteriorcingulate 0002550

5 cuneus 002550

25 precuneus 002550

30 superiortemporal 002550

6 entorhinal 002550

7 fusiform 002550

12 lateralorbitofrontal 0002550

14 medialorbitofrontal 002550

16 parahippocampal 002550

33 temporalpole 002550

9 inferiortemporal 002550

11 lateraloccipital 002550

13 lingual 002550

15 midd letemporal 002550

34 transversetemporal 0002550

10 isthmuscingulate 002550

23 posteriorcingulate 002550

19 parsorbitalis 002550

21 pericalcarine 002550

32 frontalpole $0 \quad 02550$

Figura C.2: Arquivo contendo o mapa de cores a ser utilizado no FreeSurfer para montagem de ilustrações. 